\title{
WestVirginiaUniversity
}

THE RESEARCH REPOSITORY @ WVU

Graduate Theses, Dissertations, and Problem Reports

2015

\section{Microbiology in Shale: Alternatives for Enhanced Gas Recovery}

\author{
Yael Tarlovsky Tucker
}

Follow this and additional works at: https://researchrepository.wvu.edu/etd

\section{Recommended Citation}

Tucker, Yael Tarlovsky, "Microbiology in Shale: Alternatives for Enhanced Gas Recovery" (2015). Graduate Theses, Dissertations, and Problem Reports. 6834.

https://researchrepository.wvu.edu/etd/6834

This Dissertation is protected by copyright and/or related rights. It has been brought to you by the The Research Repository @ WVU with permission from the rights-holder(s). You are free to use this Dissertation in any way that is permitted by the copyright and related rights legislation that applies to your use. For other uses you must obtain permission from the rights-holder(s) directly, unless additional rights are indicated by a Creative Commons license in the record and/ or on the work itself. This Dissertation has been accepted for inclusion in WVU Graduate Theses, Dissertations, and Problem Reports collection by an authorized administrator of The Research Repository @ WVU.

For more information, please contact researchrepository@mail.wvu.edu. 


\title{
Microbiology in Shale: Alternatives for Enhanced Gas Recovery
}

\author{
Yael Tarlovsky Tucker
}

\begin{abstract}
Dissertation submitted at West Virginia University

Doctor of Philosophy in

Genetics and Developmental Biology

\author{
Jianbo Yao, Ph.D., Chair \\ James Kotcon, Ph.D. \\ Joginder Nath, Ph.D. \\ Joseph Morton, Ph.D. \\ Tom Mroz, M.S.
}

to the Davis College of Agriculture, Natural Resources and Design

in partial fulfillment of the requirements for the degree of

Division of Plant and Soil Science

Morgantown, West Virginia

2015

Keywords: Genetics, Marcellus Shale, Enhanced Gas Recovery, Microbiology, Methanogens

Copyright 2015 Yael Tarlovsky Tucker 


\title{
ABSTRACT
}

\section{Microbiology in Shale: Alternatives for Enhanced Gas Recovery}

\author{
Yael Tarlovsky Tucker
}

The gas-productive part of the Marcellus Shale occurs in the Appalachian basin at depths of 1.5 to $2.5 \mathrm{~km}(5,000$ to $8,000 \mathrm{ft}$.), where most geologists generally assume that thermogenic processes occurring over geologic time periods are the only source of natural gas. This is because these sediments are believed to be sterile due to conditions these sediments have endured in the past, which are beyond those that most organisms are currently known to withstand. Recently, Marcellus shale drilling processes have allowed for the study of the microbiology of these sediments by analysis of microorganisms carried in "produced" waters that emerge to the surface over time after injection. Studies of geological and chemical processes and how they may impact the environment are numerous, but little has been done to characterize microbiological interactions. Many microorganisms have been identified in these samples, and composition in the produced fluids is known to change over time. These changes generally have been explained as a natural selection of the injected organisms, but growth of microbes originating from the subsurface environment provides an alternative explanation. Consequently, investigations were conducted to determine the possible sources of microorganisms and methanogens in flowback fluids. DNA extracts from pre-injection and produced fluid samples were compared to those from Marcellus core samples using Next Generation Sequencing of the barcoding region of the 16S rRNA gene. Identified organisms in the produced fluids were then compared using SourceTracker and principal components analysis. SourceTracker analysis indicated that a majority of the microorganisms found in the waters returning to the surface were more likely to have come from communities seen in shale cores than those seen in pre-injected fluids. Principal components analysis supported this as microbial communities in core samples grouped closer to those in produced fluids than in pre-injection fluids, suggesting that the deep subsurface Marcellus shale may contain native organisms. Microbes indigenous to the shale would be among the deepest living organisms ever found, possibly deposited during the original sedimentation, or transported in during a more recent water influx event.

Methanogens produce methane at a faster rate than thermogenic processes. Therefore, a second study was conducted to examine methanogens specifically. To determine whether methanogens are indigenous to the shale itself, or are introduced as contaminants during drilling and hydraulic fracturing, results from DNA extractions in the initial study were analyzed with special focus on Archaeal sequences, most specifically, DNA of known methanogens,. Absence of methanogens in injected fluids suggests that these organisms are unlikely to have been introduced with these fluids and therefore may be native to the shale itself. Bench-top growth analyses measuring methane production in these samples suggested that organisms are not only present, but are potentially alive and active in simulated shale conditions without the need for external microbial or chemical sources. Growth conditions designed to simulate conditions in shale after the hydrofracture processes indicated somewhat increased methane production compared to those seen in shale alone. Fluids alone produced little methane, supporting the conclusion that the shale is an essential element for methanogenesis. Together, these results suggest that some biogenic methane may be produced in these wells and that the introduction of hydrofracture fluids currently used to stimulate gas recovery could affect methanogens and methane production rates. Further experimentation could yield ways to increase biogenic methane production in the Marcellus Shale, providing more natural gas and reducing the number of wells drilled. These two studies indicate that microbes, possibly native to that environment, are present and further analyses may offer key information on their role in natural gas production in shale. Further experimentation may be useful to modify current well management techniques and increase biogenic methane production in these shales. 


\section{DEDICATION}

I would like to dedicate this research study to all of the people who have taken a special chance to believe in me, and to those who have believed in me when others lost faith. I would not be here today, without them. Most of all, this is for my parents who believed I could do great things despite what doctors told them, and for my husband, who believes in me so much that he even makes me believe in myself. I would also like to dedicate this to my grandmother, who has passed, but made me largely who I am today. 


\section{ACKNOWLEDGEMENTS}

Foremost, I would like to thank Tom Mroz for taking a chance on me and bringing me and this project onto NETL. I enjoyed having him as my mentor because of his infinite knowledge and excitement. Also, I am thankful to my WVU mentor, Jianbo Yao for taking me into his laboratory. I would also like to thank Dan Soeder, who took over as mentor when Tom retired. My greatest gratitude goes to Mark McKoy, who spent much time and effort to help me write papers, interpret data, and support my internship at NETL. I would also like to thank Bill Gwilliam for support at NETL. I would like to express my gratitude to my committee members, Joginder Nath, Joseph Morton, and James Kotcon for taking the time for meetings and other help, especially James Kotcon for editing and reviewing this dissertation. I would also like to thank Lee Kass for her help in reviewing this dissertation. Several thanks as well to Ida Holaskova for statistics help. Special thanks to SCNGO for providing funding for supporting this project, especially Rob Vagnetti who went above and beyond his project management duties to help the project. I appreciate Dr. James Ferry at Penn State University allowing me to come to his lab to learn about methanogens, and especially his student Eric Malberg at Penn State University for personally providing initial inoculum and lessons on growing Methanosarcina acetivorans. I would also like to thank Tullis Onstott at Princeton University for his advice, kindness, and support. Much of this work would not be possible without constant collaboration with Scot E. Dowd at MrDNA Sequencing, so I thank him for his services and troubleshooting help. Personally, I would like to thank my amazing husband and best friend, Jonathan Tucker, for undying support, being a crying shoulder, and making me laugh no matter what happened. This work would not be possible without his support, ideas, or patience. I would also like to thank my friend Christi Raines for providing moral support and for review. Finally, I would like to thank my parents who have supported me above and beyond the call of duty. 


\section{LIST OF PUBLICATIONS}

Murin, T., Bank, T., Sharma, S., Shen, R. Tucker, Y., and Eastman, H., "Integrated Chemo-Stratigraphic Characterization and Biogenic Evaluation of Organic Shale." NETL-TRS-NGEP-2014, NETL Technical Report Series, U.S. Department of Energy, National Energy Technology Laboratory, Morgantown, WV, July 31, 2014

Tucker, Y. T., Mroz, T., and Kotcon, J. "Methanogenic Archaea in Marcellus Shale: A Possible Mechanism for Enhanced Gas Recovery in Unconventional Shale Resources" Submitted to Environmental Science and Technology February 2015. (In Review). 


\section{TABLE OF CONTENTS}

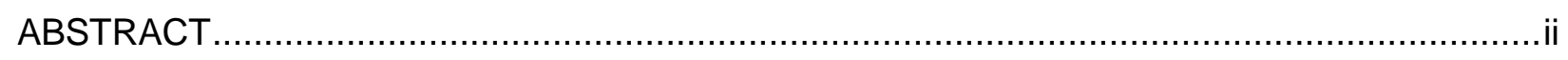

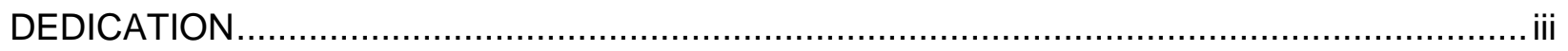

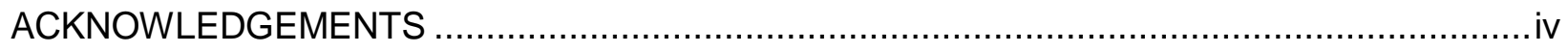

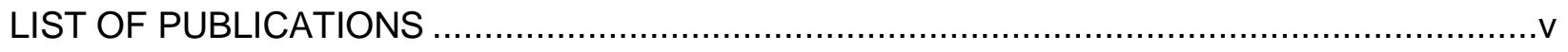

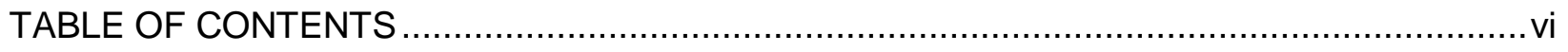

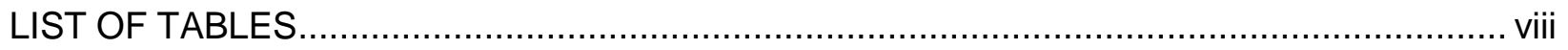

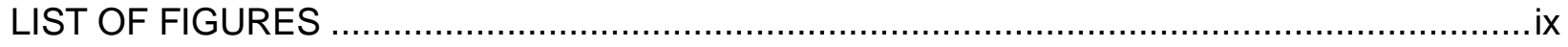

LIST OF ABBREVIATIONS

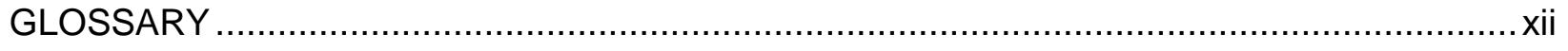

REVIEW OF LITERATURE

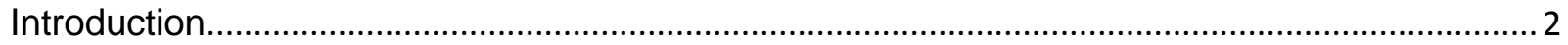

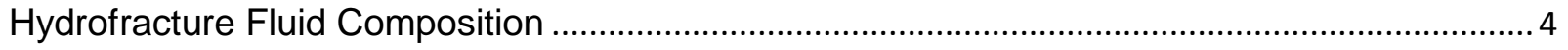

Isotope Identification of Biogenic Methane .......................................................................... 5

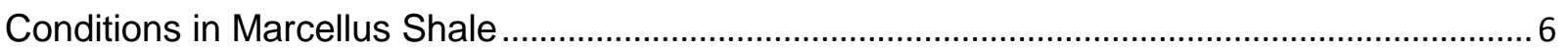

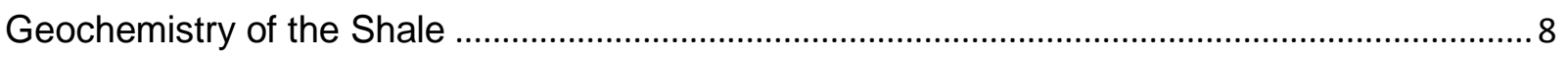

Possibility of Bacteria Living in Subsurface ........................................................................ 10

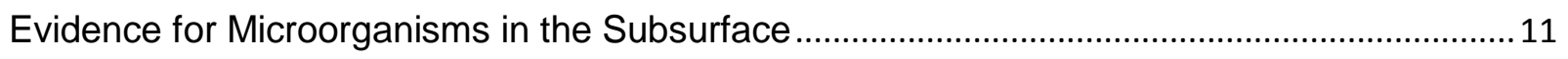

Possibility of Methanogenic Archaea Living in Subsurface ......................................................13

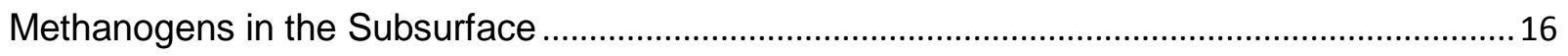

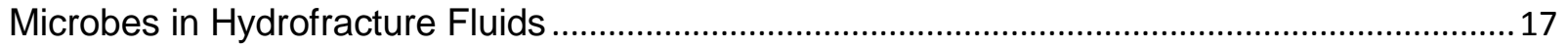

Possible Contamination Sources in Water and Core Samples..................................................19

DNA-Independent Tests Available for the Identification of Microbes in Samples .......................20

DNA Dependent Methods Available for the Study of Bacteria and Archaea in Samples .........21

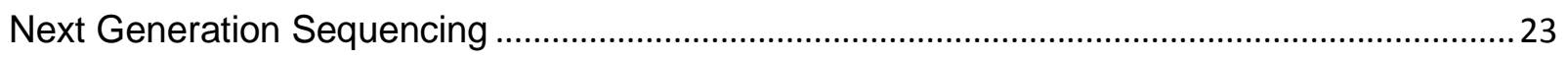

Primers Available for Analysis of Bacteria and Archaea.........................................................2

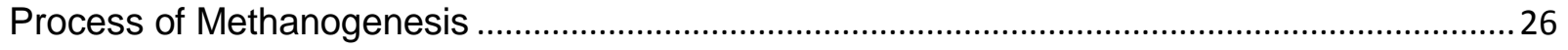

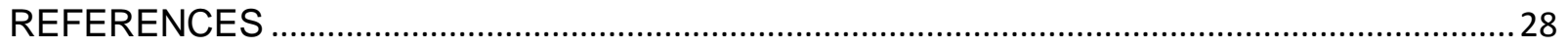

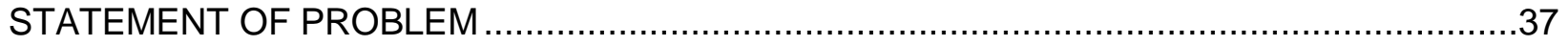

OBJECTIVES

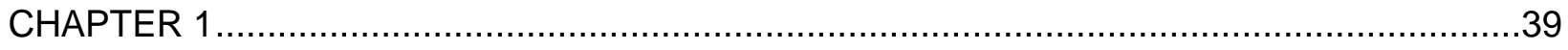

Microbes in Marcellus Shale: Extremophiles Living More Than a Mile inside the Earth? .........40 


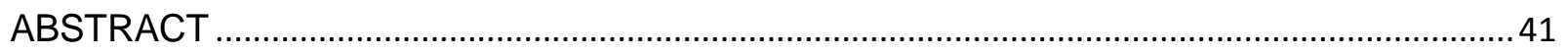

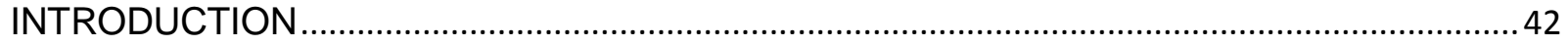

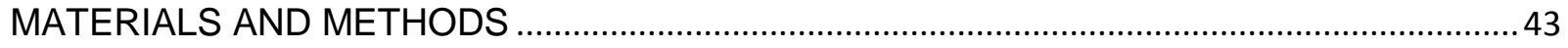

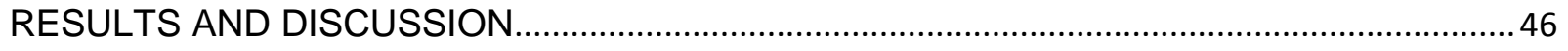

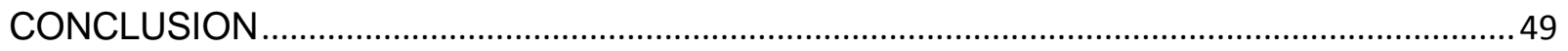

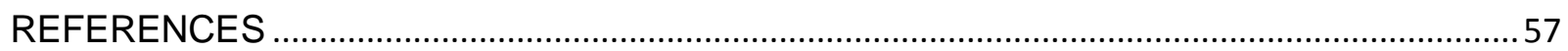

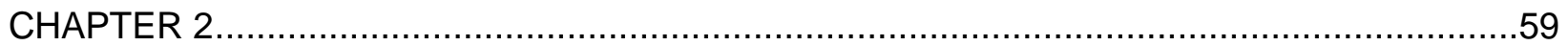

Methanogenic Archaea in Marcellus Shale: A Possible Mechanism for Enhanced Gas

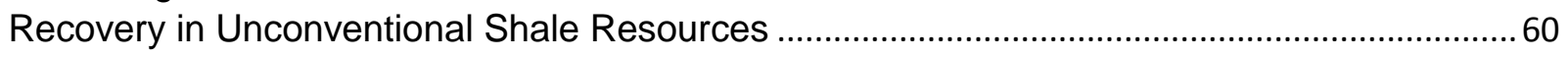

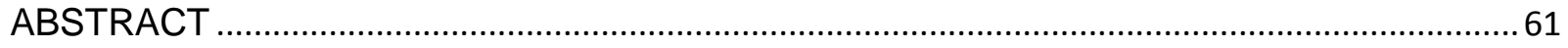

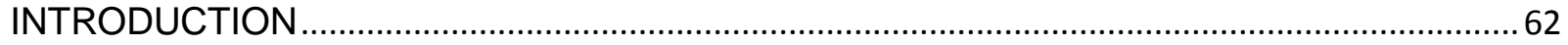

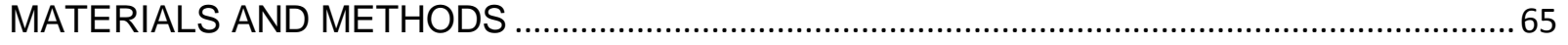

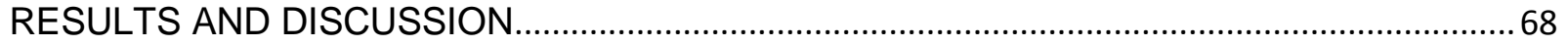

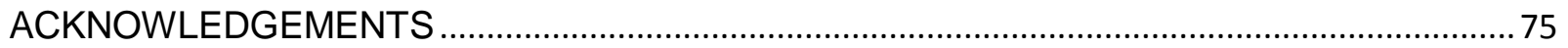

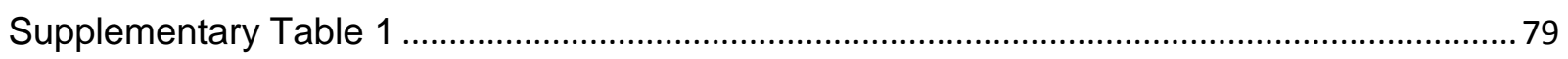

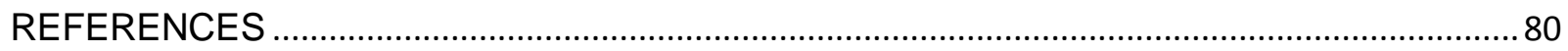

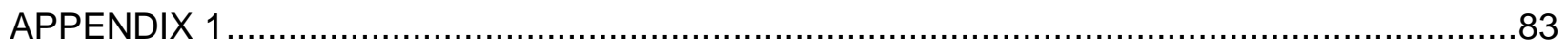

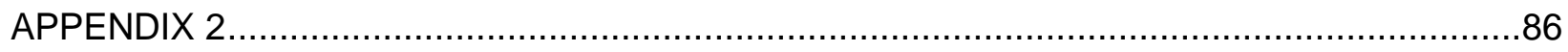

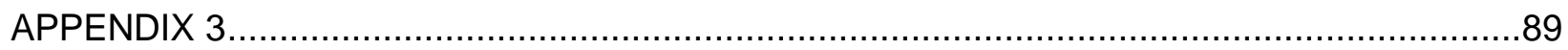

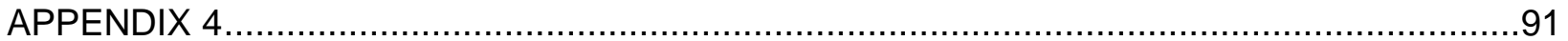




\section{LIST OF TABLES}

\section{REVIEW OF LITERATURE}

Table 1 - Levels of common minerals in Marcellus Shale and how each may affect indigenous microorganisms or organic preservation

\section{CHAPTER 1}

Table 1 - Summary of samples and parameters analyzed.

\section{CHAPTER 2}

Table 1 - Samples and number of sequences from each sample analyzed for methanogenic Archaea.....

Supplementary Table 1 - Sample types and results for 16r RNA analysis with respect to methanogenic Archaea... 


\section{LIST OF FIGURES}

\section{REVIEW OF LITERATURE}

Figure 1 - Completed well diagram illustrating a typical well, casing, and fractures.......24

Figure 2 - Phylogenetic tree of several known methanogens based on partial 16s rRNA

gene sequences based on neighbor-joining analysis .26

Figure 3 - Example pathway of methanogenic metabolism. .27

\section{CHAPTER 1}

Figure 1 - SourceTracker results on produced fluids using core and pre-injection fluids as possible sources for the microorganisms found in the different samples of produced fluids from both tank and separator.

Figure 2 - Taxonomic graph of the average microorganisms found in each kind of samples.

Figure 3 - Principal component analysis computed utilizing unweighted Unifrac methods.

\section{CHAPTER 2}

Figure 1 - MG-RAST Krona illustration of the taxonomic abundance found by metagenomic analysis of the enriched separator sample collected from well M1 669 days after production began

Figure 2 - Results of growth experiments illustrating the daily average methane production in specific tests in micro moles $(\mu \mathrm{mol})$. .78 


\section{LIST OF ABBREVIATIONS}

\begin{tabular}{|c|c|}
\hline$\mu \mathrm{M}$ & Micromoles \\
\hline 16s rRNA & Small Subunit (16S) \\
\hline ATP & Adenine Triphosphate \\
\hline bp & Base Pairs \\
\hline${ }^{\circ} \mathrm{C}$ & Degrees Celsius \\
\hline DNA & Deoxyribonucleic Acid \\
\hline${ }^{\circ} \mathrm{F}$ & Degrees Farenheit \\
\hline $\mathbf{F}$ & Forward \\
\hline $\mathbf{f t}$ & Feet \\
\hline $\mathrm{H}_{2}$ & Hydrogen \\
\hline km & Kilometers \\
\hline $\mathbf{L}$ & Liter \\
\hline m & Meter \\
\hline M & Molar \\
\hline McrA & Methane Coenzyme M Reductase Subunit \\
\hline mL & Milliliters \\
\hline $\mathrm{mM}$ & Millimoles \\
\hline My & Million Years \\
\hline $\mathbf{N}_{2}$ & Nitrogen \\
\hline $\mathrm{NaCl}$ & Sodium Chloride (Salt) \\
\hline NGS & Next Generation Sequencing \\
\hline $\mathrm{nM}$ & Nanomoles \\
\hline $\mathbf{O}_{2}$ & Oxygen \\
\hline
\end{tabular}




$\begin{array}{ll}\text { OTU } & \text { Operational Taxonomic Unit } \\ \text { PCR } & \text { Polymerase Chain Reaction } \\ \text { QIIME } & \text { Quantitative Insights Into Microbial Ecology } \\ \text { R } & \text { Reverse } \\ \text { RNA } & \text { Ribonucleic Acid } \\ \text { rRNA } & \text { Ribosomal RNA } \\ \text { ס13 CDIC } & \text { Dissolved Inorganic Carbon }\end{array}$




\section{GLOSSARY}

454 Pyrosequencing

Acetoclastic Methanogen

Core

Flowback Fluids

Greengenes

Hydrofracturing

Hydrogenotrophic Methanogen

Illumina Sequencing

Native Fluids

Naturally Occurring Radioactive Materials (NORM)

Next Generation Sequencing

Operational Taxonomic Unit (OTU)

$P C R / q P C R$
Next Generation Sequencing technique where fluorescent nucleotides are added sequentially and detected by a computerized system.

A methane-producing organism capable of producing methane using acetate as a sole carbon and hydrogen source.

A cylindrical sample of the subsurface taken using a special drill that produces a sample while drilling. Generally taken during exploratory drilling operations near where wells are intended to be drilled (not part of well drilling).

Injected fluids that emerge from the subsurface immediately after the well plug is removed, before gas production begins.

Library containing barcodes identified to relate to certain OTUs, useful for identification of organisms using sequence data.

A process in which fluids (water and chemicals) are injected at high pressures into subsurface reservoirs in order to create fractures to increase gas flow.

A methane producing organism capable of producing methane using $\mathrm{H}_{2}$ and $\mathrm{CO}_{2}$.

Next Generation Sequencing technique where a special polymerase creates a different light signal for every nucleotide added.

Fluids stored within a formation containing chemicals and microorganisms.

Radioactive elements found to exist in nature such as uranium, thorium and vanadium.

Clone library independent methods such as 454

Pyrosequencing or Illumina Sequencing that can sequence environmental samples rapidly.

A cluster of reads that is greater than $97 \%$ similar in sequence identity to determine a taxonomic level of sampling selected by the experimenter.

Amplification procedure for short fragments of DNA where a polymerase adds nucleotides in a sequence of melting and annealing processes. qPCR measures the quantity of DNA at each amplification to extrapolate original volumes present. 
Pre-Injection Fluids (Injected fluids)

Primer (forward/ reverse)

Produced Fluids

Proppant

Reservoir

Separator Fluids

Sourcetracker

Subsurface

Vitrinite Reflectance

Well Plug
A mixture of water and chemicals used for hydrofracturing processes. Sometimes re-used in industry.

A short fragment of DNA required for DNA polymerase to initiate replication during PCR.

Injected fluids that emerge from the subsurface after the well begins gas production.

Small particles, such as sand, added to hydrofracture fluids to keep fractures open after fracturing.

A geologic region containing a natural resource

Produced fluids taken from the vessel that separates gas and fluid near the head of the well, before the fluids reach the storage tank.

A tool that statistically determines the likely "source" of certain OTUs in a certain sample, given sequencing data for several possible sources.

Anywhere under the surface of the earth (generally rock material). However, in these studies generally referring to terrestrial subsurface rather than marine.

A $\beta$-diversity measure to measure environmental samples phylogenetically. It can be combined with other statistical techniques like principal components to identify factors that explain differences between microbial communities.

Is a measure of the percentage light reflected from the surface of vitrinite particles in a sedimentary rock which is used to identify the maximum temperature history of organic sediments.

A type of blocking device used to secure injected hydrofracture fluids in the well at high pressure to produce artificial fractures. 
REVIEW OF LITERATURE 


\section{Introduction}

With technology evolving at an exponential rate in the past few decades, worldwide energy demands have become more difficult to fulfill. Currently, the United States uses more than 96 Quadrillion British Thermal Units (BTUs) of energy per year, only 8\% of which comes from renewable sources (Conti et al., 2014). The majority of that energy is provided by coal, petroleum, and natural gas which originate mainly from geological sources, and require millions of years under high subsurface pressure and temperature to replenish. Natural gas is concentrated in deep subsurface due to the thermal maturity required to break down complex hydrocarbons into smaller components (Whiticar, 1990). Only recently has the technology been developed to extrude high yield gas trapped in tightly packed sediments such as Marcellus Shale. However, domestically available unconventional resources are believed to have the capacity of ensuring at least 100 more years of reliable energy, therefore this technology is of special interest.

Drilling a Marcellus Shale well is a complex process that begins by drilling a shallow hole, generally using air or city water as a coolant to minimize contamination of the aquifer (Kargbo et al., 2010). Once the hole has reached beyond the aquifer, casing is lowered into the well and cemented in place. Next, drilling begins inside that casing until near the Marcellus formation using drilling muds composed of a mixture of hydrofracture fluids or municipal water with cuttings or clays. Then, a liner is cemented in place. After that, there are two alternatives: horizontal or vertical drilling. The simplest form is a vertical well where a smaller hole continues into Marcellus Shale vertically, and stops before the end of the formation. Although simple, this type of well provides limited surface area for gas extraction. A horizontal well requires drilling at a $90^{\circ}$ angle within the formation (Figure 1). Many of these wells are drilled horizontally nearly as far $(6,500 \mathrm{ft}$. to $7,000 \mathrm{ft}$.) as the well is deep $(6,000-9,000 \mathrm{ft}$.). Despite the increased complexity and expense, this type of well significantly increases the area for gas extraction. This final 


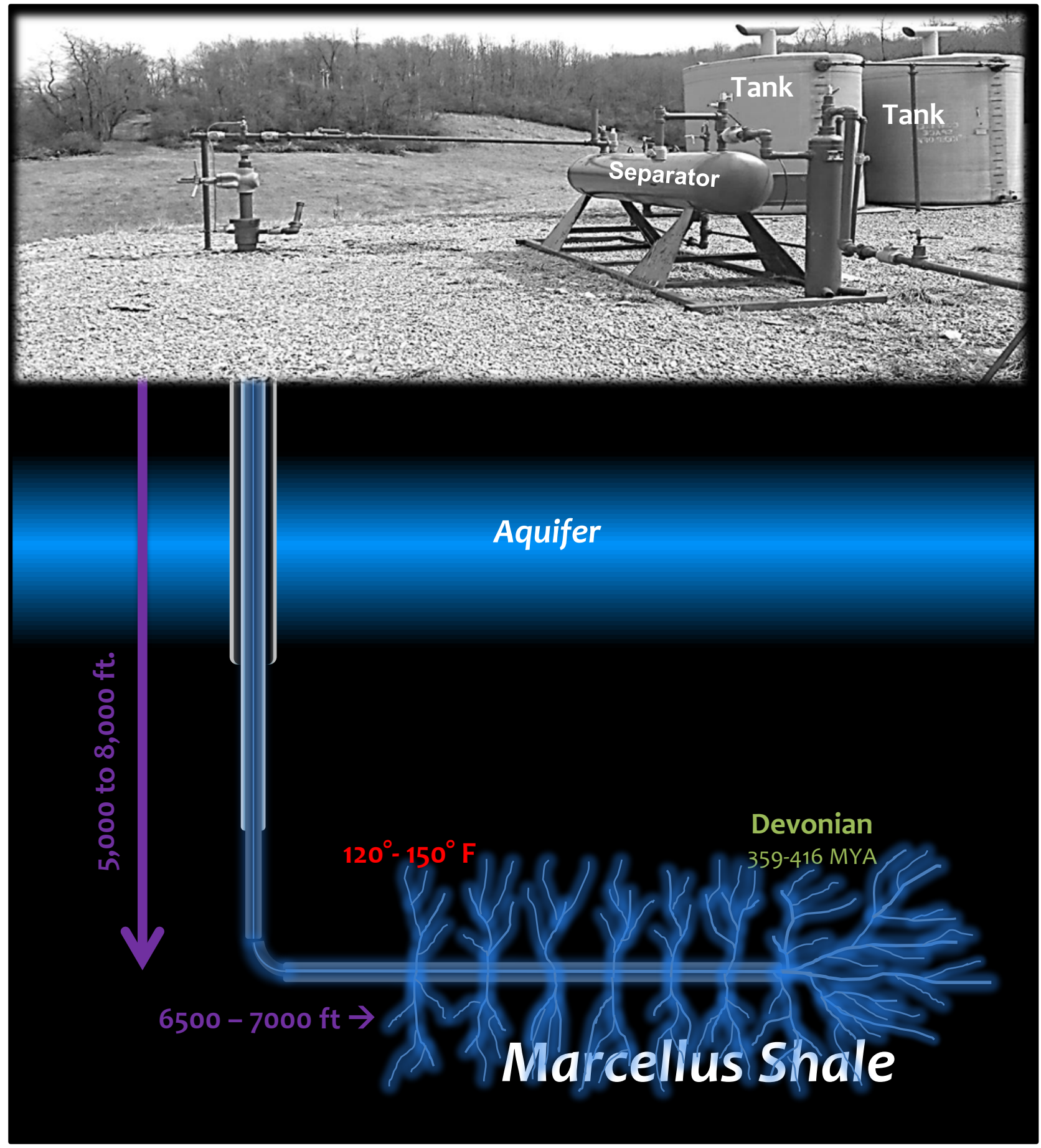

Figure 1 - Completed well diagram illustrating a typical well, casing, and fractures. Picture shows the surface of a completed Marcellus Shale well. The gas-water separator and the tanks are sample points for research. (Not to scale) 
section of the well is then "perforated" in a process that introduces initial holes (perforations) using contained explosive blasts within Marcellus Shale formation. In some wells, this section is encased as those above, while in other wells, the well bore remains exposed. Perforations are designed to initiate artificial fractures in the rock where the subsequent hydrofracturing process can then expand these fractures further into the formation.

\section{Hydrofracture Fluid Composition}

A major hurdle towards successfully extracting natural gas from the tightly packed Marcellus Shale is to free the gas from the impermeable rock (Bruner and Smosna, 2011). This is resolved by creating fractures in the rock using a procedure called "hydrofracturing". . Water, combined with several chemicals, is pumped at high pressures into perforations and natural fractures to increase the permeability and release trapped gases (Kargbo et al., 2010). This process is essential, but requires utilization of approximately 500,000-4,000,000 gallons of water. After hydrofracturing, 20 to $70 \%$ of these fluids return to the surface over the lifespan of the well and require safe disposal (Bruner and Smosna, 2011). The fluids that return to the surface initially are generally referred to as "flowback." Flowback fluids consist of up to $10 \%$ of the initial hydrofracturing fluids, which return to the surface almost immediately after the drilling of the plugs before gas production begins. After the well begins gas production, waste water continues to flow to the surface at a declining rate for several years; these are often referred to as "production fluids." These production fluids are brines which, over time, increase in salt concentration and accumulate metals, radionuclides, and organic substances from the subsurface shale.

Although injected fluids are generally $99 \%$ water, the remaining $1 \%$ contains a complex chemical composition that varies among drilling companies, and even among wells drilled by the same company. The formulation of each of these chemicals is confidential business information. 
However, chemicals likely include hydroxyethyl cellulose as a gel, petroleum distillate (or diesel) as a friction reducer, ammonium bisulfate used to scavenge oxygen, and 2-hydroxy-1,2,3propanetricaboxylic acid to inhibit reactivity of iron, $\mathrm{N}, \mathrm{n}$-dimethyl formamide used as a corrosion inhibitor, ethylene glycol (or 2-butoxyethanol) as scale inhibitor, and methanol-based compounds as surfactants (Kargbo et al., 2010). Other friction reducers, such as guar gum and acrylamide, are also used to speed up delivery and recovery of fluids to and from the shale. The fluids often contain a mixture of biocides which are most commonly reported to include glutaraldehyde. These biocides prevent the growth of sulfur-reducing microorganisms from the surface water which react with the shale and create $\mathrm{H}_{2} \mathrm{~S}$ gas that "sours" the gases and is difficult to separate from methane (Beck, 2010). Biocides may also consist of quaternary ammonium compounds, sodium hypochlorite, sodium bromide, and chlorine dioxide, among other chemicals. All of these precautions are also meant to protect wells from acid-producing organisms that may corrode the well, or other organisms that may build up products or biofilms that may prevent gas recovery.

\section{Isotope Identification of Biogenic Methane}

Methane can be produced either thermogenically in the subsurface by subjecting organic molecules to high levels of heat and pressure over extended periods of time, or through microbial, "biogenic" sources (Whiticar, 1990). Researchers often use carbon isotope measurements to discern these two sources and learn more about the environment, or to track specific gases in the subsurface. Hydrocarbons remaining in water containing organisms performing methanogenesis have a comparatively higher C-13/C-12 ratio because methanogens preferentially use C-12 to create methane. However, other hypotheses exist. Liang et al. (2007) suggest that, as methanogenesis produces "new and refreshed" carbon 
signatures, hydrocarbons in water would be enriched in C-12, while a higher $\mathrm{C}-13 / \mathrm{C}-12$ ratio indicate thermogenic processes because it is those processes that, over time, allow the elements to form their isotopic partners (Liang et al., 2007).

Methane gas from Marcellus Shale is hypothesized to be completely thermogenic (Chapman et al., 2012; Whiticar, 1987) due to the extreme pressures and temperatures these sediments have experienced since deposition. However, Sharma et al., (2013) found evidence of biogenic gases present in Marcellus Shale wells. They used isotope analysis to track the origins of methane in groundwater, and resolve whether the methane is of thermogenic or biogenic origin. They measured isotopic signatures of hydrogen and carbon in the dissolved methane, while also measuring the inorganic carbon in the water. They found high levels of carbon-13 dissolved inorganic carbon $(\delta 13 \mathrm{CDIC})$ in produced fluid, indicative of biogenic processes that preferentially convert lighter hydrocarbons to methane. They suggest the possibility that this may have been caused by methanogenesis in the produced fluid storage tank, but maintained that enriched levels in separator samples contradict that hypothesis. Thus, the issue of whether methane is of thermogenic or biogenic origin warrants additional study.

\section{Conditions in Marcellus Shale}

Conditions in shale today vary by depth and location. An organism living in the Marcellus Shale would have to survive temperatures of $120^{\circ}-150^{\circ} \mathrm{F}\left(49^{\circ}-60^{\circ} \mathrm{C}\right)$. Varying depths from $2,000 \mathrm{ft}$. along Lake Erie, 8,000 ft. in West Virginia and Maryland, to 8,000-10,000 feet in Pennsylvania indicate pressures of 400 to 4,000 psi along the formation (Bruner and Smosna, 2011). Salt $(\mathrm{NaCl})$ concentrations also can be high in this sediment, ranging between 70-150,000 ppm (1.22.58 M) (Harper, 2008; Kargbo et al., 2010). Porosity averages 6\%-10\% and may be a major limiting factor in the shale; however, natural fractures would provide enough room for 
microorganisms to exist. Each of these conditions are within the range under which some microorganisms are known to survive. Water saturation varies in the system between $20 \%-45 \%$, which satisfies the need for water in the ecosystem (Bruner and Smosna, 2011).

These shales are generally believed to be sterile because of the conditions that were present at the maximum depth after deposition and before erosion of the Appalachian Mountains began. Although estimates on the history of shale burial are still quite tentative and vary greatly among studies, several different accounts using vitrinite reflectance as well as conodont alteration indices exist. From one account, it is possible these shales were once buried over 8 kilometers under the surface of the earth and reached temperatures over $200^{\circ} \mathrm{C}$ (Laughrey et al., 2011). Those conditions may be close to the limits of what life can survive; however, increases in pressure and temperature would have occurred slowly and therefore would allow time for organisms to evolve mechanisms that may have helped them cope with such stresses. On the other hand, Bruner and Smosna (2011) indicate that temperatures may have been as low as 75$110^{\circ} \mathrm{C}$ at depths of $8,000-11,000 \mathrm{ft}$. or $110-140^{\circ} \mathrm{C}$ in the more mature shales, and it is much more likely that organisms may have been able to survive such conditions. Several species of Archaea, such as Methanopyrus kandleri, are known to survive and even thrive at temperatures above $100^{\circ} \mathrm{C}$ (Cambridge 2014), and other organisms capable of surviving such conditions are further discussed below, in the "Bacteria in the Subsurface" section. Another thing that is clear from these reports is that these conditions may have been drastically different across the same formation in different locations, adding the possibility that certain organisms could have survived in a different region of the formation. When conditions became more favorable, slow migration of fluids could have transported the microbes from the milder regions to these newly habitable areas. 


\section{Geochemistry of the Shale}

Deposition of Marcellus Shale is believed to have occurred at the bottom of an ocean; however, it is still debated whether it was a deep ocean depositional environment (where the sediment remained anoxic because of high pressures and low turbidity), or if it was a relatively shallow ocean environment such as the Black Sea (Boyce, 2010; Potter et al., 1980). These layers of organic material are interrupted by clastic wedge sediments, from the erosion of the surrounding land, which would have contributed to the mineralogical composition (Smith and Leone, 2010). It is believed that organic material was deposited at the ocean bottom, and was preserved by highly anoxic conditions. The organic material is hypothesized to have come from algal blooms. Dust storms may have increased the nutrient levels of the water causing the algae to bloom until it depleted all nutrients and died, causing rapid accumulation of thick layers of organic material (Wrightstone, 2011). This material would have provided anaerobes with nutrients for growth. However, it is not well understood how these anaerobes would be preserved in such conditions. These organisms may have been living within the sediments since they were deposited. Alternatively the organisms, although active at the time of deposition, may eventually have encountered conditions where they could no longer survive, and became no more than an addition to the remaining organic material. Some chemical analysis was also done (unpublished) along with this work that supported good preservation of organic content within the shale. For example, high levels of vanadium in Marcellus shale suggested that these sediments were deposited in a reducing environment which may imply an anoxic environment at the time of deposition favorable to anaerobic organisms.

Mineral analysis from thin sections shows the abundant presence of quartz (SiO2) in the upper Marcellus, and a somewhat abundant presence in the lower Marcellus regions. This is in line with the "ocean bottom" hypothesis because quartz is common in sand, and should support the growth and preservation of the anaerobic methanogens of interest, considering that is where 


\begin{tabular}{|c|c|c|c|}
\hline Mineral & Levels & Effect on Microbes & $\begin{array}{l}\text { Effect on Organic } \\
\text { Preservation }\end{array}$ \\
\hline Barite & Low & $\begin{array}{c}\text { Positive } \\
\text { Some types of bacteria such as } \\
\text { Desulovibrio use barite as a } \\
\text { nutrient (Phillips et al., 2001). }\end{array}$ & $\begin{array}{c}\text { Negative } \\
\text { Has been linked to organic matter } \\
\text { decomposition (Arndt et al., 2009) }\end{array}$ \\
\hline $\begin{array}{l}\text { Calcite } \\
\mathrm{CaCO}_{3}\end{array}$ & Low $\rightarrow$ High & $\begin{array}{c}\text { Positive } \\
\text { Microorganisms are associated } \\
\text { with its formation (Boquet et al., } \\
\text { 1973). }\end{array}$ & $\begin{array}{c}\text { Positive } \\
\text { Helps balance pH so that } \\
\text { sediments does not become too } \\
\text { acidic (Mekik et al., 2002). }\end{array}$ \\
\hline $\begin{array}{l}\text { Chlorite } \\
\mathrm{ClO}_{2}^{-}\end{array}$ & High & $\begin{array}{c}\text { Negative } \\
\text { Has several antibacterial } \\
\text { properties (Ruiz Cruz et al., 2006). }\end{array}$ & $\begin{array}{c}\text { Negative } \\
\text { Can oxidize certain organic } \\
\text { molecules which may be } \\
\text { detrimental in preservation (Ruiz } \\
\text { Cruz et al., 2006). }\end{array}$ \\
\hline $\begin{array}{c}\text { Dolomite } \\
\mathrm{CaMg}\left(\mathrm{CO}_{3}\right)_{2}\end{array}$ & High & $\begin{array}{c}\text { Positive } \\
\text { Often precipitated by } \\
\text { microorgansisms (Vasconcelos et } \\
\text { al., 1995). }\end{array}$ & $\begin{array}{c}\text { Positive } \\
\text { Causes pores to be smaller and } \\
\text { therefore allows for a very anoxic } \\
\text { environment (Kulm et al., 1984). }\end{array}$ \\
\hline $\begin{array}{c}\text { Feldspar } \\
(\mathrm{K} / \mathrm{Na} / \mathrm{Ca}) \\
\underline{\mathrm{AlSi}}_{3} \underline{\mathrm{O}}_{8}\end{array}$ & High $\rightarrow$ Low & $\begin{array}{c}\text { Positive } \\
\text { Those containing inclusions of P- } \\
\text { minerals are scavenged for the } \\
\text { phosphates (Ross et al., 1982). }\end{array}$ & $\begin{array}{l}\text { Positive } \\
\text { Often found in mudrocks which } \\
\text { preserve fossils well due to their } \\
\text { small grains (Rogers et al., 1998). }\end{array}$ \\
\hline $\begin{array}{l}\text { Illite-Muscovite } \\
\text { K Al Silicate }\end{array}$ & High & $\begin{array}{c}\text { Positive } \\
\text { Can aid in substrate utilization by } \\
\text { sulfate reducing bacteria } \\
\text { (Laanbroek and Geerligs, 1983). }\end{array}$ & $\begin{array}{l}\text { Positive } \\
\text { Surfactants bound to illite or } \\
\text { montmorillonite are typically } \\
\text { degraded to lesser extents } \\
\text { (Knaebel et al., 1994). }\end{array}$ \\
\hline $\begin{array}{l}\text { Pyrite } \\
\text { FeS }_{2}\end{array}$ & High & $\begin{array}{c}\text { Positive } \\
\text { Sulfur reducing organisms use } \\
\text { pyrite for their metabolism } \\
\text { (Matlakowska and Sklodowska, } \\
\text { 2007). }\end{array}$ & $\begin{array}{c}\text { Positive } \\
\text { Associated with an anoxic } \\
\text { deposition which improves } \\
\text { preservation of organics (Hedges } \\
\text { and Keil, 1995) }\end{array}$ \\
\hline $\begin{array}{l}\text { Quartz } \\
\mathrm{SiO}_{2}\end{array}$ & High & $\begin{array}{l}\text { Positive } \\
\text { Bacteria are often associated with } \\
\text { growth in quartz deposits (Smith et } \\
\text { al., 2000) }\end{array}$ & $\begin{array}{c}\text { Positive } \\
\text { Known to aid in preservation of } \\
\text { organic material such a plant } \\
\text { deposits (Rimmer et al., 2004) }\end{array}$ \\
\hline
\end{tabular}

Table 1 - Concentration levels of common minerals in Marcellus Shale and how each may affect any indigenous microorganisms or organic preservation. 
they are often found today. Calcite $\left(\mathrm{CaCO}_{3}\right)$ was uncommon in the upper portion of the Marcellus Shale, except in fossils from the lower half, and was common in the lower portions of the Marcellus Shale. Dolomite $\left(\mathrm{CaMg}\left(\mathrm{CO}_{3}\right)_{2}\right)$ was common only in the lower portion of the shale, where methanogens have been shown to live previously (Roberts et al., 2004). Roberts et al. (2004) found through experimentation that methanogens are integral to dolomite precipitation in basalt because a microbial consortium reacts with the surface and releases magnesium and calcium into solution, driving dolomite precipitation via nucleation. They found that IlliteMuscovite (K Al silicate) was abundant in the upper regions of the shale and less common in the lower regions. Chlorite (Mg Fe Al silicate) was common throughout the shale. Pyrite $\left(\mathrm{FeS}_{2}\right)$ was more common in the shale and most abundant towards the margins with the limestone concretions. Feldspar ( $\mathrm{Na}$ Al silicate) was only seen commonly in the upper Marcellus regions. Therefore, the mineral content likely found in Marcellus Shale should be conducive to bacterial life, most specifically methanogens (Table 1).

\section{Possibility of Bacteria Living in Subsurface}

Research describing microorganisms in the deep subsurface is somewhat rare due to the great limitations of acquiring and working with such samples. However some work has been done indicating that microorganisms should, in theory, be able to inhabit subsurface environments up to $3.5 \mathrm{~km}$ (Krumholz, 2000). Bacteria tolerate high temperatures, pressures and salinity levels. For example, Thermus aquaticus, was isolated from thermal springs, and has ideal growth between $70-75^{\circ} \mathrm{C}$ (Brock and Freeze, 1969). These thermophillic organisms are generally different from most organisms based on the properties of their lipid bilayer. These lipid bilayers are more similar to those in Archaea than Bacteria. (Cambridge, 2014). Bacteria utilize a 'sequence-based' mechanism to protect their proteins from denaturation due to high 
temperatures, such changes in the amino acid sequence allow for the formation of additional salt bridges or other specific interactions.

Halophilic bacteria are well known for their ability to thrive in high salt environments. With concentrations of salt between 1.2-2.58 M, the conditions of shale barely enter the hyperthermophile range of organisms that require salt concentrations over $2.5 \mathrm{M}$. A commonly known halophilic bacterium is Salinibacter ruber, which thrives in saltern crystalliser ponds. Other bacterial halophiles include Chromohalobacter beijerinckii, and Tetragenococcus halophilus (Cambridge, 2014). S. ruber relies on a high influx of potassium ions from the environment to protect itself from the high external ion concentration, leading to extremely high salt concentrations in the cytoplasm. Its amino acids are protected from high salt concentrations by an increase in acidic amino acids, and special genomic signatures that distinguish them from other organisms. The techniques they employ for protection to high salinity are very similar to those that Archaeal species use.

\section{Evidence for Microorganisms in the Subsurface}

Research on deep subsurface microorganisms is limited, but organisms in very deep environments have been found. Onstott et al., (1998) used bacterial culture methods to explore the microbial community 2,800 meters below ground at a natural gas reservoir in the Taylorsville Basin in Virginia. This reservoir, with temperatures up to $76^{\circ} \mathrm{C}$, pressure around $32 \mathrm{MPa}$, and salinity levels of approximately 0.8 wt. $\% \mathrm{NaCl}$ equivalent, contained fermenting, Fe(III)-reducing, and sulfate-reducing bacteria ( 1 to $10^{4} \mathrm{cells} / \mathrm{g}$ ). They hypothesized that due to the small pore sizes, the organisms must have been trapped in the formation waters. 
Lippmann-Pipke et al., (2011) found indigenous microbes, including viruses, 3.2 kilometers underground from an ultra-deep gold mine in Carletonville, South Africa using several methods including cell culturing, T-RFLP, and Next Generation Sequencing. An extreme alkaliphile, Alkaliphilus transvaalensis, isolated from these mines, is an endospore-forming organism with ideal growth at $40^{\circ} \mathrm{C}$ with a pH range between 8.5 and 12 (Takai et al., 2001). Chivian et al. (2008) found a single species ecosystem of the sulfur-reducing organism Candidatus Desulforudis audaxviator at a depth of 2.8 kilometers within these mines.

Despite the knowledge that many coal sediments have been heated to well above $300^{\circ} \mathrm{C}$, microorganisms in coal mines have been studied since the 1930s using culturing techniques (Burke and Wiley, 1937). Since before the 1950s, it has been known that sulfur reducing bacteria such as T. thiooxidans, which inhabit mine waters, are the culprits behind coal acid mine drainage (Temple and Delchamps, 1953). More recently, Next Generation Sequencing methods have confirmed the presence of several types of bacteria inhabiting coal sediments, including Brevundimonas, Hydrogenophaga and Acinetobacter (Guo et al., 2012). However the organisms found in each type of coal have been found to differ greatly (Opara et al., 2012).

Oil extraction processes have also allowed study of indigenous microorganisms. In 1926, Bastin et al. (1926) isolated sulfur reducing microorganisms from the waters from an oil field. These organisms were of special concern because of their ability to "sour" the gas by production of $\mathrm{H}_{2} \mathrm{~S}$, making it less valuable. More recently, high concentrations of indigenous thermophillic bacteria were discovered in a reservoir 1,670 m below the surface (L'Haridon et al., 1995). Thermatoga petrophila and Thermatoga naphthophila have been isolated from oil reservoirs, and can survive temperatures up to $80^{\circ} \mathrm{C}$ (Takahata et al., 2001). While it appears that organisms in the subsurface on land, possibly due to the impermeable rock, are very different across sites, oil reservoirs in ocean sediments have been found to contain similar organisms thousands of kilometers apart (Amend and Teske, 2005). 
The aquifers of the Fennoscandian Shield in northern Europe may be arguably the best-studied natural laboratory of deep subsurface microbiology in granitic rock (Nyyssonen et al., 2014). Water from these sediments has been explored to depths of 2516 meters using Next Generation Sequencing. That study found Comamonadaceae and Thermoanaerobacterales to dominate the population in sediments between 2300-2500 meters, while Dehalobacter and Dethiosulfatibacter were prominent in sediments at 1300-1500 meters where sulfur was greater. Nyyssonen et al. also found that Methanobacterium species increased with depth in this sediment. An earlier study using cell culture methods to explore the microorganisms in the Fennoscandian Shield found $3.7 \times 10^{5}$ cells $/ \mathrm{ml}$ as deep as 1350 meters underground (Haveman and Pedersen, 2002).

The microbial cell density found at several different sites, determined by epi-fluorescence

microscopy, was generally $10^{5}-10^{6}$ cells $/ \mathrm{mL}$ of groundwater. rRNA gene sequencing has found several organisms including methanogens, homoacetogens, methanotrophs, sulfur reducers, and Fe(III)-reducers in other subsurface conditions (Kotelnikova, 2002). The more work that is done, the more it seems clear that the microorganisms present at these depths become architects of the chemistry of their environment.

\section{Possibility of Methanogenic Archaea Living in Subsurface}

Archaea is a kingdom of organisms of similar size and shape as Bacteria and is often considered to be as distinct from Bacteria as it is from Eukaryota (Bräuer et al., 2006). Archaea often inhabit extreme environments and the kingdom is largely composed of methanogenic organisms, although some methanotrophs (methane consuming organisms) and lithotrophs (organisms that get energy from inorganic chemicals such as nitrogen or sulfur) also exist in that group. Several species of methanogens have been discovered with the ability to survive the 
harsh conditions in the shale (Bräuer et al., 2006; Chapelle et al., 2002)(Figure 2). A methanogen, Methanopyrus kandleri, still holds the record for hottest temperatures survived $\left(122^{\circ} \mathrm{C}\right)$, and most thermophiles come from the kingdom Archaea (Cambridge, 2014). Archaea use a 'structure-based' mechanism that uses increased compactness of the proteins for stabilization using disulfide bonding. For membrane thermostability, Archaea employ isoprenoid hydrocarbon chains, which provide a high permeability barrier and a liquid crystalline state across the entire biological temperature range, so lipids do not need to be adapted to changing temperatures.

Halophillic organisms that can tolerate salinities higher than $0.5 \mathrm{M}$ are common in Archaea as well. Examples of archaeal halophiles include Haloarcula, Haloferax, Halococcus and the rather confusingly named Halobacterium. All of these belong to the order Halanaerobiales. Of the methanogenic Archaea, a good example of an organism that is able to tolerate such high salt stresses is Methanohalophilus, which has been previously found in the Antrim Shale of Michigan (Kirk et al., 2012). Many of these Archaea cope by accumulating compatible solutes such as amino acids or sugars in their cytoplasm. These solutes do not impair cell function, yet they protect the cells from other kinds of stress such as high temperatures (Cambridge, 2014).

Several methanogens have the ability to tolerate temperatures found in the shale. Some Methanococcus species have been known to tolerate temperatures from $30-85^{\circ} \mathrm{C}$, and their salt tolerance ranges from 1.3 to $8.3 \%$, which is within the known range for Marcellus Shale wells (Haney et al., 1999; Huber et al., 1982). Methanocelleus also contains species that include traits which allow them to not only tolerate the environment but thrive. For example $M$. submarinus, which is found in marine sediments with methane hydrates 950 meters deep and 125 meters below the surface, has an ideal growth temperature of $45^{\circ} \mathrm{C}$ and can survive up to $1.5 \mathrm{M}$ of $\mathrm{NaCl}$, making it a great candidate for life in Marcellus Shales today (Mikucki et al., 2003). Even 


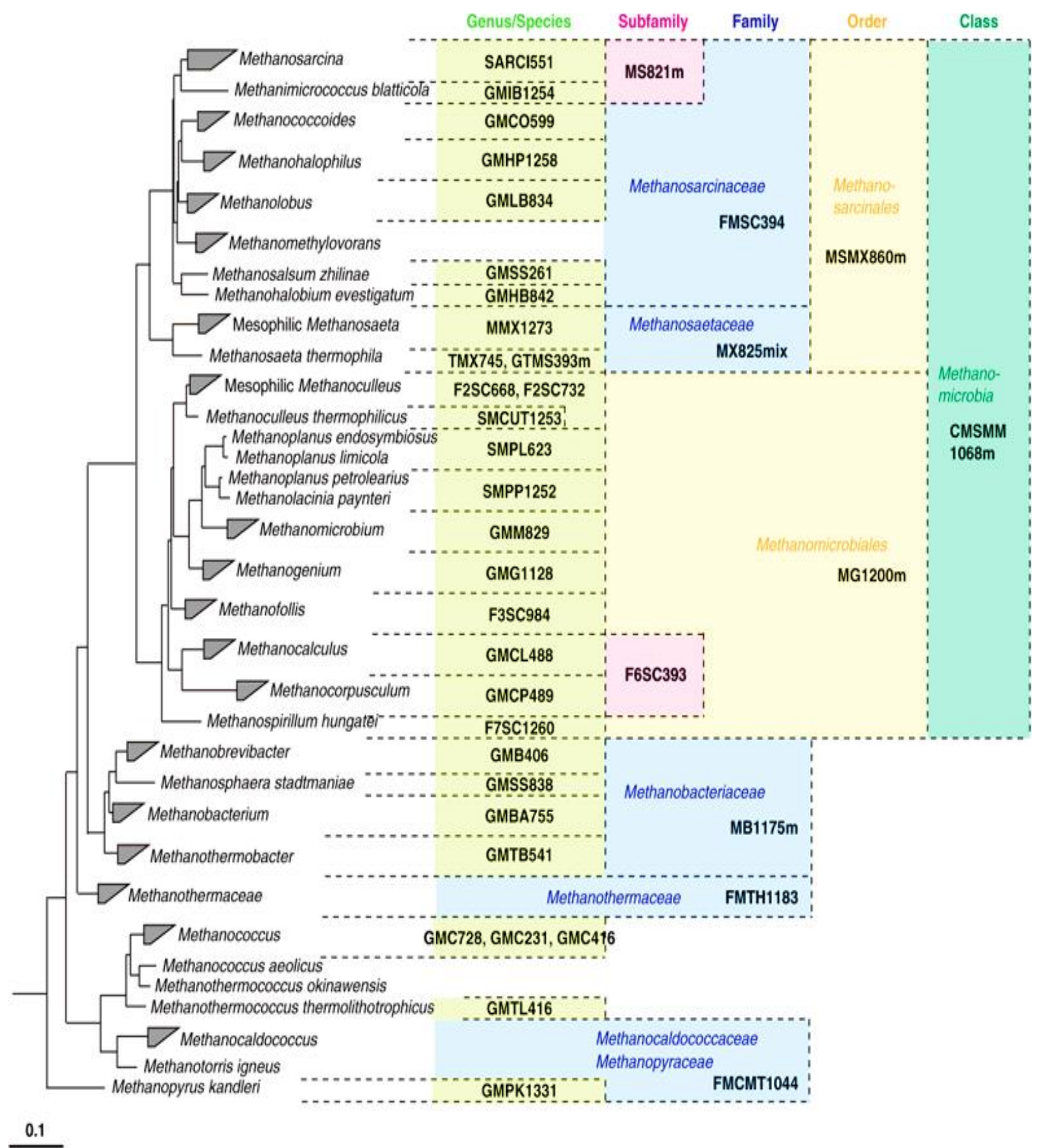

Figure 2 - Phylogenetic tree of several known methanogens based on partial 16s rRNA gene sequences based on neighbor-joining analysis. This figure was taken with permission from a paper by Narihiro et al (2009). 
Better, would be several of the species from Methanosarcina whose members have among the broadest metabolisms in the realm of methanogens. For example, Methanosarcina acetivorans, isolated from deep marine sediments, can survive at reservoir temperatures $\left(48-60^{\circ} \mathrm{C}\right)$; and can grow using sodium acetate, methanol, methylamine, dimethylamine, and trimethylamine (Sowers et al., 1984).

\section{Methanogens in the Subsurface}

Methanogens are commonly found in shallower regions of the subsurface (Beckmann et al., 2011a). Many studies have found that the isotopic composition of much of the methane present in coal bed methane deposits is largely biogenic (Bates et al., 2011; Thielemann et al., 2004). Thielemann et al. (2004) indicate that the microbial contribution of methane seems to be more pronounced at sites of coal mining (especially abandoned sites). Methanogens are often found in enriched samples (after incubation) of coal through DNA analysis, but levels of methanogenic Archaea in these resources are often undetectably low in raw samples (Beckmann et al., 2011a; Beckmann et al., 2011b; Penner et al., 2010; Shimizu et al., 2007). DNA sequencing often detects bacteria such as Paleobacter, Clostridium, Acetobacterium, and Syntrophus that may have symbiotic relationships with methanogens. Several studies using bioreactors confirm that methanogens are known to comfortably utilize coal as both a habitat and as a nutritional resource to produce methane (Beckmann et al., 2011b; Penner et al., 2010). Work to engineer nutrient solutions for methane production in coal has been ongoing since at least 2008 (Harris et al., 2008). Many researchers have tried different mixtures of supplements from BHI (brain heart infusion) to $\mathrm{CO}_{2}$, but no supplement has been agreed upon as ideal yet. Rates of methane production have also been shown to change over different incubation periods. Some papers suggest methanogens are productive within the first few days, while others indicate a long 
period (30 days to a year) is required before maximum methane production is reached (Jones et al., 2010). In general, it appears that certain coals are better at methane production than others. From Green et al. (2008), it appears that lower $\mathrm{pH}$, and higher particle sizes and temperatures are optimal for high methane production rates in these systems. Most recently, Opara et al. (2012) found that they could produce significant amounts of methane from coal by adding different enriched microbial consortia.

Methanogens have been found in shale previously. In Michigan, the Devonian Antrim Shale was discovered to contain large numbers of methanogens (Kirk et al., 2012). Although this shale is younger and shallower ( $<5,000 \mathrm{ft}$.) than the Marcellus Shale of interest, it was deposited in much the same way and has similar chemical composition, which supports the hypothesis that methanogens could exist in the Marcellus Shale. The microorganisms in this shale produce economic levels of methane which is still utilized today (Martini et al., 1996). Most of the methanogens found in these regions are Methanohalophilus species, which is logical considering the high salinity levels found in such deposits (Waldron et al., 2007). However, it has also been found that other types of methanogens such as Methanoplanus and Methanocorpuscolum also inhabit these shales and are distributed based on geochemical composition of certain regions in the shale.

\section{Microbes in Hydrofracture Fluids}

Murali et al. (2013b) published the first paper on microbial composition of hydrofracture fluids. Similarities and differences between injected fluids and the produced fluids were compared in flowback water impoundments using pyrosequencing methods. These impoundments are open lakes that expose water to the environment, so measurements focused on how different aeration methods affected the microorganisms in the impoundments. Methanogenic Archaea 
were found in these samples, but contamination from the open environment prevented any conclusions as to their origin.

Another study followed microbial communities in one well from pre-injection until day 187 of production (Murali Mohan et al., 2013a). This study determined that microbial communities in produced fluids begin to differ significantly from those in pre-injection fluids by day 7 of production, exhibiting significant decreases in bacterial diversity over the lifespan of the well. They attributed these changes to natural selection of the bacterial communities injected towards a community more favorable to life in shale. The authors attempted the use of archaeal primers for sequencing, but did not find any DNA amplification, therefore they concluded that no Archaea were present. In order to characterize the bacteria present, they utilized forward primer F515 and reverse primer R806 for amplification before 454 pyrosequencing. They also attempted to amplify drilling muds, but were unable to amplify any microbial DNA. They found that bacterial communities in day 187 fluids consisted largely of Clostridia, a group that contains several extremophiles. This work also concluded that Next Generation Sequencing techniques were more efficient at getting a full picture of the organisms present in such samples than clone library dependent Sanger sequencing.

Most recently, Cluff et al. (2014) performed a long-term study of changes in hydrofracture fluids in three wells until day 328 of production on both the geochemistry and microbiology. They used pyrosequencing of DNA extracts from produced fluids, and found some sequences that had homology to certain Methanogenic Archaea in later samples of produced fluid. On day 82, they found about $0.19 \%$ of the sequences which were homologous to Methanohalophilus and $1.9 \%$ which were homologous to Methanolobus in one well. On day 328 they found methanogens in both wells but they found more Methanohalophilus than Methanolobus. Other organisms prevalent in the produced fluids as time went on consisted largely of halotolerant bacteria and organisms associated with fermentation, hydrocarbon and sulfur cycling metabolisms. This 
included Halolactibacillus, Vibrio, Marinobacter, Halanerobium, and Halomonas. They also confirmed that the later produced fluids looked significantly different with respect to bacterial content than the pre-injection fluids, but again hypothesized this was a product of differentiation of injected communities in the subsurface. Their most important conclusion was that gas souring microorganisms are prevalent in these produced fluids.

\section{Possible Contamination Sources in Water and Core Samples}

Water samples: Contamination from the drilling method is one of the most complex problems when doing microbiological research on water and core samples. One source of microbial contamination is the storage tank where water was stored after flowback (Kirk et al., 2012). These storage tanks are not sterilized between drill operations, thus, methanogens could be introduced into the water sample from a previous operation unrelated to shale gas drilling. Other sources include: muds used to cool the drilling bit during the drilling process, the sand used as a "proppant," and the water used to drill out plugs used to keep high pressure in the hole during hydrofracturing (Struchtemeyer and Elshahed, 2012).

Core samples: When acquiring core samples, different contaminants can be introduced. These samples have never been exposed to hydrofracture fluids, storage tanks, or proppant sands. However they are exposed to drilling muds utilized to cool drill bits. After extraction, core samples may become exposed to human contact during handling. The extracted core is then placed in cardboard boxes and generally stored in a back room or warehouse. Contamination may come from the box. Also, microbial communities in the rock may begin to grow and change in composition (Mauclaire et al., 2007). 


\section{DNA-Independent Tests Available for the Identification of Microbes in Samples}

There are several methods available for the study of microbial composition. Earlier methods are DNA-independent and use a range of physiological characteristics such as those in Bergey's Manual of Determinative Bacteriology (Garrity et al., 2004). These were the original techniques for typing microorganisms and focus differentiating the microorganisms based on Gram stain, shape (cocci, bacilli, spirilla), grouping, spore formation, metabolism, oxygen requirement, motility, color, or growth conditions required. Gram stains for example, are used to differentiate bacterial species into two groups based on the physical properties of their cell walls. Gram positive bacteria are only from phyla Firmicutes and Actinobacteria, other taxa are generally negative. Another group of techniques uses fatty acid profiles (MIDI/FAME). They compare the fatty acid pattern present in the cell membrane of bacteria as it is separated from the cell and analyzed with the gas chromatograph (Sasser, 1990). Cellular fatty acid/methyl esterase analysis by gas chromatography (FAME) has been used for more than 50 years as a rapid and easy-to-use method for routine microbial identification. Branched-chain fatty acids (iso- and anteiso-acids) are common in many gram-positive bacteria, while gram-negative bacteria contain predominantly straight-chain fatty acids. The presence of lipopolysaccharide in gramnegative bacteria gives rise to the presence of hydroxy fatty acids in those genera. This technique has the ability of identify over 2,000 microbial species, including 700 environmental aerobic species, 620 anaerobic species, and 200 species of yeasts from pure culture in as little as 15 minutes. Another direct marker method of identifying species in a sample is the Enzyme Linked Immunosorbent Assay (ELISA) (Hornbeck, 1991). For this an antibody coated plate is exposed to the environmental sample. If the bacterium contains the protein which is recognized by the antibody, it will bind to the ELISA plate and be bound by a second antibody that will give a color change signal. This requires the production of specific antibodies, soluble antigens, or 
cell-surface antigens that may be present in the bacterium. Usually plates are coated with multiple antibodies, and there is a code to read it, so that it can detect multiple organisms from the sample simultaneously. A disadvantage to this technique is that the analysts have to know what they are looking for in an environmental sample in order to coat the ELISA plate with the correct antibodies. Organisms lacking antigens for the antibody used on the plate will be missed by the assay.

Other tests use indirect markers, and require live bacteria because they depend on physiological activity. One benefit of such techniques is that they give information on more than just the type of organisms present. For example, they also test for viability of organisms which ensures one is not detecting dead material in a sample. One commonly used method is a biochemical test called BIOLOG which uses carbon source utilization coupled with chemical sensitivity assays, including $\mathrm{pH}$ sensitivities to type the bacteria in a sample (Smalla et al., 1998). Communities of organisms will give a characteristic reaction pattern called a metabolic fingerprint. To do this test, each organism of interest from each sample must be grown in pure culture, and tested individually. Other indirect marker tests exist, but they all have similar downfalls. One of the biggest problems both for direct and indirect marker detection is that most of these assays are not well developed for Archaea. Few archaeal species are present in the databases, and techniques requiring identification of fatty acids in the cell membrane are not well equipped for the widely different make up of archaeal cell membranes, making them ineffective for detecting methanogens.

\section{DNA Dependent Methods Available for the Study of Bacteria and Archaea in Samples}


The problem with most of the above, DNA-independent methods for identification, is that most of them require culturing the organisms in question. Culturing microorganisms is known to introduce bias and not all of the microbes in an environmental sample may be detected, as many microorganisms require a very specific medium that is only known after the identification of the organism (Wagner et al., 1993). Newer techniques using DNA for identification are beneficial as it can be extracted directly from most samples without introducing the bias of culturing and isolation. Several methods exist which range from the simpler 4', 6-diamidino-2phenylindole (DAPI) stain (a fluorescent stain that binds strongly to the A-T rich regions of DNA and can be detected by microscopy) to the most modern and computer intensive Next Generation Sequencing techniques (Porter, 1980). The most similar technique to DAPI is fluorescent in situ hybridization (FISH). This technique uses fluorescent probes that bind to specific complementary sequences on the chromosomes of the bacteria to show both expression and localization of specific genes. By targeting specific genes, such as 16s rRNA genes, this simple technique can be used to identify Archaea and Bacteria within a sample, or can characterize the organisms present that may have certain metabolic genes (Kleikemper et al., 2002). Similarly, DNA microarray uses a DNA microchip to test multiple DNA sequence probes at once. Although most commonly used for gene expression analysis, recent efforts have found ways of utilizing its gene binding techniques to design functional gene arrays that provide information about nutrient cycling genes within a bacterial community (Zhou, 2003). Unique probes were created that target 16s rRNA genes, which can characterize the community present in an environmental sample (Pathak et al., 2011). These techniques can be done using either DNA or RNA, and use quantitative PCR (qPCR) methods to detect differences in how many of each type of microorganism is present. If researchers specifically determine the microbe they are looking for in a sample, simple quantitative PCR methods can measure the amount of DNA from that organism present in each sample. However, because specific primers must be used, the investigator must be fairly confident of the identity of the microorganism in 
question. Otherwise, general 16s rRNA primers can only detect amounts of DNA present nonspecifically (Kim, 2001). A method commonly utilized for identification of community differences between samples is denaturing gradient gel electrophoresis (DGGE), in which multiple restriction enzymes and a denaturing gradient are used on the rDNA from the community to display differences between samples. However, it has limited resolution as it can provide neither qualitative nor quantitative information on samples. Most papers on remediation use some sort of DDGE analysis. However, because it only provides qualitative information on how different two communities may be, such analysis are generally matched with some other type of study (Muyzer et al., 1993).

Currently, the most commonly utilized method for microbial identification is DNA sequencing. Sequencing was invented in 1977 by Sanger et al. and uses a polymerase chain reaction that used nucleotides to terminate chain amplification (Sanger et al., 1977). Based on which nucleotide was added before termination, a series of such reactions ordered by size could determine the sequence of any amplifiable gene. More recently, his techniques have been refined to create a computerized system that could add fluorescently labeled nucleotides that allow for amplification to continue, and can be read by a computer. However, the large volume of DNA required for these systems mean that the gene in question must be cloned into a bacterial vector for amplification.

\section{Next Generation Sequencing}

More recently, new sequencing techniques, commonly referred to as "Next Generation Sequencing" methods, were developed that could use less DNA, and therefore bypass the cloning steps. Among these are 454 Pyrosequencing, which uses a similar technique where 
fluorescent nucleotides are added sequentially and detected by a computerized system. DNA is attached to beads which are placed in a plate and undergo PCR amplification to coat the bead with several copies of the gene that produce detectable levels of light when a labelled nucleotide is added (Rothberg and Leamon, 2008). In 2010, "Illumina Sequencing" was developed by Gloor et al. (2010) where DNA is bound to a chip before amplification, and uses a special polymerase that creates a different colored light signal when each different nucleotide is added. Therefore, all of the nucleotides can be added at once instead of one at a time as in 454 Pyrosequencing. 454 Pyrosequencing and Illumina also differ in their maximum size of amplification. 454 Pyrosequencing was originally able to amplify fragments up to 400 bp when Illumina could only amplify 150 bp. fragments; however, amplification length increases as Illumina improves their technology. Despite its small fragments, Illumina prevailed as it was often believed that it was more accurate than 454 Pyrosequencing methods. These error rates are especially important when small changes in nucleotide composition are instrumental to differentiate organisms in the sample. Other sequencers exist and several are being developed to this day, but those two are the leading methods in the field at the moment. Without the need for cloning, more sequences can be amplified per sample, creating a more complete picture of the microbiome.

\section{Primers Available for Analysis of Bacteria and Archaea}

Next Generation Sequencing techniques cannot quickly or practically amplify long regions of DNA; therefore, primers targeting a short, specific region of DNA are required for amplification. 16s rRNA primers are generally used for bacterial DNA amplification in environmental samples (Wang and Qian, 2009). These primers target short conserved fragments of DNA that are spaced around hypervariable regions and allow very accurate barcoding of many different 
species of bacteria. Commonly used primers are often better than less common specific primers considering the database will contain a more robust basis for comparison, and therefore provide better assignments.

Despite the fact that the archaeal ribosome is different from that of bacteria, it seems that some of the conserved regions in genes required to generate some of the $16 \mathrm{~s}$ rRNA are conserved enough in Archaea that certain bacterial 16s rRNA primers will amplify Archaea (Baker et al., 2003). The $515 \mathrm{~F}, 806 \mathrm{R}$ primers that target the $\mathrm{V} 4$ variable region are among these. They are also among the most popular pairs of primers for bacterial amplification, making them good candidates for single amplification sequencing to identify entire microbiomes.

Ribosomal primers specific to Archaea also exist; however if analysis is focused on finding methanogens in a sample, the accepted manner of identification is by amplification of a gene for a methane metabolism enzyme. The most accepted set of primers for methanogen amplification target the gene for methyl coenzyme M reductase a subunit (mcrA) (Hallam et al., 2003; Juottonen et al., 2006). This gene codes for protein required in methanogenesis so it is somewhat conserved in methanogens (Luton et al., 2002). However conserved, this gene still contains enough variation to allow for generic identification. An important difficulty with this gene is that it is not quite as conserved as 16s rRNA (Figure 3). Therefore, primers designed to target the region need to be highly degenerate, which reduces their efficacy. Also, although they have been utilized in quantitative PCR (qPCR) techniques for quantitation of methanogens in a sample, they have the unfortunate trait of also amplifying genes from methanotrophs (methane degraders); therefore, any results would not distinguish between organisms that consume methane and those that produce methane. 


\section{Process of Methanogenesis}

Methanogenic Archaea have several metabolic pathways for methane production (Figure 3). All methanogens can produce methane from $\mathrm{CO}_{2}$ and $\mathrm{H}_{2}$ and are referred to as hydrogenotrophic methanogens. Acetoclastic methanogens are those that can convert acetate to methane. Other reactions are more organism specific. For example, Methanosarcina acetivorans, isolated from deep marine sediments, can grow using sodium acetate, methanol, methylamine, dimethylamine, and trimethylamine (Sowers et al., 1984). Despite the broad differences among pathways, all lead to the formation of a mixed disulfide from coenzyme $M$ and coenzyme $B$ that functions as an electron acceptor of certain anaerobic respiratory chains (Ferry, 1994). Molecular hydrogen, reduced coenzyme F420, or reduced ferredoxins are used for the donation of electrons to the reaction. These resulting redox reactions are catalyzed by the membranebound electron transport chain which is coupled to proton translocation across the cytoplasmic membrane and results in ATP synthesis catalyzed by an A1A0-type ATP synthase (Deppenmeier, 2002). The full process is outlined, with enzymes, in figure 4 . This figure outlines the processes for methanogenesis, and summarizes the enzymes used by methanogens such as Methanosarcina acetivorans. This methanogen was chosen because it contains among the most diverse methane metabolisms known from all species, as one of the few acetoclastic species. It should also be noted that fermenting bacteria can also produce methane as a byproduct of their digestion and therefore may present an important percentage of the methane producers in Marcellus Shale. 


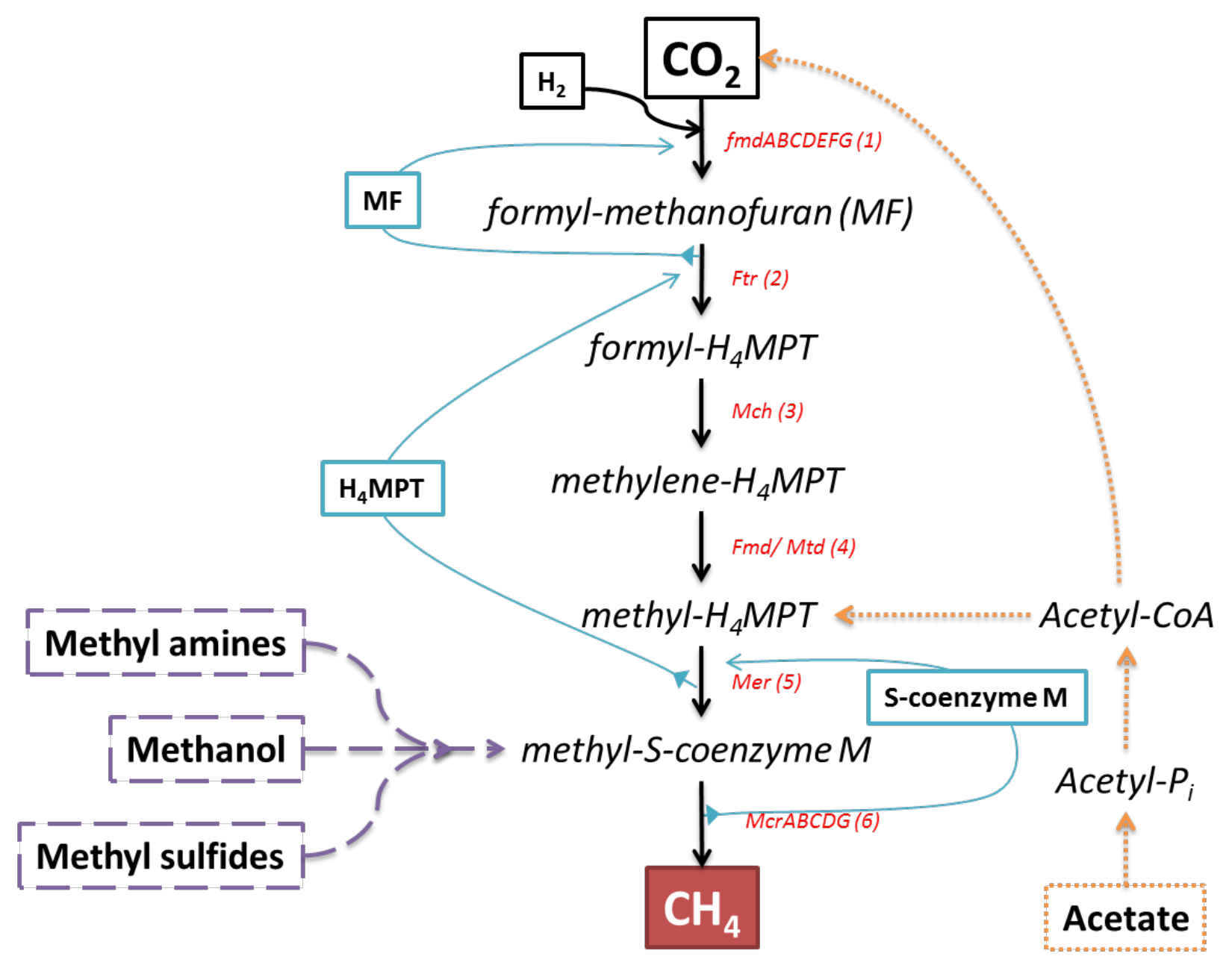

Figure 3 - Example of the methanogenic metabolic pathway. Possible metabolites for methanogens are marked in boxes and include acetate, methyl-amines, methanol, methylsulfides, and a combination of $\mathrm{H}_{2}$ and $\mathrm{CO}_{2}$. Enzymes responsible for reactions are coded in red/italic: (1) Formylmethanofuran dehydrogenase (2) Formylmethanofurantetrahydromethanopterin N-formyltransferase (3) Methenyltetrahydromethanopterin cyclohydrolase (4) Methylenetetrahydromethanopterin dehydrogenase, (5) Coenzyme F420dependent N5,N10-methenyltetrahydromethanopterin reductase (6) Methyl-coenzyme M reductase. The hydrogenotrophic pathway (black/solid) makes up the backbone while the acetotrophic pathway (orange/dotted) and other possible carbon sources (purple/dashed) feed into the system.. 


\section{REFERENCES}

Allers, T., \& Mevarech, M. 2005. Archaeal genetics - the third way. Nature Reviews in Genetics,. 6(1), 58-73.

Amend, J. P., \& Teske, A. 2005. Expanding frontiers in deep subsurface microbiology. Palaeogeography, Palaeoclimatology, Palaeoecology, 219(1), 131-155.

Arndt, S., Hetzel, A., \& Brumsack, H.-J. 2009. Evolution of organic matter degradation in Cretaceous black shales inferred from authigenic barite: A reaction-transport model. Geochimica Et Cosmochimica Acta, 73(7), 2000-2022.

Baker, G. C., Smith, J. J., \& Cowan, D. A. 2003. Review and re-analysis of domain-specific 16S primers. Journal of Microbiological Methods, 55(3), 541-555. doi: http://dx.doi.org/10.1016/j.mimet.2003.08.009

Beck, T., Bales, M., Lillard, D. 2010. Bacteria - the Arch-Nemeses of Hydraulically Fractured Wells. Well Servicing Magazine.

Beckmann, S., Kruger, M., Engelen, B., Gorbushina, A. A., \& Cypionka, H. 2011. Role of Bacteria, Archaea and Fungi involved in methane release in abandoned coal mines. Geomicrobiology Journal, 28(4), 347-358.

Beckmann, S., Lueders, T., Krüger, M., von Netzer, F., Engelen, B., \& Cypionka, H. 2011. Acetogens and acetoclastic methanosarcinales govern methane formation in abandoned coal mines. Applied and Environmental Microbiology, 77(11), 3749-3756.

Boyce, M. L. 2010. Sub-surface stratigraphy and petrophysical analysis of the Middle Devonian interval of the central Appalachian basin; West Virginia and southwest Pennsylvania. Ph. D. Dissertation. West Virginia University. Morgantown, WV. 159 p.

Bräuer, S. L., Cadillo-Quiroz, H., Yashiro, E., Yavitt, J. B., \& Zinder, S. H. 2006. Isolation of a novel acidiphilic methanogen from an acidic peat bog. Nature, 442(7099), 192-194. 
Brock, T. D., \& Freeze, H. 1969. Thermus aquaticus gen. n. and sp. n., a nonsporulating extreme thermophile. J Bacteriol, 98(1), 289-297.

Bruner, K., \& Smosna, R. 2011. A comparative study of the Mississippian Barnett Shale, Fort Worth Basin, and Devonian Marcellus Shale: Appalachian Basin: Technical Report DOE/NETL-2011/1478, National Energy Technology Laboratory (NETL) for The United States Department of Energy.

Cambridge, U. o. 2014. Map of Life - "Extremophiles: Archaea and Bacteria". from http://www.mapoflife.org/topics/topic 354 Extremophiles-Archaea-and-Bacteria/

Chapelle, F. H., O'Neill, K., Bradley, P. M., Methé, B. A., Ciufo, S. A., Knobel, L. L., \& Lovley, D. R. 2002. A hydrogen-based subsurface microbial community dominated by methanogens. Nature, 415(6869), 312-315.

Chapman, E. C., Capo, R. C., Stewart, B. W., Kirby, C. S., Hammack, R. W., Schroeder, K. T., \& Edenborn, H. M. 2012. Geochemical and strontium isotope characterization of produced fluids from Marcellus Shale natural gas extraction. Environmental Science and Technology, 46(6), 3545-3553.

Chivian, D., Brodie, E. L., Alm, E. J., Culley, D. E., Dehal, P. S., DeSantis, T. Z., . . Lowry, S. R. 2008. Environmental genomics reveals a single-species ecosystem deep within Earth. Science, 322(5899), 275-278.

Cluff, M. A., Hartsock, A., MacRae, J. D., Carter, K., \& Mouser, P. J. 2014. Temporal changes in microbial ecology and geochemistry in produced fluid from hydraulically fractured Marcellus shale gas wells. Environmental Science and Technology. 48(11), 6508-6517.

Deppenmeier, U. 2002. The unique biochemistry of methanogenesis. Progress in Nucleic Acid Research and Molecular Biology, 71, 223-283.

DOE, U.S. 2009. Modern shale gas development in the United States: A primer. Office of Fossil Energy and National Energy Technology Laboratory, United States Department of 
Energy. Prepared for the US Department of Energy under contract No. DE-FG2604NT15455: Oklahoma City. OK, Ground Water Protection Council

Ferry, J. G. 1994. Methanogenesis: ecology, physiology, biochemistry \& genetics: Springer.

Garrity, G. M., Bell, J. A., \& Lilburn, T. G. 2004. Taxonomic outline of the prokaryotes. Bergey's Manual of Systematic Bacteriology. Springer, New York, Berlin, Heidelberg.

Gloor, G. B., Hummelen, R., Macklaim, J. M., Dickson, R. J., Fernandes, A. D., MacPhee, R., \& Reid, G. 2010. Microbiome profiling by Illumina sequencing of combinatorial sequencetagged PCR products. PLoS ONE, 5(10), e15406. doi: 10.1371/journal.pone.0015406

Hallam, S. J., Girguis, P. R., Preston, C. M., Richardson, P. M., \& DeLong, E. F. 2003. Identification of Methyl Coenzyme M Reductase A (mcrA) genes associated with methane-oxidizing Archaea. Applied and Environmental Microbiology, 69(9), 5483-5491. doi: 10.1128/aem.69.9.5483-5491.2003

Haney, P. J., Badger, J. H., Buldak, G. L., Reich, C. I., Woese, C. R., \& Olsen, G. J. 1999. Thermal adaptation analyzed by comparison of protein sequences from mesophilic and extremely thermophilic Methanococcus species. Proceedings of the National Academy of Sciences, 96(7), 3578-3583.

Harper, J. 2008. The Marcellus Shale-An old "new" gas reservoir in Pennsylvania. Pennsylvania Geology, 28(1), 2-13.

Hornbeck, P. 1991. Enzyme-Linked Immunosorbent Assays. Current protocols in immunology, 2.1. 1-2.1. 22.

Huber, H., Thomm, M., König, H., Thies, G., \& Stetter, K. O. 1982. Methanococcus thermolithotrophicus, a novel thermophilic lithotrophic methanogen. Archives of Microbiology, 132(1), 47-50.

Juottonen, H., Galand, P. E., \& Yrjala, K. 2006. Detection of methanogenic Archaea in peat: comparison of PCR primers targeting the mcrA gene. Research in Microbiology, 157(10), 914-921. 
Kanehisa, M., Goto, S., Sato, Y., Kawashima, M., Furumichi, M., \& Tanabe, M. 2014. Data, information, knowledge and principle: back to metabolism in KEGG. Nucleic Acids Research, 42(Database issue), D199-205.

Kargbo, D. M., Wilhelm, R. G., \& Campbell, D. J. 2010. Natural gas plays in the Marcellus shale: Challenges and potential opportunities. Environmental Science and Technology, 44(15), 5679-5684.

Kim, D.-W. 2001. Real time quantitative PCR. Experimental \& Molecular Medicine, 33(1 Suppl), 101.

Kirk, M. F., Martini, A. M., Breecker, D. O., Colman, D. R., Takacs-Vesbach, C., \& Petsch, S. T. 2012. Impact of commercial natural gas production on geochemistry and microbiology in a shale-gas reservoir. Chemical Geology, 332-333(0), 15-25.

Kleikemper, J., Schroth, M. H., Sigler, W. V., Schmucki, M., Bernasconi, S. M., \& Zeyer, J. 2002. Activity and diversity of sulfate-reducing bacteria in a petroleum hydrocarboncontaminated aquifer. Applied and Environmental Microbiology, 68(4), 1516-1523. doi: 10.1128/aem.68.4.1516-1523.2002

Knaebel, D. B., Federle, T. W., McAvoy, D. C., \& Vestal, J. R. 1994. Effect of mineral and organic soil constituents on microbial mineralization of organic compounds in a natural soil. Applied and Environmental Microbiology, 60(12), 4500-4508.

Kotelnikova, S. 2002. Microbial production and oxidation of methane in deep subsurface. EarthScience Reviews, 58(3-4), 367-395.

Krumholz, L. R. (2000. Microbial communities in the deep subsurface. Hydrogeology Journal, 8(1), 4-10.

Laanbroek, H. J., \& Geerligs, H. J. (1983). Influence of clay particles (illite) on substrate utilization by sulfate-reducing bacteria. Archives of Microbiology, 134(2), 161-163.

Laughrey, C., Ruble, T., Lemmens, H., Kostelnik, J., Butcher, A., Walker, G., \& Knowles, W. 2011. AV black shale diagenesis: Insights from integrated high-definition analyses of 
post-mature Marcellus Formation rocks, Northeastern Pennsylvania. Is this reference complete?

Liang, X., Dong, Y., Kuder, T., Krumholz, L. R., Philp, R. P., \& Butler, E. C. 2007. Distinguishing abiotic and biotic transformation of tetrachloroethylene and trichloroethylene by stable carbon isotope fractionation. Environmental Science and Technology, 41(20), 70947100.

Lippmann-Pipke, J., Sherwood Lollar, B., Niedermann, S., Stroncik, N. A., Naumann, R., van Heerden, E., \& Onstott, T. C. 2011. Neon identifies two billion year old fluid component in Kaapvaal Craton. Chemical Geology, 283(3-4), 287-296.

Luton, P. E., Wayne, J. M., Sharp, R. J., \& Riley, P. W. 2002. The mcrA gene as an alternative to $16 \mathrm{~S}$ rRNA in the phylogenetic analysis of methanogen populations in landfill. Microbiology, 148(11), 3521-3530.

Martini, A. M., Budai, J. M., Walter, L. M., \& Schoell, M. 1996. Microbial generation of economic accumulations of methane within a shallow organic-rich shale. Nature, 383, 155-158.

Mauclaire, L., McKenzie, J. A., Schwyn, B., \& Bossart, P. 2007. Detection and cultivation of indigenous microorganisms in Mesozoic claystone core samples from the Opalinus Clay Formation (Mont Terri Rock Laboratory). Physics and Chemistry of the Earth, Parts $A / B / C, 32(1-7), 232-240$.

Mikucki, J. A., Liu, Y., Delwiche, M., Colwell, F. S., \& Boone, D. R. 2003. Isolation of a methanogen from deep marine sediments that contain methane hydrates, and description of Methanoculleus submarinus sp. nov. Applied and Environmental Microbiology, 69(6), 3311-3316.

Murali Mohan, A., Hartsock, A., Hammack, R. W., Vidic, R. D., \& Gregory, K. B. 2013. Microbial communities in flowback water impoundments from hydraulic fracturing for recovery of shale gas. FEMS Microbiological Ecology, 86(3), 567-580. 
Muyzer, G., de Waal, E. C., \& Uitterlinden, A. G. 1993. Profiling of complex microbial populations by denaturing gradient gel electrophoresis analysis of polymerase chain reaction-amplified genes coding for 16S rRNA. Applied and Environmental Microbiology, 59(3), 695-700.

Nyyssonen, M., Hultman, J., Ahonen, L., Kukkonen, I., Paulin, L., Laine, P., Itavaara, M., and Auvinen, P. (2014). Taxonomically and functionally diverse microbial communities in deep crystalline rocks of the Fennoscandian shield. ISME J 8, 126-138.

Opara, A., Adams, D., Free, M., McLennan, J., \& Hamilton, J. 2012. Microbial production of methane and carbon dioxide from lignite, bituminous coal, and coal waste materials. International Journal of Coal Geology, 96, 1-8.

Pathak, A., Shanker, R., Garg, S. K., \& Manickam, N. 2011. Profiling of biodegradation and bacterial 16S rRNA genes in diverse contaminated ecosystems using 60-mer oligonucleotide microarray. Appllied Microbiology Biotechnology, 90(5), 1739-1754.

Phillips, E. J., Landa, E. R., Kraemer, T., \& Zielinski, R. 2001. Sulfate-reducing bacteria release barium and radium from naturally occurring radioactive material in oil-field barite. Geomicrobiology Journal, 18(2), 167-182.

Porter, K. G. 1980. The use of DAPI for identifying and counting aquatic microflora. Limnology and Oceanography, 25, 943-948.

Potter, P., Maynard, B., \& Pryor, W. 1980. Final report of special geological, geochemical, and petrological studies of the Devonian shales of the Appalachian Basin, prepared for US Department of Energy under contract DE-AC21-76MC05201: Cincinnati. OH, University of Cincinnati.

Rimmer, S. M., Thompson, J. A., Goodnight, S. A., \& Robl, T. L. 2004. Multiple controls on the preservation of organic matter in Devonian-Mississippian marine black shales: geochemical and petrographic evidence. Palaeogeography, Palaeoclimatology, Palaeoecology, 215(1-2), 125-154. 
Roberts, J. A., Bennett, P. C., González, L. A., Macpherson, G., \& Milliken, K. L. 2004. Microbial precipitation of dolomite in methanogenic groundwater. Geology, 32(4), 277-280.

Rogers, J., Bennett, P., \& Choi, W. 1998. Feldspars as a source of nutrients for microorganisms. American Mineralogist, 83, 1532-1540.

Rothberg, J. M., \& Leamon, J. H. 2008. The development and impact of 454 sequencing. Nature biotechnology, 26(10), 1117-1124.

Ruiz Cruz, S., Luo, Y., Gonzalez, R. J., Tao, Y., \& González, G. A. 2006. Acidified sodium chlorite as an alternative to chlorine to control microbial growth on shredded carrots while maintaining quality. Journal of the Science of Food and Agriculture, 86(12), 18871893.

Sanger, F., Nicklen, S., \& Coulson, A. R. 1977. DNA sequencing with chain-terminating inhibitors. Proceedings of the National Academy of Sciences, 74(12), 5463-5467.

Sasser, M. 1990. Identification of bacteria by gas chromatography of cellular fatty acids. 101.

Schrider, L., \& Wise, R. 1980. Potential new sources of natural gas. Journal of Petroleum Technology, 32(4), 703-716.

Sharma, S., Mulder, M. L., Sack, A., Schroeder, K., \& Hammack, R. 2014. Isotope approach to assess hydrologic connections during Marcellus Shale drilling. Groundwater. 52(3), 424433.

Smalla, K., Wachtendorf, U., Heuer, H., Liu, W.-T., \& Forney, L. 1998. Analysis of BIOLOG GN substrate utilization patterns by microbial communities. Applied and Environmental Microbiology, 64(4), 1220-1225.

Smith, L., \& Leone, J. 2010. Integrated characterization of Utica and Marcellus black shale gas plays, New York State. American Association of Petroleum Geologists, Search and Discovery Article, 50289, 11-14. 
Sowers, K. R., Baron, S. F., \& Ferry, J. G. 1984. Methanosarcina acetivorans sp. nov., an acetotrophic methane-producing bacterium isolated from marine sediments. Applied and Environmental Microbiology, 47(5), 971-978.

Sowers, K. R., \& Ferry, J. G. 1983. Isolation and Characterization of a Methylotrophic Marine Methanogen, Methanococcoides methylutens gen. nov., sp. nov. Applied and Environmental Microbiology, 45(2), 684-690.

Spring, S., Scheuner, C., Lapidus, A., Lucas, S., Glavina Del Rio, T., Tice, H., . . Klenk, H.-P. 2010. The genome sequence of Methanohalophilus mahii SLPT reveals differences in the energy metabolism among members of the Methanosarcinaceae inhabiting freshwater and saline environments. Archaea, 2010, 16.

Struchtemeyer, C. G., \& Elshahed, M. S. 2012. Bacterial communities associated with hydraulic fracturing fluids in thermogenic natural gas wells in North Central Texas, USA. FEMS Microbiol Ecol, 81(1), 13-25.

Wagner, M., Amann, R., Lemmer, H., \& Schleifer, K.-H. 1993. Probing activated sludge with oligonucleotides specific for proteobacteria: inadequacy of culture-dependent methods for describing microbial community structure. Applied and Environmental Microbiology, 59(5), 1520-1525.

Waldron, P. J., Petsch, S. T., Martini, A. M., \& Nusslein, K. 2007. Salinity constraints on subsurface archaeal diversity and methanogenesis in sedimentary rock rich in organic matter. Appl Environ Microbiol, 73(13), 4171-4179. doi: 10.1128/aem.02810-06

Wang, Y., \& Qian, P.-Y. 2009. Conservative fragments in bacterial 16S rRNA genes and primer design for $16 \mathrm{~S}$ ribosomal DNA amplicons in metagenomic studies. PLoS ONE, 4(10), e7401.

Whiticar, M. J. 1987. Isotopic distinction of biogenic and thermogenic hydrocarbon gases. Abstracts of Papers of the American Chemical Society, 193, 59-Geoc. 
Whiticar, M. J. 1990. A geochemical perspective of natural gas and atmospheric methane. Organic Geochemistry, 16(1-3), 531-547.

Wrightstone, Gregory R. 2011. Bloomin'Algae! How paleogeography and algal blooms may have significantly impacted deposition and preservation of the Marcellus Shale. Paper presented at the Geologic Society of America Abstracts with Programs, Pittsburgh, PA

Zhou, J. 2003. Microarrays for bacterial detection and microbial community analysis. Current Opinion in Microbiology, 6(3), 288-294. 


\section{STATEMENT OF PROBLEM}

The goals of these studies were to increase what is known about the microbiology of Marcellus shale using comparisons between produced fluids and core samples. The initial study tested the hypothesis that the organisms found in later produced fluids may have been introduced by exposure to the Marcellus Shale subsurface. The second study tested the hypothesis that there is biogenic methane production in Marcellus Shale created by methanogenic Archaea that are either native to the shale itself or are introduced by the drilling process. 


\section{OBJECTIVES}

The overall objective is to improve current understanding of the microorganisms involved in the Marcellus Shale hydrofracturing process and identify if methanogenic Archaea may be utilized to increase natural gas yield. Specific objectives of this study are to:

1. Isolate and sequence microbial DNA from Marcellus Shale cores to determine the diversity of prokaryotic microorganisms are present in Marcellus Shale core samples.

2. Assess the overlap between microorganisms found in shale cores and flowback fluids to determine if any of these organisms from the produced fluids may have originated in the core.

3. Investigate whether a native microbial community exists in Marcellus Shale, over 7000 feet underground.

4. Determine presence of methanogens in Marcellus Shale.

5. Identify any methanogens present in the flowback fluids and shale.

6. Conduct microcosm experiments to test formethane production under conditions similar to those in the subsurface. These tests will determine if the methanogens in shale and flowback fluids are still physiologically active at shale subsurface conditions.

7. Evaluate of the strategy of enhancing native methanogens to increase methane production in the shale. 
CHAPTER 1 


\section{Microbes in Marcellus Shale: Extremophiles}

\section{Living More Than a Mile inside the Earth?}

Yael Tarlovsky Tucker $^{1,2}$, Thomas $\mathrm{Mroz}^{1}$, and Jianbo $\mathrm{Yao}^{2}$

${ }^{1}$ National Energy Technology Laboratory, United States Department of Energy, Morgantown, West Virginia, 26505, United States

${ }^{2}$ Division of Plant and Soil Science, Davis College of Agriculture, West Virginia University, Morgantown, West Virginia, 26506, United States

KEYWORDS: Marcellus Shale drilling, deep subsurface microbiology, Next Generation

Sequencing

\section{AUTHOR CONTRIBUTIONS}

YTT designed and performed most of the experiments including sample acquisition, DNA extractions. TM helped design experiments, wrote proposal for project and supervised activities at the National Energy Technology Laboratory. JY helped design experiments and supervised activities at West Virginia University.

* In preparation for publication. 


\section{ABSTRACT}

Marcellus Shale drilling is a relatively new activity that has expanded natural gas resources in the United States. Although many assumed that Marcellus Shale buried today is sterile due to extreme conditions the shale has endured since deposition over 360 million years ago, conditions present in the shale today are within the range where many species of microorganisms occur. Few studies have explored the nature of microorganisms in produced fluids or compared microorganisms in produced and injected fluids. No studies been done to characterize microorganisms in core samples from Marcellus Shale and compared them to these water samples. Here we consider whether some of the microbes seen in produced fluids may be native to shale rather than from injected organisms, by comparing organisms found in core samples and produced fluids to those found in injected fluids collected from active wells in Pennsylvania. In this study, Illumina sequencing was utilized to identify organisms based on $16 \mathrm{~s}$ rRNA barcoding regions from DNA extracts from Marcellus Shale core samples, as well as injected and produced fluids. Identified microbial communities were then compared using principal components analysis and SourceTracker tools.. The frequency of homology between sequences from produced fluids and shale core show that these fluids contain more microorganisms in common with shale cores than with injected fluids. Possible native organisms found in these samples include radiotolerant extremophiles such as Deinococcus radiodurans, and coal dwelling organisms such as Acidobacteria capsulatum. Many of the other organisms found in both cores and produced fluid were not present in the reference databases, suggesting they may be unique. This implies that deep subsurface Marcellus Shale, previously believed sterile, may contain native microorganisms, which may either have been deposited during the original deposition of the shale or may have migrated into the deep subsurface Marcellus during a more recent water influx. 


\section{INTRODUCTION}

Marcellus Shale was deposited during the Devonian Period (416-359.2 My) and is now buriedbetween 5,000 to 9,000 feet underground in a tightly packed formation believed to contain enough natural gas to support the United States for more than 100 years (Kargbo et al., 2010). Beyond the difficulty of drilling a well over a mile underground, the greatest challenge of natural gas extraction from shale has been to release this gas from its highly impermeable shale source. This problem has been solved by hydrofracturing, a process in which water and chemicals are pumped at high pressures into both natural and induced fractures underground creating interconnected flow paths for the natural gas. This process uses between 7.7 and 38 million liters (2-10 million gallons) of water depending on the formation (Arthur et al., 2008). The water returns to the surface over time along with native fluids, containing natural gas. The fluids pass through a "separator" that partitions gas from liquids and diverts the water into a holding tank for collection. The water that emerges from the subsurface after the well begins its gasproduction phase is called "produced" fluid.

Investigations on produced fluid found significant differences in composition of microbial communities when compared to those in injected fluids (Murali Mohan et al., 2013a). Subsequent studies found that, over time, microbial communities in later-collected water samples become increasingly different from those in injected fluid. A longer study confirmed that these differences became more marked over time (Cluff et al., 2014). These studies suggested that preferential growth of organisms supplied to the subsurface from the injected fluid might be occurring. Cluff, et al. (2014) mentioned the possibility that certain microorganisms, not found in pre-injected fluids, could be native to the shale itself, but did not offer further evidence. The idea that native microbial communities could exist in the shale and be entering produced fluids was not originally considered as these reservoirs were thought to be sterile. This was because, during geologic history, shale has was subjected to dewatering along with high heat and 
pressure, which may have exceeded conditions for microbial life. Bruner and Smosna (2011) used vitrinite reflectance to estimate that Marcellus Shale reached a maximum temperature between $110^{\circ}$ and $140^{\circ} \mathrm{C}$ at depths between 11,000 and $14,000 \mathrm{ft}$. On the other hand, these conditions developed slowly, within geological time periods that may have allowed for resident microorganisms to adapt to the changing conditions. Current reservoir temperatures of $120^{\circ}$ $150^{\circ} \mathrm{F}\left(49^{\circ}-60^{\circ} \mathrm{C}\right)$, pressures between 185 and 374.25 atmospheres, and $\mathrm{NaCl}$ concentrations of 70,000-150,000 ppm are within the range tolerated by some microorganisms (Kirk, 2011; Schlegel et al., 2009).

Here, for the first time, DNA extracts from Marcellus Shale core samples were compared to DNA from produced and injected fluid samples using Illumina sequencing. We show SourceTracker analysis suggesting that the majority of microbes found in produced fluids were more closely related to those from a shale source than from injected fluids (Knights et al., 2011). These analyses were coupled with principal components analysis, which corroborated the grouping seen by SourceTracker. Close analysis of organisms common between core samples and produced fluids suggests that possible candidates for native species include those in the acidophilic phylum Acidobacteria and radiotolerant species such as Deinococcus geothermalis or Deinococcus radiodurans among others. This implies that deep subsurface Marcellus Shale, previously believed by some to be sterile, may have contained a microbial community prior to drilling, which either could have been deposited along with the shale itself or could have migrated with a water influx event long after deposition but still many millions of years ago.

\section{MATERIALS AND METHODS}

\section{Sample Collection}


Fluid samples: samples were collected based on availability, as we faced much resistance when trying to obtain samples from wells belonging to gas companies. We collected produced fluid samples from four proprietary Greene County wells in Pennsylvania (M1, M2, M3, and M6) from both storage tanks and a separator (Table 1). We sampled "produced" water from the storage tank while "separator" samples were collected from the gas/water separator at each well. Limited access dictated which samples were utilized. Additionally, researchers at West Virginia University shared their pre-injection and post-injection water samples acquired from another well (MB) in Greene County, PA. These fluid samples were transported to the lab in bottles that had been rinsed with $100 \%$ bleach several hours before collection. Fluid samples brought to the laboratory were stored in the freezer at $-20^{\circ} \mathrm{C}$ until processing.

Shale core samples: were collected (Core 1 and Core 2), at two different depths (7860 and 7872 feet respectively) from a Greene County coring site in Pennsylvania (Table 1). They were acquired from a Shikha Sharma pre-ground, so quality control techniques could not be assessed. They had been stored for several months at room temperature in a cardboard box before pulverization and processing for DNA extraction.

\section{DNA Extraction}

Fifteen milliliters of each fluid sample were filtered using $0.22 \mu \mathrm{m}$ filters (MoBio Laboratories Inc., Carlsbad, CA). Water filters and one gram of crushed shale were separately processed utilizing the MoBio PowerSoil DNA extraction kit using its standard protocol (MoBio Carlsbad,CA). Smaller, rather than larger (2-10 grams), amounts of shale were used in this study to minimize contaminants and to reduce DNA degradation before processing. Efforts were also made in this study to process DNA as quickly as possible before degradation occurred. Extracted DNA was eluted in $100 \mu \mathrm{l}$ of nuclease free $\mathrm{H}_{2} \mathrm{O}$ and frozen at $-20^{\circ} \mathrm{C}$ until shipment to MrDNA laboratories. 


\section{Library preparation and Illumina Sequencing}

Library preparation and sequencing was performed by MrDNA laboratories (www.mrdnalab.com, Shallowater, TX, USA) on a MiSeq following the manufacturer's guidelines. The 16S rRNA gene V4 variable region PCR primers 515/806 with barcode on the forward primer were used in a 30-cycle PCR using the HotStarTaq Plus Master Mix Kit (Qiagen, USA) under the following conditions: $94^{\circ} \mathrm{C}$ for 3 minutes, 28 cycles of $94^{\circ} \mathrm{C}$ for 30 seconds, $53^{\circ} \mathrm{C}$ for 40 seconds, $72^{\circ} \mathrm{C}$ for 1 minute, and a final elongation step at $72^{\circ} \mathrm{C}$ for 5 minutes. After amplification, PCR products were checked in $2 \%$ agarose gel to determine the success of amplification and the relative intensity of bands. Multiple amplifications were pooled together in equal proportions based on their molecular weight and DNA concentrations. Pooled samples were purified using calibrated Ampure XP beads. Then the pooled and purified PCR product was used to prepare a DNA library by following Illumina TruSeq DNA library preparation protocol (Illumina, San Diego, CA).

\section{Data Processing and Statistical Analysis}

DNA sequences were uploaded to MG-RAST (Meyer et al., 2008) and processed utilizing a standard pipeline with an OTU (operational taxonomic unit) level of $97 \%$ homology for assigned groups using the GreenGenes database (McDonald et al., 2011). Those results were mapped using best fit classification methods (e-value cutoff of 1e-20). OTU group tables were transferred to QIIME software (Caporaso et al., 2010), and averaged among equal triplicate samples. Results were visualized and graphed in Microsoft Excel 2013.

Triplicate DNA aliquot samples from each sample extraction (15 total) were sequenced analyzed and results were averaged together before statistical analysis was performed to minimize variation due to sequencing and sampling. Statistical tests, including UniFrac analysis (Lozupone and Knight, 2005) and principal components analysis tests visualized using EMPeror (Vázquez-Baeza et al., 2013), were performed using QIIME software 11. OTUs present in less 
than $1 \%$ of samples were filtered from samples and input into SourceTracker. The Shannon Weaver Diversity Index, Chao Richness, and Coverage Percent were calculated for each sample using Microsoft Office Excel set at species level using formulas from the literature (Hughes et al., 2001; Oksanen, 2011).

\section{RESULTS AND DISCUSSION}

\section{Sourcetracker Results}

SourceTracker assigns OTUs of microbial communities present in produced fluids into three "source" categories: Pre-injection water, core (as a proxy for reservoir), or "unknown." The majority (28-97\%) of the microbes found in the produced fluids likely were sourced (derived) from core samples (Figure 1). The first separator sample from well M1 contained the greatest percentage of organisms similar to that of the core $(97 \%)$ the first tank sample taken from that well contained the least $(21 \%)$. On the other hand, a low percentage $(0-36 \%)$ of the organisms in the produced fluid from both separator and storage tanks are attributed to the injected fluid in all samples. Several samples contained no microorganisms solely attributed to the injected fluids, and the greatest sample, containing $36 \%$ of the organisms from the produced fluids, was the second tank sample from well M1. That sample was also the only one that contained a greater percentage of organisms from the pre-injected fluid than from the core. Despite being the only sample of produced fluids from the same well as the injected fluids, the sample taken from the tank in well MB did not contain a greater proportion of microorganisms attributed to the injected fluids (0\%) than other wells. From $0-78 \%$ of microorganisms, depending on the sample, were attributed to "unknown" sources. As expected, the percentage of organisms similar to those in cores increased in tank samples as the well aged. The opposite relationship in the separator samples of well M1 cannot be explained. 
Although shale core samples were not sterile, they had not been in contact with any hydrofracture fluid. If the reservoir rock did not contain bacteria at the time of drilling, with exposure to microbes being limited to microbes in the drilling muds and drilling equipment, there would likely be less microbial community signature (both species and counts considered together) in the core samples in common with the signature found in the produced fluids. This implies that there may be a native community of organisms in these rocks. Possible "unknown" sources could be microorganisms that were low abundance and were therefore below the sequencing resolution. More likely, many of the species present in the samples have not had their DNA sequences added to the database, or are part of the 16s small-subunit rRNA gene records in the GenBank database that are aggregated into the pseudo-divisions "unclassified" or "environmental samples". Regardless, the high percentages of organisms attributed to the shale core samples provide evidence that there may be microorganisms in these produced fluids that are native to the deep subsurface Marcellus Shale in this region.

\section{Potentially Native Organisms}

Several organisms found in shale core samples are also seen in produced fluids returning to the surface after contact with Marcellus Shale, suggesting they may be native to the sub-surface (Figure 2). Of these organisms, many contain 16s rRNA regions with less than $97 \%$ homology to any known species in the database. This could be explained by the presence of uncultured species, which would be expected in an environment as unexplored as Marcellus Shale. Of those identified, many are homologous to known extremophillic organisms that are anaerobic and halotolerant. This would be expected for any organism that needs to survive high salinity of both the shale and produced fluid and the high temperatures of the subsurface. Therefore, it is not surprising to find several species of Acidobacteria only shale core and produced fluid samples. This phylum is abundant in soil samples and encompasses organisms with a broad metabolic range (Quaiser et al., 2003). Acidobacteria capsulatum was found in 
these samples, and is often found to dominate in abandoned coal mines suggesting it is equipped for life in shallower sediments, (Kishimoto et al., 1991). A. capsulatum can tolerate the low $\mathrm{pH}$ levels seen in produced fluids and contain genes that allow it to inhibit DNA and protein synthesis processes in low nutrient conditions. They use an iron reduction metabolism to produce ferric iron for the other organisms in the community. In the shale, these organisms may use pyrite as an iron source.

Deinococcus-Thermus species, which are represented in the core and in produced fluid samples, are also known extremophiles. Deinococcus species are frequently studied because of their ability to withstand radiation to the point that they have been found consuming nuclear waste (Griffiths and Gupta, 2007). This trait may be instrumental in their ability to survive in shale with high levels of naturally occurring radioactive materials such as uranium and thorium. Species from this phylum included Deinococcus radiodurans, identified from DNA homology. $D$. radiodurans can tolerate high levels of acid, cold, dehydration and even vacuum environments making it an ideal candidate for a native subsurface organism. This trait may be attributed to extensive DNA repair systems, which surpass those of any other known prokaryote, it also contains several mechanisms designed to protect its DNA from damage (Cox and Battista, 2005). A close relative, Deinococcus geothermalis was also found in these samples. This organism is a thermophillic radiophile known to grow at temperatures of $45-50^{\circ} \mathrm{C}$ (Ferreira et al., 1997). It has a similar ability to tolerate radioactivity and has been engineered, by transforming it with a plasmid from $D$. radiodurans, for remediation of radioactive waste, to reduce Fe (III)nitrilotriacetic acid, $\mathrm{U}(\mathrm{VI})$, and $\mathrm{Cr}(\mathrm{VI})$ as well as $\mathrm{Hg}$ at elevated temperatures.

\section{Principal Components Analysis}

Principal components analysis (Figure 3) groups samples very consistently with the SourceTracker results. Unifrac methods were used to weigh percent similarity values at several different percentage levels independent of taxonomic classification and therefore provides an 
unbiased three dimensional graph of the groupings (Vázquez-Baeza et al., 2013). For example, the second sample from the storage tank in well M2 (M2 Produced), which indicated 80\% identity with core samples, plots closely with both core samples. Similarly, the first separator sample from well M1 (M1 Separator), which has among the highest percentages of microbes attributed to the core, also plots near the core. The same can be said about many of the other samples where SourceTracker indicated rock was the source. The angle of view for the threedimensional plot does affect the apparent proximity of samples. On the other hand, it may also be seen that the principal components analysis plots the sample of pre-injected fluid distant from nearly all samples of produced fluid, supporting that most of the microorganisms seen in the produced fluids have been recovered from the rock at depth. Congruence between the principal components analysis and the SourceTracker analysis further supports the hypothesis that some microorganisms seen in produced fluid samples and shale cores are likely native to the subsurface environment. More importantly, the congruence between principal components analysis and SourceTracker analysis indicates that the observed differences and similarities between samples are not of the result of variation in analytic technique.

\section{CONCLUSION}

In this study, results from SourceTracker analysis of microorganisms present in each sample suggest that a large proportion of the microorganisms found in the produced fluids come from the shale itself rather than potential introduction from injected fluids. As expected, some of the microorganisms found are suggested to have come from injected fluids, while others come from "unknown" sources. These sources may be either contaminants introduced during drilling by different sources or may be species found in produced fluids that had not been preserved in core samples. Because it is possible that lack of quality control of core samples may have 
changed the microbial composition either by means of contamination or due to microbe deaths during the months of sample storage; these samples are not regarded as pure samples of the microbial community in the subsurface. Fortunately, most of the possible contaminants, such as those from human contact, do not overlap with likely contaminants in the produced fluids, thereby supporting the theory that organisms in common to both types of samples would be indicative of potential sub-surface organisms. These experiments indicate that, despite the lack of ideal samples (i.e., using sources that may have been contaminated in different ways as well as limited number of samples), SourceTracker software can identify and use the population overlaps in these sets of samples to suggest the sources of microorganisms. It is unclear why separator samples indicated higher homology to the injected fluid than samples acquired from a storage tank. Based on the data, as thoughthere is a lack of consistency over time in the microorganisms that come out of these wells. This may be caused by different sources of water from the subsurface becoming part of the samples or it may be related to well tending activities.

Water samples were selected by availability rather than by design. For this study, unfortunately, pre-injection water was only available from one well, and this one sample was used as a comparison for all produced fluid samples from wells in the region. It is possible that organisms not found in this pre-injection water sample, but found in produced fluids from other wells, could explain the differences between the two types of samples. Support for the acceptance of the single sample of pre-injection water as a representative sample of hydraulic fracturing waters used in all the other wells comes from the fact that the MB well, where the single sample of pre-injection water was collected, shows no more homology between the DNA sequences in this well's produced fluids and the pre-injection water than to the other wells. Also, pre-injection water from the MB well was identified as containing similar microbial compositions to the other wells. 
Purely graphical displays that show higher taxonomic levels may be simpler for visualizing community structure, but may provide a false sense of homology between samples. By using genus or species level displays, the differences between samples become much more obvious. Close analysis of the organisms found in core and produced fluids suggested that species within the taxa Deinococcus - Thermus and Acidobacteria may be good candidates for introduction from subsurface shale. Their known abilities to survive harsh environments support this hypothesis. Deinococcus radiodurans or D. geothermalis appear to be the best candidates since they are known to prefer temperatures within the range of the shale and their ability to tolerate radioactivity may give them an advantage in the Marcellus Shale environments known to contain some levels of naturally occurring radioactive materials (NORM)(Chapman et al., 2012). ElementsElements such as uranium, thorium or vanadium may pose difficulties for other organisms in these sediments by causing damage to genetic material; however, these species have special repair mechanisms that may aid in their survival. On the other hand, it is likely that many of the species found in the shale belong to unclassified species that have not been previously cultured. Principal components analysis groupings corroborate SourceTracker results and therefore endorse the use of SourceTracker software.

These findings challenge the theory that these deep subsurface rock formations are sterile and suggest that there is a community of microorganisms that are native to Marcellus Shale over 7,000 feet underground. This community could be the evolutionary descendants of organisms that were deposited during the Devonian Period when the sediments were laid down. Alternatively, a more recent water influx, occurring millions of years ago, assisted the bacteria in migration into the strata where the wells produce methane gas. An alternative but less likely hypothesis for the Source Tracker results is that the core and produced fluids have substantial overlap in sequence homologies because the organisms that were introduced into the core by drilling and that survived in the core have DNA sequence homologies in common with 
organisms that were injected along with the hydrofracturing water and that survived the injection and production processes to become part of the community in the produced fluid samples. Further study is justified. Our findings also indicate that many of the microbes in produced fluids may be different from those found at the surface and should be studied regarding their identity, potential uses, and best practices for handling. In the interest of further understanding the types of organisms that may be able to survive such extreme environments, more work should be done to characterize these organisms common to both rock and produced fluids, as several new species may exist in these samples and could provide new insights towards the limits of extremophillic bacteria on Earth. 


\begin{tabular}{|c|c|c|c|c|c|c|c|}
\hline Well & $\begin{array}{l}\text { Age of } \\
\text { Well } \\
\text { (Days) }\end{array}$ & Type & OTU $^{\mathrm{ab}}$ & $\begin{array}{l}\text { Total } \\
\text { Sequences } \\
b\end{array}$ & $\begin{array}{l}\text { Shannon } \\
\text { Weaver } \\
\text { Diversity }^{\text {ab }}\end{array}$ & $\begin{array}{l}\text { Chao } \\
\text { Richness }^{a} \\
b\end{array}$ & $\begin{array}{l}\text { Coverage } \\
\text { Percent }^{\text {ab }}\end{array}$ \\
\hline \multicolumn{8}{|c|}{ Pre- Injection } \\
\hline MB & - & Before Injection & 212 & 25040 & 1.37 & 370 & $79 \%$ \\
\hline \multicolumn{8}{|c|}{ Produced fluid } \\
\hline \multicolumn{8}{|l|}{ Tank } \\
\hline MB & 139 & Produced & 221 & 32621 & 0.95 & 297 & $87 \%$ \\
\hline \multirow[t]{3}{*}{ M1 } & 210 & Produced & 231 & 40739 & 1.41 & 305 & $79 \%$ \\
\hline & 689 & Produced & 198 & 36897 & 1.43 & 372 & $60 \%$ \\
\hline & 787 & Produced & 196 & 38186 & 1.66 & 460 & $62 \%$ \\
\hline \multirow[t]{2}{*}{ M2 } & 220 & Produced & 233 & 22747 & 1.33 & 295 & $86 \%$ \\
\hline & 787 & Produced & 191 & 74234 & 1.09 & 450 & $60 \%$ \\
\hline M3 & 230 & Produced & 159 & 21145 & 1.62 & 285 & $73 \%$ \\
\hline M6 & 1825 & Produced & 221 & 23151 & 1.56 & 395 & $80 \%$ \\
\hline \multicolumn{8}{|c|}{ Gas-Water Separator } \\
\hline \multirow[t]{3}{*}{ M1 } & 661 & Separator & 250 & 317056 & 0.66 & 405 & $80 \%$ \\
\hline & 689 & Separator & 160 & 78568 & 1.36 & 300 & $71 \%$ \\
\hline & 787 & Separator & 204 & 18937 & 1.66 & 357 & $67 \%$ \\
\hline M2 & 787 & Separator & 158 & 23905 & 1.56 & 298 & $64 \%$ \\
\hline \multicolumn{8}{|c|}{ Shale Cores } \\
\hline Core 1 & - & Core & 289 & 23943 & 1.79 & 408 & $87 \%$ \\
\hline Core 2 & - & Core & 241 & 23897 & 1.76 & 324 & $83 \%$ \\
\hline
\end{tabular}

\footnotetext{
${ }^{a}$ Average from triplicate measurements

${ }^{\mathrm{b}}$ Calculated at putative species level (>97\% homology)
}

Table 1- Summary of samples and statistics analyzed. OTU values were calculated at $>97 \%$ homology. Shannon Weaver diversity, Chao Richness and Coverage Percent values were all calculated using species-level OTU values. Wells M1, M2 and M3 were side by side wells drilled simultaneously while M6 was a nearby well from Greene County, PA. Well MB was also in Greene County, a short distance away from the other wells. Cores were taken from a Greene County coring site. 


\section{SourceTracker \% Composition of Produced Fluids}

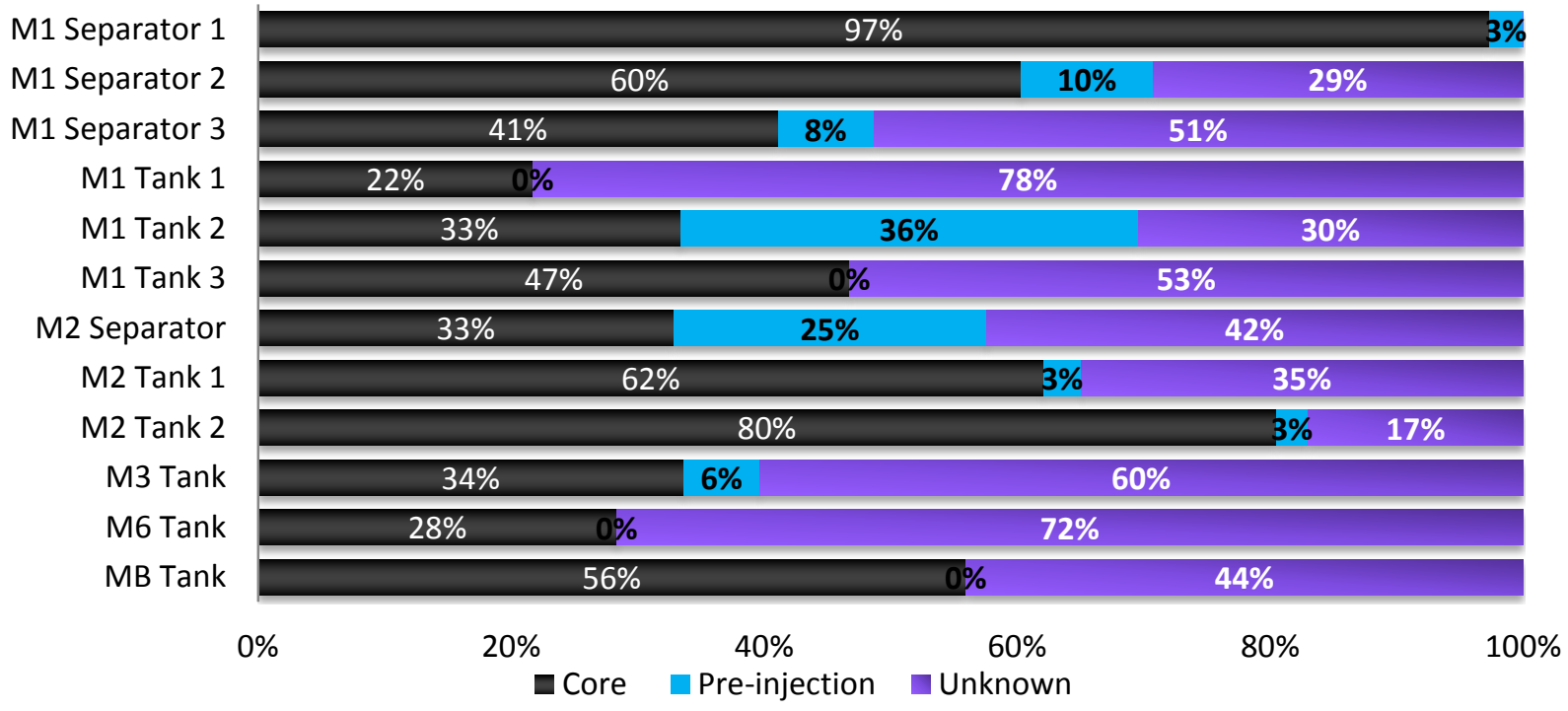

Figure 1 - SourceTracker (Knights et al., 2011) results on produced fluids using core and pre-injection fluids as possible sources for the microorganisms found in the different samples of produced fluids from both tank and separator. All core samples are averaged together to produce these results. M1, M2, M3, M6 and MB are all samples from Green County, PA. 


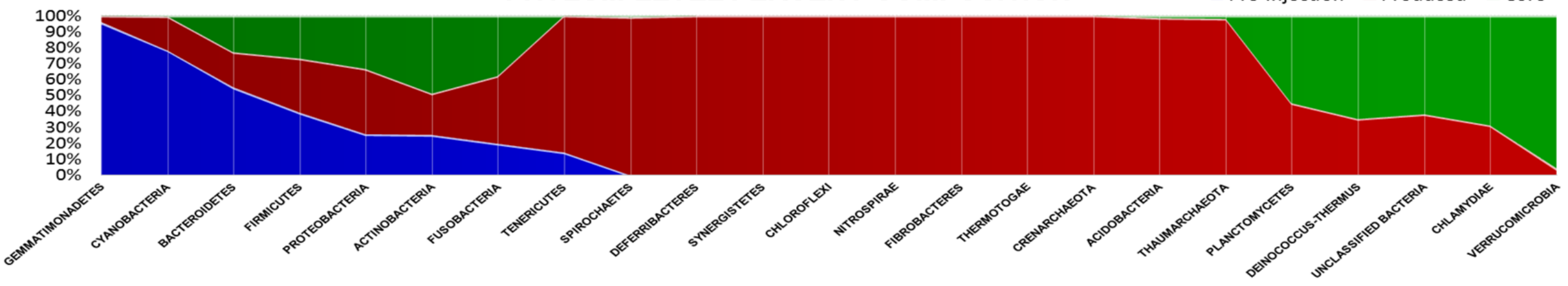

GENUS-LEVEL PERCENT COMPOSITION
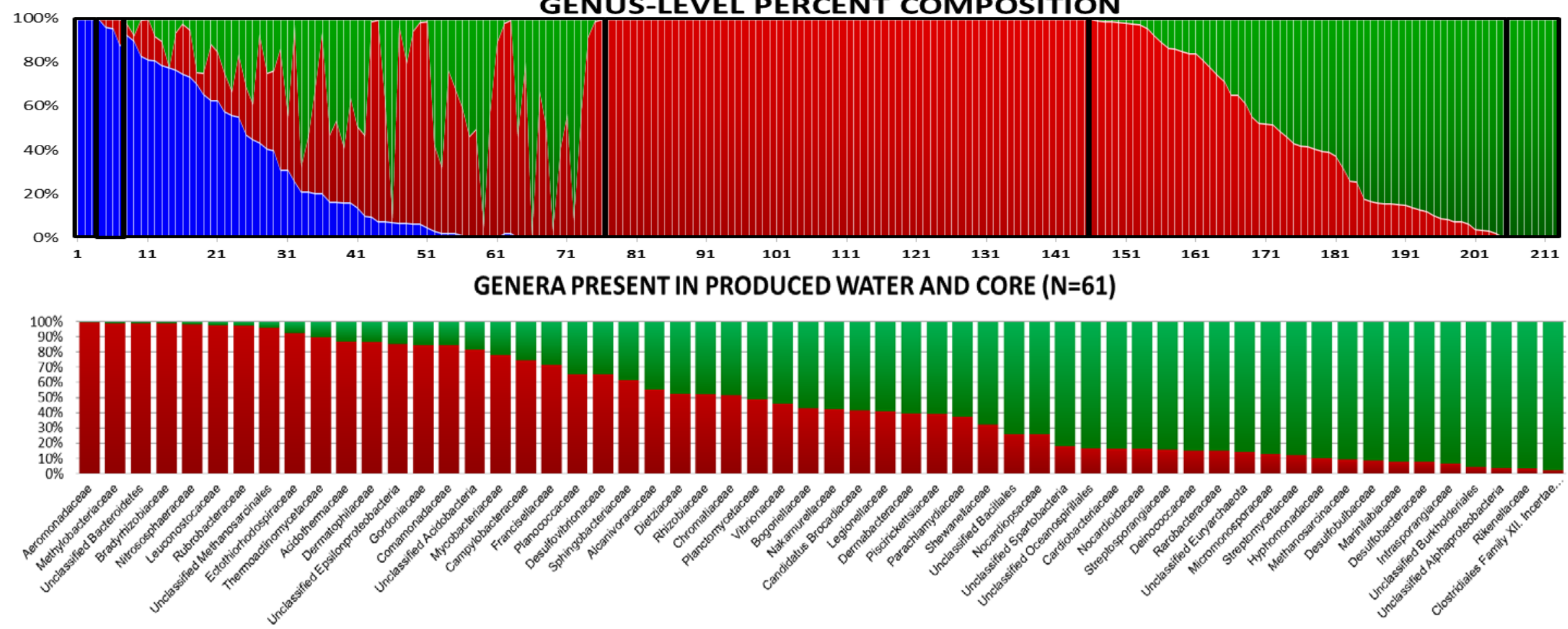

Figure 2 - Graph illustrating average microorganisms found in each kind of samples. Organisms found in pre-injection fluids are depicted in blue, those from produced fluids in red, and those found in cores are shown in green. Section A illustrates relationships at phylum-level while section B illustrates the same samples at genus level. Since there were too many organisms found at genus-level to illustrate in this graph, they are numbered and a magnified version of only the organisms found in produced fluid and core displayed in section C. (Magnified versions of the other sections in this graph can be found in Appendices 1,2 and 3) 


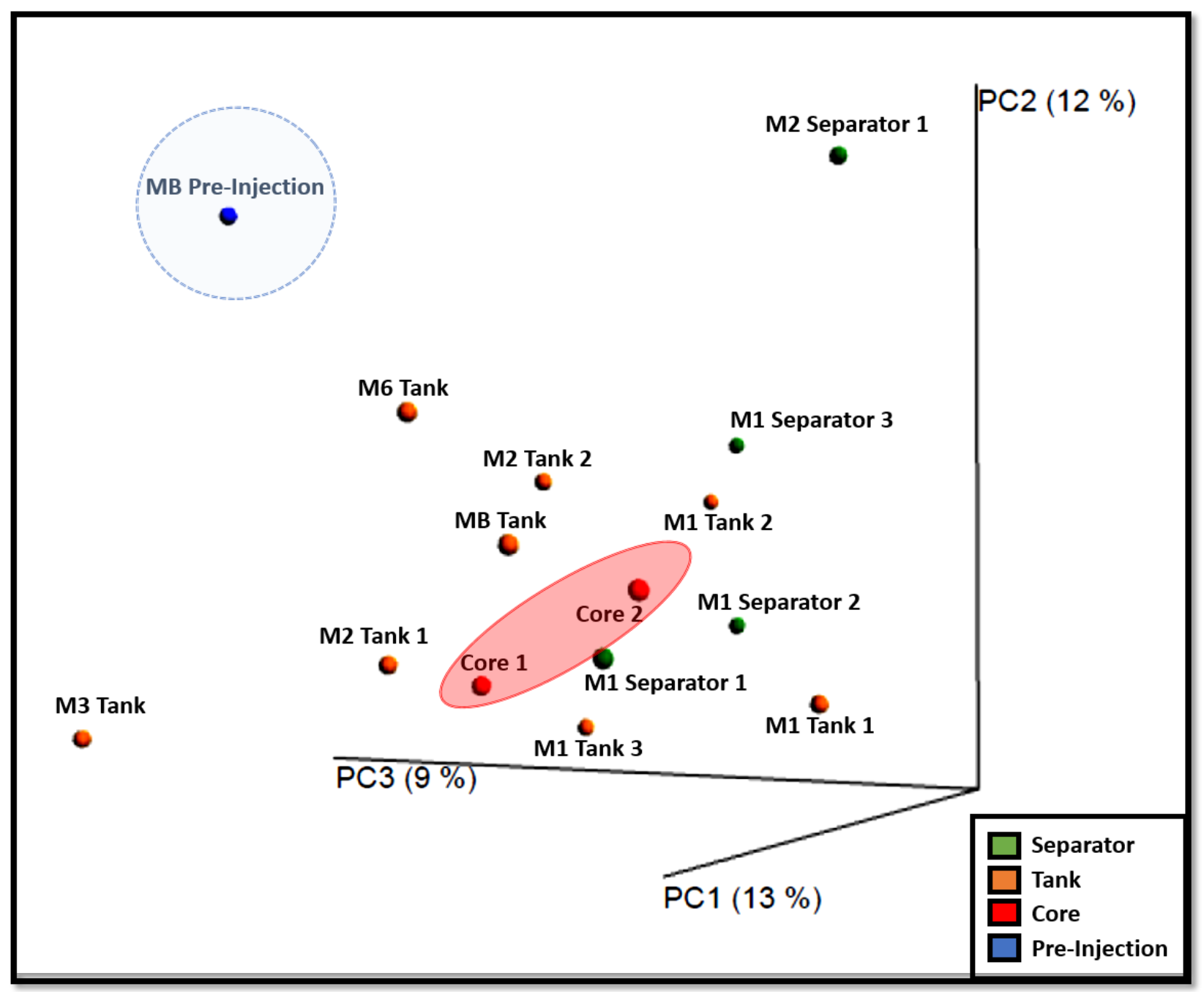

Figure 3 - Principal component analysis computed utilizing unweighted Unifrac methods. Core samples are illustrated in red and are outlined by the shaded oval which shows the average region using those two samples. The pre-injection fluid sample is indicated in the dotted blue circle. Produced fluid samples taken from the storage tank of each well (M1, M2, M3, M6 and MB) are displayed in yellow, while separator samples from wells M1 and M2 are shown in green. 


\section{REFERENCES}

Bruner, K. and R. Smosna (2011). A comparative study of the Mississippian Barnett Shale, Fort Worth Basin, and Devonian Marcellus Shale, Appalachian Basin: Technical Report DOE/NETL-2011/1478, National Energy Technology Laboratory (NETL) for The United States Department of Energy.

Caporaso, J. G., J. Kuczynski, J. Stombaugh, K. Bittinger, F. D. Bushman, E. K. Costello, N. Fierer, A. G. Pena, J. K. Goodrich and J. I. Gordon (2010). "QIIME allows analysis of high-throughput community sequencing data." Nature Methods 7(5): 335-336.

Cluff, M. A., A. Hartsock, J. D. MacRae, K. Carter and P. J. Mouser (2014). "Temporal changes in microbial ecology and geochemistry in produced fluid from hydraulically fractured Marcellus Shale gas wells." Environmental Science \& Technology. 48:6508-6517.

DOE, U. S. (2009). "Modern shale gas development in the United States: A primer." Office of Fossil Energy and National Energy Technology Laboratory, United States Department of Energy.

Hughes, J. B., J. J. Hellmann, T. H. Ricketts and B. J. M. Bohannan (2001). "Counting the Uncountable: Statistical approaches to estimating microbial diversity." Applied and Environmental Microbiology 67(10): 4399-4406.

Kirk, M. F. (2011). "Variation in energy available to populations of subsurface anaerobes in response to geological carbon storage." Environmental Science \& Technology 45(15): 6676-6682.

Knights, D., J. Kuczynski, E. S. Charlson, J. Zaneveld, M. C. Mozer, R. G. Collman, F. D. Bushman, R. Knight and S. T. Kelley (2011). "Bayesian community-wide cultureindependent microbial source tracking." Nat Meth 8(9): 761-763.

Lozupone, C. and R. Knight (2005). "UniFrac: a new phylogenetic method for comparing microbial communities." Applied and Environmental Microbiology 71(12): 8228-8235. 
Meyer, F., D. Paarmann, M. D'Souza, R. Olson, E. M. Glass, M. Kubal, T. Paczian, A. Rodriguez, R. Stevens, A. Wilke, J. Wilkening and R. A. Edwards (2008). "The metagenomics RAST server - a public resource for the automatic phylogenetic and functional analysis of metagenomes." BMC Bioinformatics 9: 386.

Murali Mohan, A., A. Hartsock, K. J. Bibby, R. W. Hammack, R. D. Vidic and K. B. Gregory (2013). "Microbial community changes in hydraulic fracturing fluids and produced fluid from shale gas extraction." Environmental Science \& Technology 47(22): 13141-13150.

Oksanen, J. (2011). "Multivariate analysis of ecological communities in R: vegan tutorial." $\underline{\mathrm{R} \text { package version } \mathbf{1}(7) .}$

Schlegel, M. E., J. C. Mclntosh, B. L. Bates, M. F. Kirk and A. M. Martini (2009). "Hydrogeologic controls on microbial methanogenesis in shales and coalbeds in the Illinois Basin." Geochimica Et Cosmochimica Acta 73(13): A1175-A1175.

Vázquez-Baeza, Y., M. Pirrung, A. Gonzalez and R. Knight (2013). "EMPeror: a tool for visualizing high-throughput microbial community data." GigaScience 2(1): 16. 
CHAPTER 2 


\title{
Methanogenic Archaea in Marcellus Shale: A Possible Mechanism for Enhanced Gas Recovery in Unconventional Shale Resources
}

\author{
Yael Tarlovsky Tucker ${ }^{1,2}$, Thomas Mroz ${ }^{1}$, and James Kotcon ${ }^{2}$ \\ ${ }^{1}$ National Energy Technology Laboratory, United States Department of Energy, Morgantown, \\ West Virginia, 26505, United States \\ ${ }^{2}$ Department of Plant and Soil Science, Davis College of Agriculture, Natural Resources and \\ Design, West Virginia University, Morgantown, West Virginia, 26506, United States
}

KEYWORDS: Marcellus Shale drilling, Next Generation Sequencing, methanogens, Enhanced Gas Production

\section{AUTHOR CONTRIBUTIONS}

YTT designed and performed most of the experiments, including DNA extractions, methanogen growth measurements, and bioinformatics. TM helped design experiments, wrote whole proposal for project and supervised activities at the National Energy Technology Laboratory. JK helped edit the paper and advised on experimental design at West Virginia University.

*Submitted for publication to Environmental Science and Technology, February 2015. (In Review) 


\section{ABSTRACT}

Marcellus Shale occurs at depths of 1.5 to $2.5 \mathrm{~km}(5,000$ to $8,000 \mathrm{ft}$.) where most geologists generally assume that thermogenic processes are the only source of natural gas. However, methanogens in produced fluids and isotopic signatures of biogenic methane in this deep shale have recently been discovered. This study explores whether those methanogens are indigenous to the shale or are introduced during drilling and hydraulic fracturing. DNA was extracted from Marcellus Shale core samples, pre-injected fluids and produced fluids and was analyzed using Miseq sequencing of $16 \mathrm{~s}$ rRNA genes. Methanogens present in shale cores were similar to methanogens in produced fluids. No methanogens were detected in injected fluids, suggesting that this is an unlikely source and that they may be native to the shale itself. Bench-top methane production tests of shale core and produced fluids suggest that these organisms are alive and active under simulated reservoir conditions. Growth conditions designed to simulate the hydrofracture processes indicated somewhat increased methane production; however, fluids alone produced relatively little methane. Together, these results suggest that some biogenic

methane may be produced in these wells and that hydrofracture fluids currently used to stimulate gas recovery could stimulate methanogens and their rate of producing methane. 


\section{INTRODUCTION}

With continued development of second- and third-world economies and continued population growth, worldwide energy demands have become more difficult to fulfill. Currently, the United States uses more than 96 quadrillion British Thermal Units (BTUs) of energy per year, only $8 \%$ of which comes from renewable sources (EIA, 2014). A majority of that energy is provided by coal, petroleum, and natural gas. One of the newest and most controversial frontiers in energy production is the natural gas in the Marcellus Shale of the Appalachian Basin. That gas is believed to have the capacity of ensuring at least 100 years of additional reliable energy and can be acquired domestically. Although other sources of natural gas were used in the past, it is within recent years that technology has been used advantageously to extract natural gas trapped in the deep, low-permeability shale rock. (Kargbo et al., 2010) However, due to its continuing development, both challenges and benefits are still arising.

Although it has been generally accepted that methane gas from Marcellus Shale is completely thermogenic, recent studies using isotope measurements have found evidence of potentially biogenic gases present in these shale wells (Sharma et al., 2013). The significance of this is that biogenic methane is generated by micro-organisms at a much more rapid rate than methane generated by inorganic, thermogenic processes, which require geologic time periods at current reservoir temperatures (Whiticar, 1987). Therefore, biogenic sources would mean faster regeneration of natural gas in these shales and potential for secondary gas recovery. Such recovery efforts can be seen in coal today because coal has been shown to contain methanogens that are able to produce significant amounts of biogenic methane (Beckmann et al., 2011a; Beckmann et al., 2011b). Similarly, methanogens have been engineered to recover gas from waste coal materials (Strąpoć et al., 2008; Thielemann et al., 2004 ; Unal et al., 2012). Economically feasible production of biogenic methane also has been found in shales. For example, in Michigan, where the Devonian-age Antrim Shale in Michigan contains large 
numbers of Methanohalophilus, and naturally produces enough biogenic methane for economic recovery (Kirk et al., 2012). Although this shale is younger and shallower $(<5,000 \mathrm{ft}$.) than the Marcellus Shale, it was deposited in much the same way and has similar chemical composition. These similarities support the hypothesis that methanogens could exist and produce methane in the Marcellus Shale. Biogenic methane production is a particularly attractive strategy because most methanogens have the ability to use $\mathrm{CO}_{2}$ (which is a greenhouse gas that can be stored underground to prevent negative environmental impacts) as a feed stock to produce methane.

After the well bore has been drilled, large volumes of water and chemicals are pumped into the well at high pressure to hydraulically fracture the shale rock and release the associated gas. During well completion, some of this water, as well as brines associated with the shale, return to the surface, and are separated from the gas stream, to yield what are called "produced fluids". Several studies have analyzed the microbial communities in pre-injected and produced fluids of the Barnett Shale and Marcellus Shale (Cluff et al., 2014; Murali Mohan et al., 2013a; Murali Mohan et al., 2013b; Struchtemeyer et al., 2011; Struchtemeyer and Elshahed, 2012). Studies exploring Barnett Shale wells have not identified any methanogens in either injected or produced fluids (Davis et al., 2012; Struchtemeyer et al., 2011; Struchtemeyer and Elshahed, 2012). The most recent study on Marcellus Shale wells, however, has indicated the presence of some methanogenic Archaea (Cluff et al., 2014). These methanogens were found to be a small portion $(<1 \%)$ of the population in the produced fluids during the two months of sampling after the hydrofracturing began (Cluff et al., 2014). This study mentioned the possibility that at least some of the organisms may be native to the shale, while in previous studies it was hypothesized that these organisms were introduced with injected fluids as these depths were believed to have experienced in the geologic past environmental conditions beyond the range of any native organisms (Struchtemeyer and Elshahed, 2012). Notably, sources of those organisms, either from injected fluids, or shale,were not directly investigated (Murali Mohan et al., 2013b). 
In this study, we test the hypothesis that methanogens are present in the reservoir and active before the drilling process. Based on geological data for our area of study, this shale has temperatures of $120^{\circ}-150^{\circ} \mathrm{F}\left(49^{\circ}-60^{\circ} \mathrm{C}\right)$, pressures between 185 and 374.25 atmospheres, and $\mathrm{NaCl}$ concentrations of 70,000-150,000 ppm (Kirk, 2011; Schlegel et al., 2009). The literature reveals that there are several known species of methanogens with the ability to survive the harsh conditions present in the shale today (Amend and Shock, 2001; Balch et al., 1979; Beckmann et al., 2011a; Borrel et al., 2013; Bräuer et al., 2006; Chapelle et al., 2002; Colwell et al., 2008; Conrad, 2007). Methanosarcina spp., include methanogens found in deep ocean sediment (Colwell et al., 2008). While environmental conditions in the shale have changed much since deposition, the slow changes occurring over geologic time could have allowed native organisms to adapt. These evolutionary forces make it unlikely that microbes found in the shale would be from a previously-described species since these microbes would be among the deepest subsurface living organisms (Beckmann et al., 2011a; Ferry and Lessner, 2008). Although the question of how these organisms could come to live at such conditions still eludes us, it is possible that they were introduced either when the sediment was deposited, or during a more recent water influx.

We examined microbial activity levels from the viewpoint of gas production from shale. We used the sequencing results from samples in Chapter 1 to analyze Archaea present within samples of pre-injection hydrofracturing water, produced fluid from both holding tanks and gaswater separators, and shale cores. To confirm these results, we also identified several methanogenic species and found several of the genes required for methanogenesis using shotgun metagenomics on one of the water samples. We also examined methanogen activity levels from the viewpoint of gas production from shale. Bottle-scale tests were developed to measure methane generation rates under different conditions that may relate to the Marcellus Shale reservoir. In an approximate way, these latter tests represent the different environments 
these organisms could experience in separator and storage tanks and in the reservoir, both before and after the hydraulic fracturing process.

\section{MATERIALS AND METHODS}

Sampling, Extraction and DNA Amplification- The samples and DNA extracts used were described in chapter 1. For amplification, originally, primers targeting the conserved methane reductase co-enzyme A (McrA) were chosen for DNA amplification of methanogenic Archaea specifically as they are the accepted standard. Primers attempted included METH-F/ METH-R (RTRYTMTWYGACCARATMTG/ YTGDGAWCCWCCRAAGTG) from Colwell et al. (2008), and mcrIRD-F/ mcrIRD-R (TWYGACCARATMTGGYT/ ACRTTCATBGCRTARTT) from Lever (2008) at the outlined conditions. However, McrA primers failed to produce visible bands on agarose gels. Attempts were made at concentrating the extracted DNA to increase the methanogen material, but extraneous contaminants co-isolating with the genetic material were also concentrated in these samples and therefore prevented amplification or caused degradation before DNA could be prepared for sequencing. To circumvent these complications, samples were sent to MrDNA laboratories where several primers were attempted that would selectively amplify Archaeal DNA, but none worked. Finally, it was concluded that since $16 \mathrm{~S}$

rRNA gene V4 variable region polymerase chain reaction (PCR) primers 515/806 (GTGYCAGCMGCCGCGGTAA GGACTACNVGGGTWTCTAAT) would also amplify methanogens, the same data from Chapter 1 were analyzed focusing solely on archaeal microbiology. Processing of amplified sequences was performed along with the sequences for all of the microorganisms (both by the proprietary pipeline at MrDNA laboratories and using QIIME software). 
Metagenomic Analysis. Metagenomic analysis was done at MrDNA laboratories on DNA extracts from the sample from the separator of the M1 well from day 661 of production because diversity analysis indicated this sample contained enriched levels of methanogens. The library was prepared using Nextera DNA Sample Preparation Kit (Illumina, San Diego, CA) following the manufacturer's user guide. Briefly, the initial concentration of genomic DNA was measured using the Qubit ${ }^{\circledR}$ dsDNA HS Assay Kit (Life Technologies, Frederick, MD). As a result of recording too little DNA, the sample was linearly amplified at $30^{\circ} \mathrm{C}$ for $16 \mathrm{~h}$ using the REPLI-g Midi Kit (Qiagen, Valencia, CA) according to the manufacturer's instructions for 2.5- $\mu \mathrm{L}$ of input DNA. Once the amplification was complete, concentration of the sample was again quantified using the Qubit $\circledast$ dsDNA HS Assay Kit (Life Technologies, Fredrick, MD). The sample was then diluted accordingly to achieve the recommended DNA input of 50-ng at a concentration of $2.5-\mathrm{ng} / \mathrm{\mu l}$. Subsequently, the sample was subjected to simultaneous fragmentation and addition of adapter sequences. These adapters were utilized during a limitedcycle PCR (5 cycles) in which unique indices were added to the sample. Following library preparation, the final concentration of the library was measured using the Qubit $₫$ dsDNA HS Assay Kit (Life Technologies Fredrick, MD), and the average library size was determined using the Agilent 2100 Bioanalyzer (Agilent Technologies, Wilmington, DE). The library (12.5-pM) was sequenced using 600 Cycles v3 Reagent Kit in MiSeq (Illumina, San Diego, CA). Data were analyzed using MG-RAST online software (MG-RAST version 2.5) (Meyer et al., 2008). The lowest common ancestor chart was computed at the genus level from metagenomic analysis of the separator sample and compared using a maximum e-value of $1 \mathrm{e}-5$, a minimum identity of $85 \%$, and a minimum alignment length of fifteen measured in amino acids for protein and base pairs for RNA databases. 
Growth of Methanosarcina acetivorans. As a positive control, Methanosarcina acetivorans (C2A) was grown following procedures developed by Sowers, et al. ( 1984). Five hundred milliliters of high salt media (from above protocols) were inoculated with $10 \%$ base culture of Methanosarcina acetivorans (C2A) (ATCC 35395) acquired from researchers at Pennsylvania State University. Cultures were grown at $37^{\circ} \mathrm{C}$ in darkened $500-\mathrm{ml}$ Wheaton media bottles inside a Coy anaerobic glove box (Coy Laboratory Products, Grass Lake, MI) containing a gas mix of $20 \% \mathrm{CO}_{2}, 4 \% \mathrm{H}_{2}$, and $76 \% \mathrm{~N}_{2}$ to provide the ideal headspace.

Methane Production Experiments. Methane production was measured in real time using the Challenge Technologies ${ }^{\mathrm{TM}}$ Methane Potential Analyzer (Challenge Technologies, Springdale Arkansas). This unit consists of eight, 500-ml bottles, connected using a needleseptum system that maintains atmospheric pressure inside the bottle by venting any produced gasses through the needle and into the system where measurement is made. These bottles were covered to simulate dark conditions. Samples were incubated for several weeks with their methane output logged every minute over a period of 28-79 days.

To observe methane production from undisturbed shale, two bottles in the methane analyzer contained $30 \mathrm{~g}$ of crushed shale (Core 3) in $200 \mathrm{ml}$ of sterile distilled water. To mimic a produced fluid storage tank, two bottles containing $500 \mathrm{ml}$ of produced fluid retrieved from the Green County wells were tested (M1 Day 210). For separator conditions, we used two bottles containing $500 \mathrm{ml}$ of separator fluids (M1 Separator Day 661), which, unlike tank fluids, had not been exposed to open air. To understand conditions in the shale after the hydrofracturing process has occurred, samples with $500 \mathrm{ml}$ of produced fluid from the separator (M1 Separator Day 661) and $30 \mathrm{~g}$ of crushed shale (Core 3) were used. A control of autoclaved shale and separator fluids was utilized as a test for desorption of thermogenic methane from shale. All of these samples were maintained in the dark at $48^{\circ} \mathrm{C}$ to mimic reservoir temperature. Each test 
was intended to represent, in microcosm, the most important factors in the reservoir and in well components (e.g., conditions in hydraulic fracture zones within the reservoir, separator tank, and storage tanks).

Analysis of Data. Measurements were taken in milliliters of methane and were converted to $\mu \mathrm{mol}$ using the ideal gas law with standard temperatures and pressures. Statistical analysis was done using Excel 2010. F-tests of significance were performed on raw data of daily methane production from the duplicate samples. Matched pair analysis to compare numbers of methanogen sequences to other taxa was performed using JMP 8 statistical software (2009) (SAS Institute Inc., Rockville, MD). Samples have been submitted to NCBI under BioProject ID: PRJNA274234 under sample numbers SAMN03273679-SAMN03273731.

\section{RESULTS AND DISCUSSION}

Sequencing. Texas Barnett Shale samples of pre-injection hydrofracture fluid were compared to produced fluid from day 60 of production. Methanogens were found in produced fluid ( $0.2 \%$ of total amplified sequences) but not in the pre-injection (0\%) hydrofracture fluid from the Barnett Shale (Table 1). All of the produced fluid Barnett Shale samples were homologous with sequences of uncultured Methanosarcina. This suggests that methanogens are present in the Barnett well rather than introduced from the injected hydrofracture fluid. Alternatively, it is possible that methanogenic Archaea were at concentrations that are too low for detection in these Barnett Shale pre-injection fluids.

Five Marcellus Shale wells were sampled for produced fluids; however, pre-injection samples were only available for one well (MB). Produced fluid samples were collected from the separator the storage tank or both (Table 1). The pre-injection water from well MB contained no 
sequences that could be identified with methanogens and a few sequences that identified with uncultured Archaea (and therefore may belong to non-methanogenic species). However, produced fluid from the storage tank on the same well (MB), on day 60 of production, did contain organisms with sequence homology to those from the genus Methanococcoides and other uncultured species from the order Methanosarcinales. Organisms in Methanococcoides are characterized as methanogens that consume methylated compounds (Sowers and Ferry, 1983). The water from the holding tanks of the other wells from the same region, (M1, M2, M3) all contained DNA with homologies to methanogenic Archaea. Wells M1 and M2 were also sampled later in production but only well M2 contained sequences with homology to methanogenic Archaea in the later samples. Samples of separator water from both M1 and M2 were also analyzed to consider possible contamination from the holding tank or negative selection due to the oxygenated conditions during storage. The initial sample taken from the M1 well separator on day 661 of production contained an enriched methanogenic culture (17\%); however, other samples taken from this separator at later times did not contain sequences from methanogenic Archaea. It is unclear why this sample was so much more enriched than the others at just one point in time. Notably, this sample also contained a biofilm producer (Halanaerobium prevalens) in a high percentage, so it is possible that a biofilm dislodged from the well and was carried into the separator. This may indicate why a small percentage of methanogens are usually seen in produced fluids, as methanogens may normally be immobile in their biofilms (Neria-González et al., 2006).

DNA isolated from two different depths (7860 and 7872 feet) of Marcellus Shale core samples from Greene County, PA (Core 1, 2 respectively) indicated the presence of methanogens in the population (0.01-0.47\%). Nearly all of these methanogenic sequences were $>97 \%$ homologous to sequences of uncultured Methanosarcina, much like the produced fluid samples above. Evidence of methanogens in produced fluids was paired with evidence from core samples to examine any overlap in methanogenic species. Despite the non-sterile nature 
of these samples, the cores have never come in contact with hydrofracturing fluids; therefore, contamination from injection water would not explain an overlap in organisms between core and produced fluid. Presence of methanogens in both sets of samples suggests that the methanogens seen in produced fluids may have come from the shale, and that there may be a native community of these organisms in the shale before drilling began. that the lack of similarity between these organisms and currently isolated organisms also supports this hypothesis, since these organisms would have had much time while in isolation to differentiate from methanogens at the Earth's surface (Hedderich et al., 2005; Pritchett and Metcalf, 2005).

A matched pairs test indicated that the number of sequences from methanogenic Archaea was highly correlated with the number of sequences from some non-methanogenic organisms, with $r$ values of $0.99,0.95,0.96$, and 0.95 for Halanaerobium, Anaerophaga, Clostridium and Fastidosipila, respectively (NCBI sample numbers SAMN03273679SAMN03273731). These genera all include extremophiles that could have sourced alongside methanogens. Diversity analysis illustrated both differences and similarities between the organisms present in samples of pre-injection water, storage tank water, separator water, and cores. Although the absence of organism detection in any sample may have been because their abundance was below detectable levels, overlaps between all types of organisms found in storage tank water, separator water, and cores but absent in pre-injection water provides information on which organisms may be in (or perhaps native to) the shale.

Metagenomic Assay. To eliminate possible primer bias, an enriched separator sample (from well M1) containing $17 \%$ methanogenic composition, as identified by the DNA sequencing, was analyzed using metagenomic techniques. Although the percentages are different, metagenomic analysis identified sequences that are homologous to proteins or 16S rRNA regions of several methanogenic Archaea (Figure 1). Despite its relatively low (<8\%) composition of archaeal species, subsystem metagenomic analysis of the sample indicated 
sequence homology $(<60 \%)$ to several methanogenesis-related proteins. These proteins included CoB--CoM heterodisulfide reductase subunit A (responsible for the regeneration of coenzyme M and coenzyme B after the action of EC coenzyme-B sulfoethylthiotransferase), Formylmethanofuran dehydrogenase (molybdenum) operon gene G, N5methyltetrahydromethanopterin: coenzyme $M$ methyltransferase subunit $E$, and Methanol: corrinoid methyltransferase (which is crucial for methanol metabolism in Methanosarcina acetivorans). Unfortunately, the indicator gene mcrA was not found to be among these genes.

Results from 16s sequences and metagenomic analysis, considered together, strongly suggests that at least some of the methanogens present in water produced from gas wells are native organisms in the shale reservoir that were entrained into the fluids flowing from the well. It is unlikely that all of these methanogens derived from the injected fluid used for hydraulic fracturing of the shale reservoir around the well.

Relative Methane Production under Various Conditions. To determine if these organisms are alive and able to produce methane at reservoir conditions, methane production was measured in tests simulating different environments encountered by methanogenic Archaea (Figure 2). Many problems were experienced when working with the Challenge Technologies $^{\mathrm{TM}}$ Methane Potential Analyzer. Therefore, to verify proper functioning of the test, a culture of Methanosarcina acetivorans (C2A) was acquired from Dr. Gregory Ferry's laboratory at Penn State University and used as a positive control of the methane potential of these organisms under ideal conditions (Sowers et al., 1984). This control was selected due to the presence of Methanosarcina acetivorans found in shale and produced waters (Supplementary Table 1) This positive control maintained the highest methane production values at an average $34.5 \mu \mathrm{mol}$ of methane daily. 
Methane emission amounts appeared to spike up and down for no clear reason, and no trend in these values was apparent. They did not display patterns consistent with a lag phase or an incubation period. Of the simulated environments, the samples containing shale and separator water (intended to simulate shale after hydraulic fracturing) produced the most methane averaging $33.6 \mu \mathrm{mol}$ of methane per day. This rate was higher than the $31.4 \mu \mathrm{mol}$ from the samples containing shale and distilled water (intended to simulate shale before the hydrofracture process). However, this difference was not statistically significant ( $p \geq 0.05$ ), nor was there a significant difference compared to bottles containing storage tank water (less than $1 \%$ methanogens) combined with shale $(28.4 \mu \mathrm{mol})$. The addition of nutrients that are likely to exist in the samples of produced fluid did not have as much effect as expected, perhaps because the produced fluid may contain traces of biocides, which are routinely added to hydraulic fracture fluids. Notably, the bottles containing shale and separator water that were inoculatedwith separator water from well M1 from day 661 after production which contained a greater proportion of methanogens ( $-17 \%$ composition) compared to the inoculum supplied to other bottles lacked a significant difference in the levels of methane production between the sets of bottles, suggesting that the number of methanogens may not be the limiting factor for methane production in these samples. In comparison, the negative control (which was designed to test if methane generation may be desorption or thermogenic production), containing autoclaved shale and produced fluid, yielded only $13.7 \mu \mathrm{mol}$ of methane per day, which was significantly less than its non-sterile counterparts (Figure 2.) The least amount of methane was produced by the samples of water without shale, indicating that produced fluid alone (with its dissolved organics) does not provide a good substrate for methane production. Together, these results suggest that the methanogens in samples are alive and are able to produce methane at the approximate temperatures and chemical conditions present in shale before and after hydrofracturing. It also indicates that these organisms are robust since they were able to survive sampling procedures not designed to preserve their vitality. Since the concentration and type of 
methanogens in the inoculum were not a limiting factor means that special inoculation of the shale reservoir may not be a requirement for enhanced methane recovery where native species are present.

Quality Control Limitations with Samples. Samples of pre-injection fluid were limited and many components from the drilling process and well site may have been re-used, bringing into question whether methanogens were introduced with the hydrofracturing water, drilling mud or equipment, or introduced into the sub-surface during the recent decades of drilling for deeper oil and gas in this area. To deal with these constraints, comparisons were made between produced fluid, injected fluid, and shale core samples. Despite the non-sterile nature of these samples, the cores never came in contact with hydrofracturing fluids. Therefore, contamination from injection fluids was unlikely to have affected the cores and could not explain an overlap in organisms between cores and produced fluid.

Direction of Future Testing. Based on our studies, at least a portion of the methane production in the reservoir may be of biogenic origin. Ways to maintain favorable conditions in the shale for methanogens and exploration of their use for enhanced gas production should be considered further. However, the liquid medium was not a significant factor in our tests, so enhanced methane projects may not be highly dependent on delivering to the reservoir precise mixtures of nutrients and water. More testing is needed to determine if changes to hydrofracture fluids could aid in increasing long term methane yield from wells. Biocides, which are routinely mixed into hydraulic fracture fluids, may adversely affect native methanogenic activity. Elimination of biocides from hydraulic fracture fluids may increase the chance of hydraulic fracture fluids stimulating enhanced methane generation near the well and hydraulic fractures where the injected fluid penetrates the rock. More importantly, there is a need to test whether injecting gas-phase $\mathrm{CO}_{2}$ into shale formations to induce preferential release of 
adsorbed methane from shale pore surfaces, and to sweep methane toward producing wells, in a process known as "enhanced gas recovery" can encourage increased generation of methane via microbial community metabolic pathways.

Implications. Although these data do not to prove conclusively that methanogens are native in the deep Marcellus Shale, it is important to consider the possible repercussions of such a find. If methanogens have always been present in the subsurface, it would counter the currently accepted hypothesis that all gas produced at such depths is thermogenic in origin.(Whiticar, 1987) If not all of the gas is thermogenic, it gives hope that there may be a faster recovery time than expected for the renewal of gas reserves in these reservoirs. If an economic way to increase the rate of methane production is found, recoverable quantities could be produced in only a few years and therefore could make natural gas, which is currently considered to be one of the "cleanest" energy sources, much more abundant. 


\section{ACKNOWLEDGEMENTS}

Special thanks to the Rob Vagnetti and US-DOE Strategic Center of Natural Gas and Oil for providing support and funding for this work. We thank Jianbo Yao for mentoring the senior author at WVU through this work and Dan Soeder for mentoring part of this work at NETL. Also, to Dr. Gregory Ferry and his student Eric Malberg at Penn State University for providing initial inoculum and lessons on growing Methanosarcina acetivorans, Tullis Onstott at Princeton University for his advice, and Scot E. Dowd at MrDNA Sequencing for his services and troubleshooting help. We also thank Shikha Sharma for supplying the core and pre-injected fluid samples. For support, special thanks to Joginder Nath, Joseph Morton, and Bill Gwilliam. We also thank Dr. Lee Kass for her aid in editing this manuscript. Most of all, we thank Mark McKoy for his support and time in reviewing and editing the manuscript as well as guiding some of the final work. 
Table 1. Samples and number of sequences from each sample analyzed for methanogenic Archaea. Well and core names are in the first column. Age of well is determined by the day that gas production began. Non-zero values are in bold. Sequences represented are 16s rRNA gene sequences amplified with universal primers.

\begin{tabular}{|c|c|c|c|c|c|c|c|}
\hline Well & $\begin{array}{c}\text { Age } \\
\text { of } \\
\text { Well }\end{array}$ & $\begin{array}{l}\text { Sample } \\
\text { Type }\end{array}$ & Source & OTU $^{\text {ab }}$ & $\begin{array}{c}\text { Total } \\
\text { Sequences }^{\text {ab }}\end{array}$ & $\begin{array}{c}\text { Total } \\
\text { Archaea }\end{array}$ & $\begin{array}{c}\text { Total } \\
\text { Methanogens }\end{array}$ \\
\hline \multicolumn{8}{|c|}{ Barnett Shale } \\
\hline B1 & - & $\begin{array}{c}\text { Before } \\
\text { Injection }\end{array}$ & - & 203 & 11655 & $0 \%$ & $0 \%$ \\
\hline B1 & 60 & Produced & Tank & 125 & 15746 & $0.20 \%$ & $0.20 \%$ \\
\hline \multicolumn{8}{|c|}{ Marcellus Shale } \\
\hline \multicolumn{8}{|c|}{ Pre- Injection } \\
\hline MB & - & $\begin{array}{c}\text { Before } \\
\text { Injection }\end{array}$ & - & 212 & 25040 & $0.02 \%$ & $0 \%$ \\
\hline \multicolumn{8}{|c|}{ Produced fluid Tank } \\
\hline MB & 139 & Produced & Tank & 221 & 32621 & $0.02 \%$ & $0.02 \%$ \\
\hline \multirow[t]{3}{*}{ M1 } & 210 & Produced & Tank & 231 & 40739 & $0.05 \%$ & $0.01 \%$ \\
\hline & 689 & Produced & Tank & 198 & 36897 & $0 \%$ & $0 \%$ \\
\hline & 787 & Produced & Tank & 196 & 38186 & $0 \%$ & $0 \%$ \\
\hline \multirow[t]{2}{*}{ M2 } & 220 & Produced & Tank & 233 & 22747 & $0.24 \%$ & $0.14 \%$ \\
\hline & 787 & Produced & Tank & 191 & 74234 & $0.15 \%$ & $0.15 \%$ \\
\hline M3 & 230 & Produced & Tank & 159 & 21145 & $0.01 \%$ & $0.01 \%$ \\
\hline M6 & 1825 & Produced & Tank & 221 & 23151 & $0.04 \%$ & $0.00 \%$ \\
\hline \multicolumn{8}{|c|}{ Gas-Water Separator } \\
\hline \multirow[t]{3}{*}{ M1 } & 661 & Produced & Separator & 250 & 317056 & $24 \%$ & $17 \%$ \\
\hline & 689 & Produced & Separator & 160 & 78568 & $0 \%$ & $0 \%$ \\
\hline & 787 & Produced & Separator & 204 & 18937 & $0 \%$ & $0 \%$ \\
\hline M2 & 787 & Produced & Separator & 158 & 23905 & $0 \%$ & $0 \%$ \\
\hline \multicolumn{8}{|c|}{ Shale Cores } \\
\hline Core 1 & - & Core & Core & 289 & 23943 & $0.01 \%$ & $0.01 \%$ \\
\hline Core 2 & & Core & Core & 241 & 23897 & $0.49 \%$ & $0.47 \%$ \\
\hline Core 3 & - & Core & Quarry & 173 & 7561 & $0.00 \%$ & $0.00 \%$ \\
\hline
\end{tabular}

${ }^{\mathrm{a}}$ Average from triplicate measurements

${ }^{\mathrm{b}}$ Calculated at putative species level (>97\% homology) 


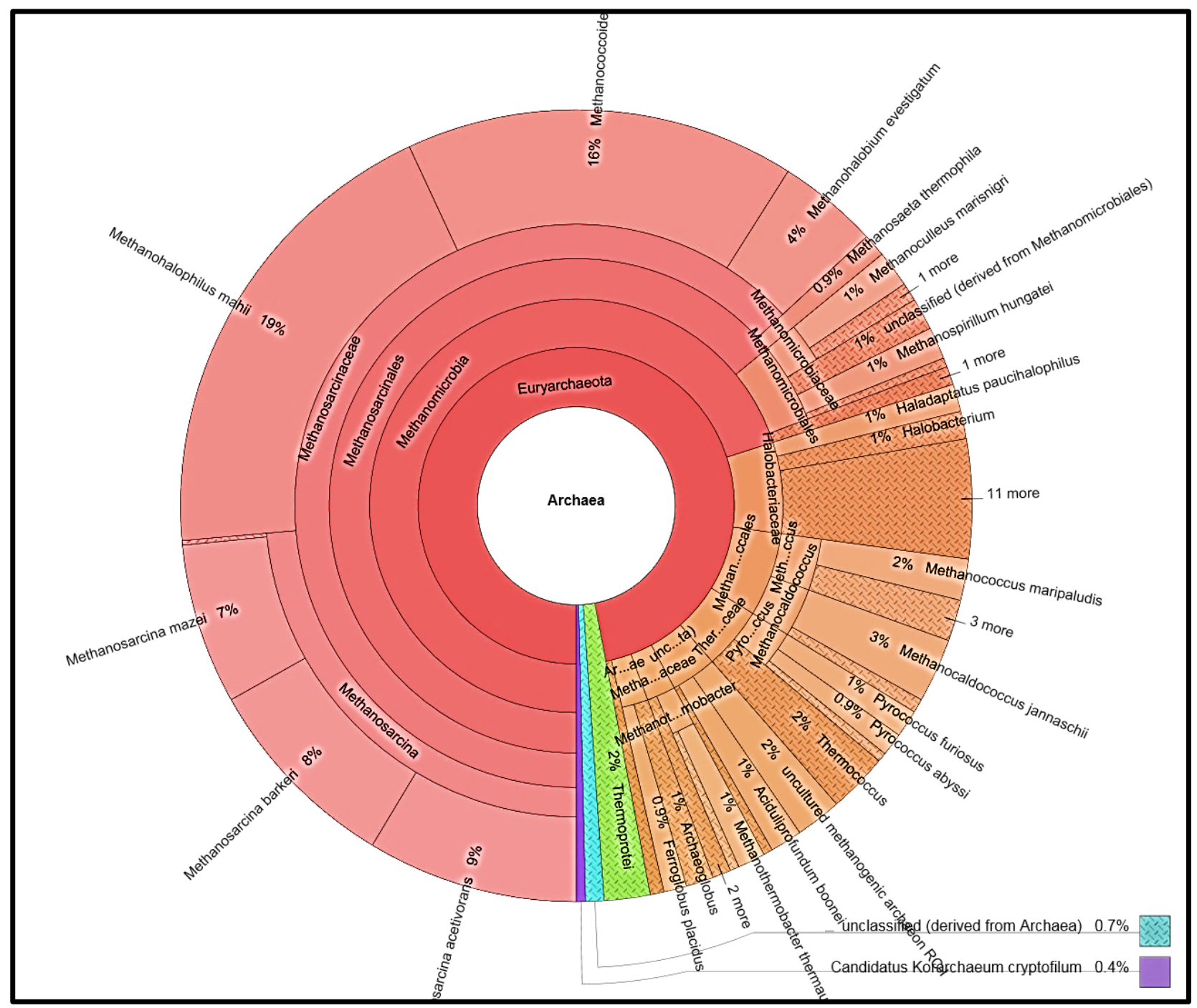

Archaeal Taxonomic Abundance

Figure 1. MG-RAST(Meyer et al., 2008) Krona (Ondov et al., 2011) illustration of the taxonomic abundance found by metagenomic analysis of the enriched separator sample from well M1 on day 669, after production began. These results are an average of the Archaeal species present in several annotation libraries (Greengenes, LSU, SSU, and RDP). In this figure, rings progress outwards by taxonomic levels, where the larger ring is a more specific level of the greater taxonomic group in the smaller ring. 


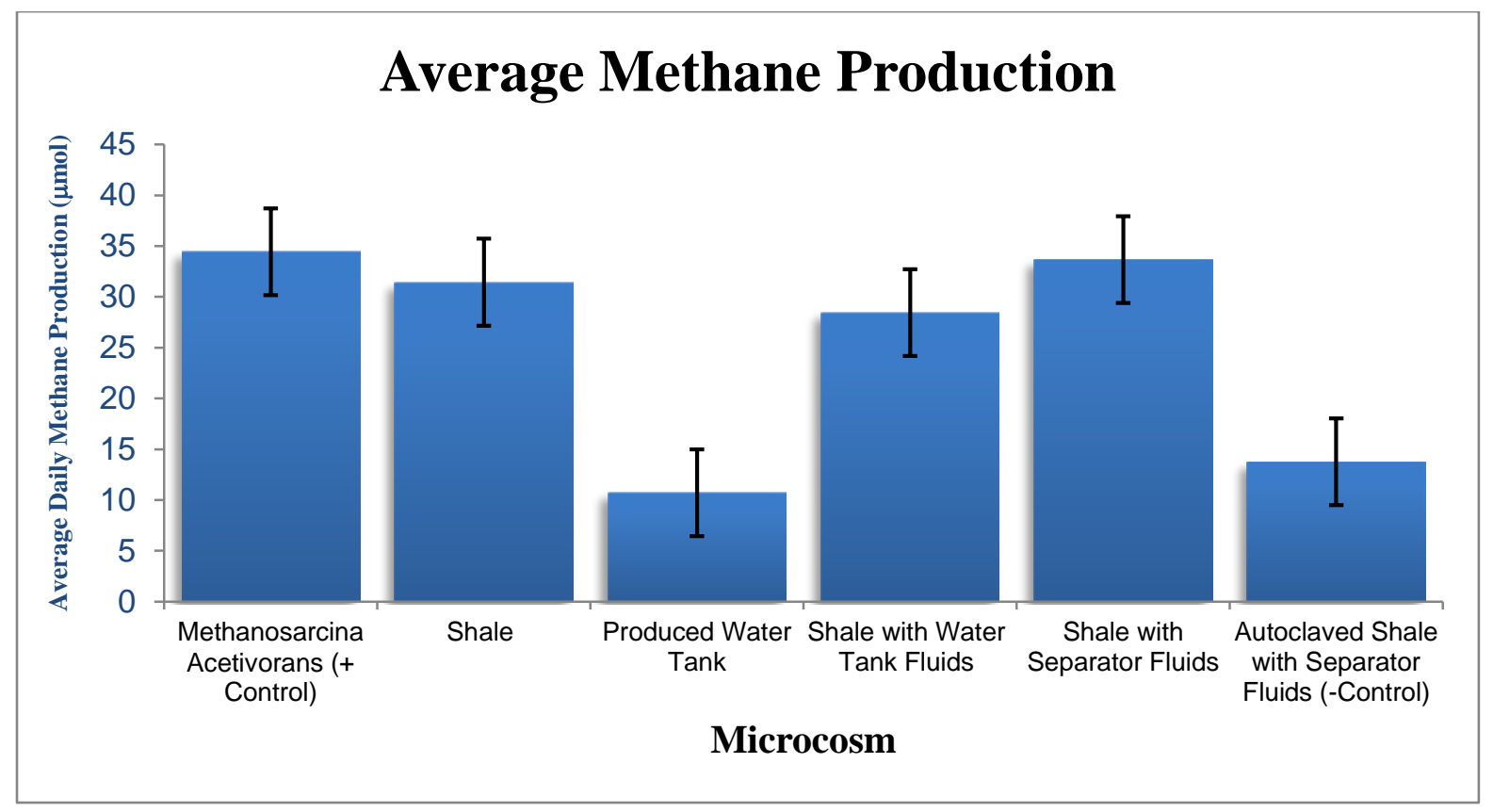

Figure 2. Results of growth experiments illustrating the daily average methane production in specific tests in micro moles $(\mu \mathrm{mol})$. Error bars on the graph indicate the standard error of the average daily methane production of the samples. These measurements are averaged across duplicate samples and throughout the incubation period. Samples were incubated between 28 and 79 days. 
Supplementary Table 1. Sample types and results for $16 r$ RNA analysis with respect to methanogenic Archaea. Well and core names are in the first column. Age of well is determined by the day that gas production began. Non-zero values are in bold. Sequences represented are 16s rRNA gene sequences amplified with universal primers. Core 1 and Core 2 were taken from 7860 and 7873 feet underground respectively.

\section{Supplementary Table 1. Summary of Methanogens in Samples}

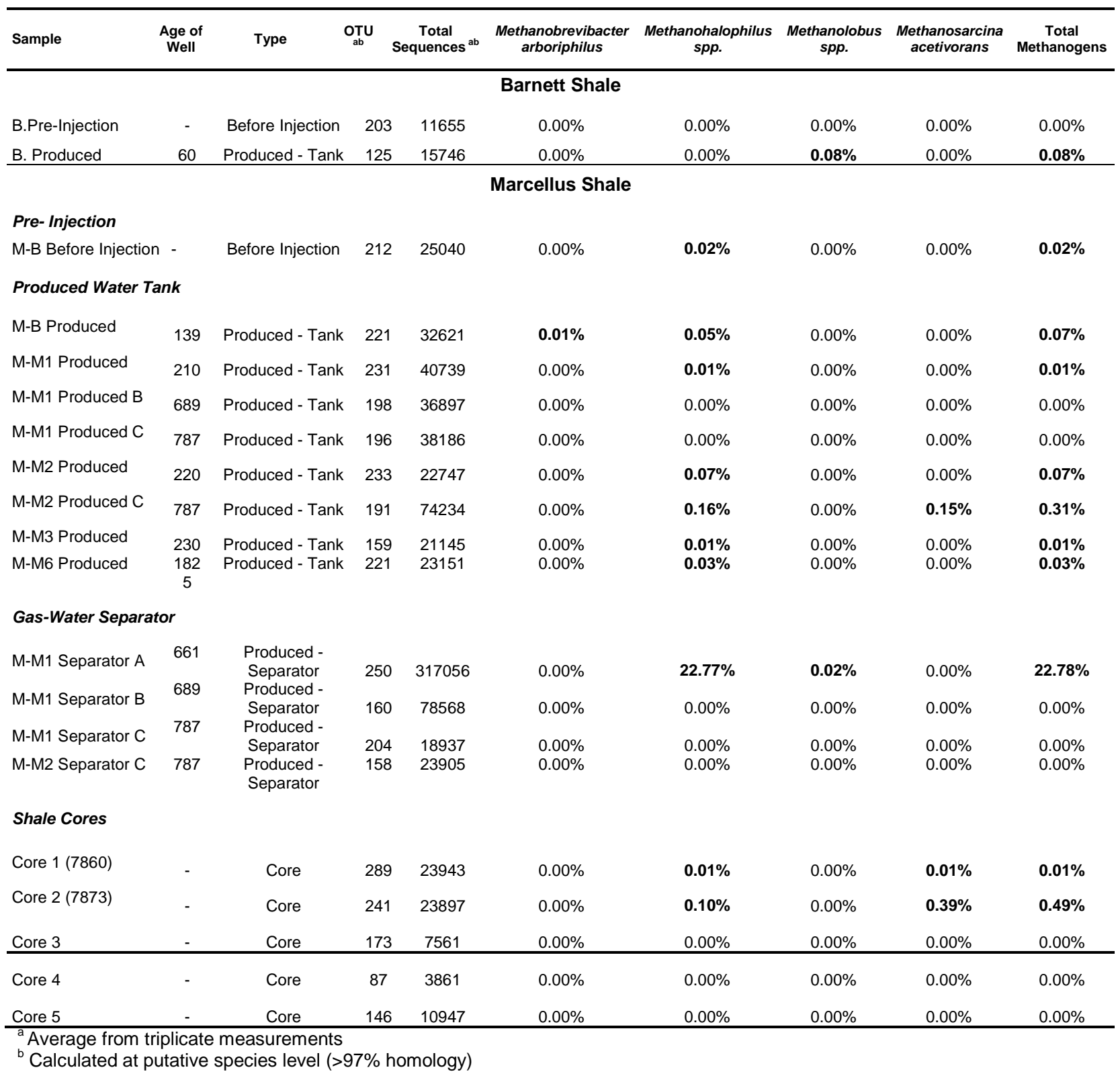




\section{REFERENCES}

(2009). JMP® (Cary, North Carolina SAS Institute Inc.).

Amend, J.P., and Shock, E.L. (2001). Energetics of overall metabolic reactions of thermophilic and hyperthermophilic Archaea and Bacteria. FEMS Microbiol Rev 25, 175-243.

Balch, W., Fox, G., Magrum, L., Woese, C., and Wolfe, R. (1979). Methanogens: reevaluation of a unique biological group. Microbiol Rev 43, 260.

Beckmann, S., Kruger, M., Engelen, B., Gorbushina, A.A., and Cypionka, H. (2011a). Role of bacteria, archaea and fungi involved in methane release in abandoned coal mines. Geomicrobiol J 28, 347-358.

Beckmann, S., Lueders, T., Krüger, M., von Netzer, F., Engelen, B., and Cypionka, H. (2011b). Acetogens and acetoclastic methanosarcinales govern methane formation in abandoned coal mines. App Env Microbiol 77, 3749-3756.

Borrel, G., O'Toole, P.W., Harris, H.M.B., Peyret, P., Brugère, J.-F., and Gribaldo, S. (2013). Phylogenomic data support a seventh order of methylotrophic methanogens and provide insights into the evolution of methanogenesis. Genome Bio Evol 5, 1769-1780.

Bräuer, S.L., Cadillo-Quiroz, H., Yashiro, E., Yavitt, J.B., and Zinder, S.H. (2006). Isolation of a novel acidiphilic methanogen from an acidic peat bog. Nature 442, 192-194.

Buhler, J.D., Lancaster, J.M., Jacob, A.C., and Chamberlain, R.D. (2007). Mercury BLASTN: Faster DNA sequence comparison using a streaming hardware architecture. Proc of Reconfigurable Systems Summer Institute.

Chapelle, F.H., O'Neill, K., Bradley, P.M., Methé, B.A., Ciufo, S.A., Knobel, L.L., and Lovley, D.R. (2002). A hydrogen-based subsurface microbial community dominated by methanogens. Nature 415, 312-315.

Cluff, M. A.; Hartsock, A.; MacRae, J. D.; Carter, K.; Mouser, P. J., (2014) Temporal changes in microbial ecology and geochemistry in produced fluid from hydraulically fractured Marcellus Shale gas wells. Environ. Sci. Technol. 48 (11), pp 6508-6517

Colwell, F.S., Boyd, S., Delwiche, M.E., Reed, D.W., Phelps, T.J., and Newby, D.T. (2008). Estimates of biogenic methane production rates in deep marine sediments at Hydrate Ridge, Cascadia Margin. App Env Microbiol 74, 3444-3452.

Conrad, R. (2007). Microbial ecology of methanogens and methanotrophs. Adv in Agron 96, 163.

Davis, J.P., Struchtemeyer, C.G., and Elshahed, M.S. (2012). Bacterial communities associated with production facilities of two newly drilled thermogenic natural gas wells in the Barnett Shale (Texas, USA). Micro Ecol 64, 942-954. 
Dowd, S.E., Callaway, T.R., Wolcott, R.D., Sun, Y., McKeehan, T., Hagevoort, R.G., and Edrington, T.S. (2008a). Evaluation of the bacterial diversity in the feces of cattle using 16S rDNA bacterial tag-encoded FLX amplicon pyrosequencing (bTEFAP). BMC Microbiol. 8, 125.

Dowd, S.E., Wolcott, R.D., Sun, Y., McKeehan, T., Smith, E., and Rhoads, D. (2008b). Polymicrobial nature of chronic diabetic foot ulcer biofilm infections determined using bacterial tag encoded FLX amplicon pyrosequencing (bTEFAP). PloS One 3, e3326.

Ferry, J.G., and Lessner, D.J. (2008). Methanogenesis in marine sediments. Ann. N. Y. Acad. of Sci. 1125, 147-157.

Hedderich, R., Hamann, N., and Bennati, M. (2005). Heterodisulfide reductase from methanogenic archaea: a new catalytic role for an iron-sulfur cluster. Biol. Chem. 386, 961-970.

Kargbo, D.M., Wilhelm, R.G., and Campbell, D.J. (2010). Natural gas plays in the Marcellus Shale: challenges and potential opportunities. Environ Sci Technol. 44, 5679-5684.

Kirk, M.F. (2011). Variation in energy available to populations of subsurface anaerobes in response to geological carbon storage. Environ Sci Technol. 45, 6676-6682.

Kirk, M.F., Martini, A.M., Breecker, D.O., Colman, D.R., Takacs-Vesbach, C., and Petsch, S.T. (2012). Impact of commercial natural gas production on geochemistry and microbiology in a shale-gas reservoir. Chem Geol. 332-333, 15-25.

McDonald, D., Price, M.N., Goodrich, J., Nawrocki, E.P., DeSantis, T.Z., Probst, A., Andersen, G.L., Knight, R., and Hugenholtz, P. (2011). An improved Greengenes taxonomy with explicit ranks for ecological and evolutionary analyses of bacteria and archaea. ISME J. 6, 610-618.

Meyer, F., Paarmann, D., D'Souza, M., Olson, R., Glass, E.M., Kubal, M., Paczian, T., Rodriguez, A., Stevens, R., Wilke, A., et al. (2008). The metagenomics RAST server - a public resource for the automatic phylogenetic and functional analysis of metagenomes. BMC Bioinform. 9, 386.

Murali Mohan, A., Hartsock, A., Bibby, K.J., Hammack, R.W., Vidic, R.D., and Gregory, K.B. (2013a). Microbial community changes in hydraulic fracturing fluids and produced fluid from shale gas extraction. Environ Sci Technol. 47, 13141-13150.

Murali Mohan, A., Hartsock, A., Hammack, R.W., Vidic, R.D., and Gregory, K.B. (2013b). Microbial communities in flowback water impoundments from hydraulic fracturing for recovery of shale gas. FEMS Microbiol Ecol. 86, 567-580.

Neria-González, I., Wang, E.T., Ramírez, F., Romero, J.M., and Hernández-Rodríguez, C. (2006). Characterization of bacterial community associated to biofilms of corroded oil pipelines from the southeast of Mexico. Anaerobe 12, 122-133. 
Ondov, B.D., Bergman, N.H., and Phillippy, A.M. (2011). Interactive metagenomic visualization in a web browser. BMC Bioinform. 12, 385.

Opara, A., Adams, D., Free, M., McLennan, J., and Hamilton, J. (2012). Microbial production of methane and carbon dioxide from lignite, bituminous coal, and coal waste materials. Int. J Coal Geol. 96, 1-8.

Pritchett, M.A., and Metcalf, W.W. (2005). Genetic, physiological and biochemical characterization of multiple methanol methyltransferase isozymes in Methanosarcina acetivorans C2A. Mol Microbiol 56, 1183-1194.

Schlegel, M.E., McIntosh, J.C., Bates, B.L., Kirk, M.F., and Martini, A.M. (2009). Hydrogeologic controls on microbial methanogenesis in shales and coalbeds in the Illinois Basin. Geochim Cosmochim Ac 73, A1175-A1175.

Sharma, S., Mulder, M.L., Sack, A., Schroeder, K., and Hammack, R. (2013). Isotope approach to assess hydrologic connections during Marcellus Shale drilling. Groundwater.

Sowers, K.R., Baron, S.F., and Ferry, J.G. (1984). Methanosarcina acetivorans sp. nov., an acetotrophic methane-producing bacterium isolated from marine sediments. Appl Environ Microbiol 47, 971-978.

Sowers, K.R., and Ferry, J.G. (1983). Isolation and Characterization of a Methylotrophic Marine Methanogen, Methanococcoides methylutens gen. nov., sp. nov. Appl Environ Microbiol 45, 684-690.

Struchtemeyer, C.G., Davis, J.P., and Elshahed, M.S. (2011). Influence of the drilling mud formulation process on the bacterial communities in thermogenic natural gas wells of the Barnett Shale. Appl Environ Microbiol 77, 4744-4753.

Struchtemeyer, C.G., and Elshahed, M.S. (2012). Bacterial communities associated with hydraulic fracturing fluids in thermogenic natural gas wells in North Central Texas, USA. FEMS Microbiol Ecol. 81, 13-25.

Whiticar, M.J. (1987). Isotopic distinction of biogenic and thermogenic hydrocarbon gases. Abstr Pap Am Chem S 193, 59-Geoc.

Whiticar, M.J. (1990). A geochemical perspective of natural-gas and atmospheric methane. Org Geochem 16, 531-547. 


\section{APPENDIX 1}

\section{Organisms found in all three sources}
\# Genus
1 Heliobacteriaceae
2 Coxiellaceae
3 Acholeplasmataceae
4 Syntrophobacteraceae
5 Listeriaceae
6 Gemmatimonadaceae Unclassified
9 Thermoanaerobacterales
7 Bifidobacteriaceae Unclassified
8 Betaproteobacteria
10 Unclassified Oscillatoriales Thermoanaerobacterales
11 Family III. Incertae Sedis
12 Pasteurellaceae
13 Bacteroidaceae
14 Unclassified Rhizobiales
15 Unclassified Archaea
16 Peptococcaceae
17 Flavobacteriaceae
18 Brevibacteriaceae
19 Cellulomonadaceae Clostridiales Family XI.

20 Incertae Sedis

21 Prevotellaceae

22 Veillonellaceae

23 Bacillaceae

24 Burkholderiaceae

25 Staphylococcaceae

26 Porphyromonadaceae

27 Unclassified Proteobacteria

28 Aerococcaceae

29 Streptococcaceae

30 Thermomonosporaceae

31 Leptotrichiaceae

$\begin{array}{ccl}\begin{array}{c}\text { Pre.injectio } \\ \text { n }\end{array} & \begin{array}{c}\text { Produce } \\ \mathbf{d}\end{array} & \text { Core } \\ 0.01 \% & 0.00 \% & 0.00 \% \\ 0.01 \% & 0.00 \% & 0.00 \% \\ 0.01 \% & 0.00 \% & 0.00 \% \\ 0.01 \% & 0.00 \% & 0.00 \% \\ 0.15 \% & 0.01 \% & 0.00 \% \\ 0.73 \% & 0.03 \% & 0.00 \%\end{array}$

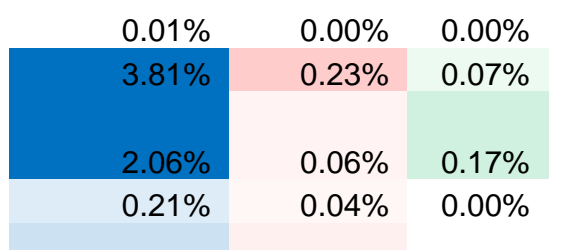

$88.01 \%$

$92.76 \%$

$90.15 \%$

$83.34 \%$

$81.61 \%$ $80.96 \%$

$79.08 \%$

$77.87 \%$

$76.76 \%$

$75.09 \%$

$73.74 \%$

$70.56 \%$

$65.71 \%$

$0.01 \%$

$0.00 \%$

$0.00 \%$

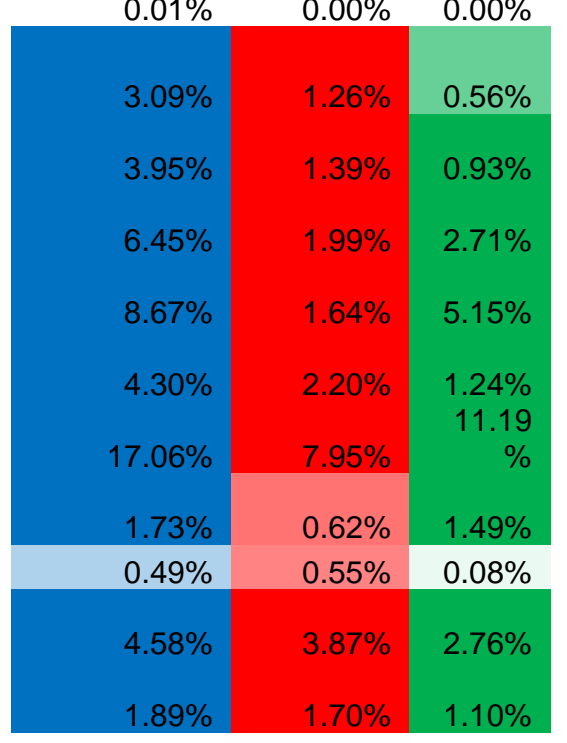

$63.01 \%$

$62.97 \%$

$57.85 \%$

$56.06 \%$

$55.56 \%$

$47.13 \%$

$45.07 \%$

$43.67 \%$

$40.88 \%$

$40.19 \%$

$31.21 \%$

$31.01 \%$
$\%$ in

Produce

$0.00 \%$

$0.00 \%$

$0.00 \%$

$0.16 \%$

$3.40 \%$

$4.25 \%$

$11.99 \%$

$5.55 \%$

$0.00 \%$

$1.69 \%$

$2.48 \%$

$7.37 \%$

$16.42 \%$

$0.24 \%$

$18.24 \%$

$0.15 \%$

$11.05 \% \quad 7.99 \%$

10.13

$10.79 \% \quad \%$

22.12

$0.01 \% \quad \%$

$17.02 \% \quad 6.21 \%$

$22.87 \% \quad 2.05 \%$

$21.21 \% \quad 5.05 \%$

24.11

$5.33 \% \quad \%$

24.76

$9.53 \% \quad \%$

11.32

$25.67 \% \quad \%$

14.83

$22.20 \% \quad \%$

24.30

$17.85 \% \quad \%$

33.34

$10.60 \% \quad \%$

16.04

$28.39 \% \quad \%$

30.91

$21.97 \% \quad \%$

38.71

$16.23 \% \quad \%$

$49.44 \% \quad 6.88 \%$

24.62

$34.50 \% \quad \%$

23.52

$36.29 \% \quad \%$

13.52

$55.28 \% \quad \%$

44.54

$24.45 \% \quad \%$ 
32 Halomonadaceae

33 Micrococcaceae

34 Corynebacteriaceae

35 Actinomycetaceae

36 Rhodospirillaceae

37 Pseudomonadaceae

38 Xanthomonadaceae

39 Neisseriaceae

40 Carnobacteriaceae

41 Caulobacteraceae

42 Pseudonocardiaceae Unclassified

43 Chroococcales

44 Brucellaceae

45 Nocardiaceae

46 Dermacoccaceae

47 Halanaerobiaceae

48 Paenibacillaceae

49 Rhodocyclaceae Unclassified

50 Deltaproteobacteria

51 Flammeovirgaceae

52 Peptostreptococcaceae

53 Enterococcaceae

54 Sphingomonadaceae

55 Fusobacteriaceae

56 Microbacteriaceae

57 Alcaligenaceae

58 Eubacteriaceae

59 Lactobacillaceae

60 Cytophagaceae

61 Clostridiaceae

62 Ruminococcaceae

63 Promicromonosporaceae

64 Lachnospiraceae

65 Unclassified Clostridiales

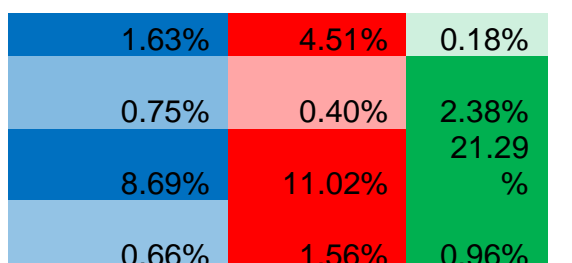

\begin{tabular}{|c|c|c|}
\hline $25.82 \%$ & $71.37 \%$ & $\begin{array}{r}2.81 \% \\
67.42\end{array}$ \\
\hline $21.31 \%$ & $11.26 \%$ & $\%$ \\
\hline & & $\begin{array}{r}51.92 \\
0\end{array}$ \\
\hline $21.20 \%$ & $26.88 \%$ & $\begin{array}{r}\% \\
30.24\end{array}$ \\
\hline $20.65 \%$ & $49.11 \%$ & $\%$ \\
\hline $20.45 \%$ & $73.41 \%$ & $\begin{array}{r}6.14 \% \\
52.76\end{array}$ \\
\hline $16.67 \%$ & $30.57 \%$ & \\
\hline $16.49 \%$ & $37.23 \%$ & $\begin{array}{r}\% \\
58.71\end{array}$ \\
\hline $16.34 \%$ & $24.95 \%$ & $\begin{array}{r}\% \\
36.04\end{array}$ \\
\hline $16.29 \%$ & $47.67 \%$ & $\begin{array}{r}\% \\
48.76\end{array}$ \\
\hline $14.12 \%$ & $37.12 \%$ & $\begin{array}{r}\% \\
53.02\end{array}$ \\
\hline $10.08 \%$ & $36.90 \%$ & $\%$ \\
\hline
\end{tabular}

$9.84 \%$

$89.14 \%$

$1.02 \%$

\begin{tabular}{|l|l|l|}
\hline $0.01 \%$ & $0.05 \%$ & $0.00 \%$
\end{tabular}

$0.05 \% \quad 0.64 \% \quad 0.00 \%$

$7.82 \%$

$0.02 \% \quad 0.11 \% \quad 0.09 \%$

$7.62 \%$

$91.94 \%$

$0.24 \%$

41.57

$50.81 \%$

\begin{tabular}{r|r|r|r}
\hline $0.14 \%$ & $0.03 \%$ & $1.74 \%$ & $7.37 \%$ \\
\hline $1.05 \%$ & $13.93 \%$ & $0.38 \%$ & $6.85 \%$
\end{tabular}

$1.71 \%$

90.92

$1.05 \% \quad 13.93 \% \quad 0.38 \%$

$0.01 \%$

$0.17 \% \quad 0.05 \%$

$\begin{array}{lll}0.01 \% & 0.15 \% & 0.00 \%\end{array}$

$0.01 \%$

$0.11 \% \quad 0.00 \%$

$0.01 \%$

$0.07 \% \quad 0.10 \%$

$0.04 \%$

$0.47 \% \quad 1.06 \%$

$0.01 \%$

$0.18 \% \quad 0.06 \%$

$0.05 \%$

$0.76 \%$

$0.01 \%$

$0.18 \% \quad 0.22 \%$

$0.01 \% \quad 0.44 \% \quad 0.46 \%$

$0.01 \%$

$0.03 \% \quad 0.60 \%$

$0.22 \% \quad 0.00 \%$
$90.71 \%$

$6.81 \%$

$6.58 \%$

$73.07 \%$

$88.04 \%$

$6.53 \%$

$4.62 \%$

$3.21 \%$

$91.88 \%$

$94.39 \%$

$39.65 \%$

$2.43 \%$

$29.74 \%$

$2.26 \%$

$2.25 \%$

$74.03 \%$

$66.48 \%$

$1.34 \%$

$57.54 \%$

$1.33 \%$

$1.18 \%$

$45.22 \%$

$0.86 \%$

$48.43 \%$

$4.43 \%$

$0.89 \%$

$0.92 \%$

$57.08 \%$

$87.86 \%$

$2.39 \%$

$95.77 \%$

$97.38 \%$

$2.37 \%$

$0.78 \%$

$45.55 \%$

$79.19 \%$

$2.44 \%$

20.12

$5.38 \%$

$1.59 \%$

$0.99 \%$

57.14

67.83

$\%$

23.71

$\%$

31.27

$\%$

41.12

53.45

$\%$

50.39

94.71

$\%$

42.03

11.22

$\%$

$1.84 \%$

$0.25 \%$

53.68

$0.73 \%$ 
66 Beutenbergiaceae

67 Oxalobacteraceae

68 Rhodobacteraceae Unclassified

69 Gammaproteobacteria

70 Moraxellaceae

71 Unclassified Bacteria Unclassified

72 Sphingobacteriales

73 Enterobacteriaceae

74 Alteromonadaceae

75 Spirochaetaceae

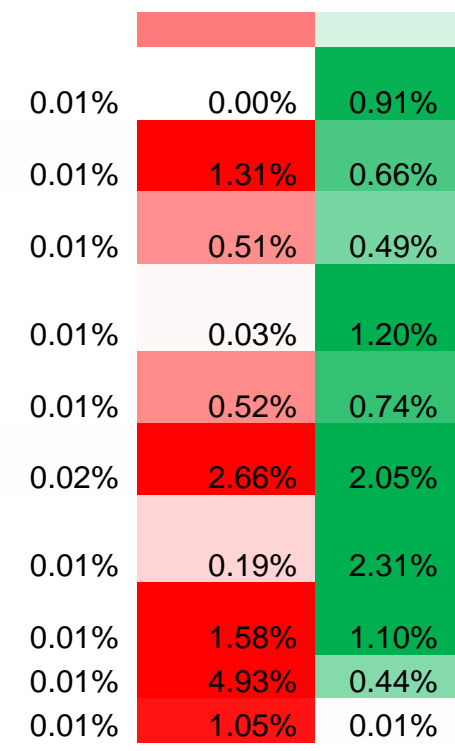

\begin{tabular}{|c|c|c|}
\hline & & $\begin{array}{r}\% \\
99.29\end{array}$ \\
\hline $0.59 \%$ & $0.11 \%$ & $\%$ \\
\hline $0.55 \%$ & $66.19 \%$ & $\begin{array}{r}33.27 \\
\%\end{array}$ \\
\hline & & 49.04 \\
\hline $.54 \%$ & $50.42 \%$ & \\
\hline $0.44 \%$ & $2.52 \%$ & $\begin{array}{r}97.04 \\
\%\end{array}$ \\
\hline & & 58.64 \\
\hline $0.43 \%$ & $40.93 \%$ & $\%$ \\
\hline $0.34 \%$ & $56.29 \%$ & $\begin{array}{r}43.37 \\
\%\end{array}$ \\
\hline & & 92.12 \\
\hline $0.22 \%$ & $7.66 \%$ & $\%$ \\
\hline $0.20 \%$ & $58.73 \%$ & $\begin{array}{r}41.06 \\
\%\end{array}$ \\
\hline $0.10 \%$ & $91.64 \%$ & $8.26 \%$ \\
\hline $0.51 \%$ & $98.27 \%$ & $1.22 \%$ \\
\hline
\end{tabular}




\section{APPENDIX 2}

\section{Organisms Found Only in Produced Fluids}

\begin{tabular}{|c|c|c|c|c|c|c|c|}
\hline \# & Genus & $\begin{array}{l}\text { Pre.injectio } \\
\mathrm{n}\end{array}$ & $\begin{array}{l}\text { Produce } \\
\text { d }\end{array}$ & $\begin{array}{c}\text { Core } \\
0.00\end{array}$ & $\begin{array}{l}\% \text { in } \\
\text { Pre- } \\
\text { Injectio } \\
\text { n }\end{array}$ & $\begin{array}{l}\% \text { in } \\
\text { Produce } \\
\text { d }\end{array}$ & $\begin{array}{l}\% \text { in } \\
\text { Core }\end{array}$ \\
\hline 78 & Psychromonadaceae & $0.00 \%$ & $0.00 \%$ & $\begin{array}{r}\% \\
0.00\end{array}$ & $0.00 \%$ & $100.00 \%$ & $0.00 \%$ \\
\hline 79 & $\begin{array}{l}\text { Nitrosomonadaceae } \\
\text { Pseudoalteromonadacea }\end{array}$ & $0.00 \%$ & $0.00 \%$ & $\begin{array}{r}\% \\
0.00\end{array}$ & $0.00 \%$ & $100.00 \%$ & $0.00 \%$ \\
\hline 80 & e & $0.00 \%$ & $0.01 \%$ & $\begin{array}{r}\% \\
0.00\end{array}$ & $0.00 \%$ & $100.00 \%$ & $0.00 \%$ \\
\hline 81 & Moritellaceae & $0.00 \%$ & $0.00 \%$ & $\begin{array}{r}\% \\
0.00\end{array}$ & $0.00 \%$ & $100.00 \%$ & $0.00 \%$ \\
\hline 82 & Phyllobacteriaceae & $0.00 \%$ & $0.10 \%$ & & $0.00 \%$ & $100.00 \%$ & $0.00 \%$ \\
\hline 83 & Kineosporiaceae & $0.00 \%$ & $0.04 \%$ & $\begin{array}{r}\% \\
0.00\end{array}$ & $0.00 \%$ & $100.00 \%$ & $0.00 \%$ \\
\hline 84 & Methylophilaceae & $0.00 \%$ & $0.00 \%$ & $\begin{array}{r}\% \\
0.00\end{array}$ & $0.00 \%$ & $100.00 \%$ & $0.00 \%$ \\
\hline 85 & Propionibacteriaceae & $0.00 \%$ & $0.00 \%$ & $\begin{array}{r}\% \\
0.00\end{array}$ & $0.00 \%$ & $100.00 \%$ & $0.00 \%$ \\
\hline 86 & Methylococcaceae & $0.00 \%$ & $0.00 \%$ & $\begin{array}{r}\% \\
0.00\end{array}$ & $0.00 \%$ & $100.00 \%$ & $0.00 \%$ \\
\hline 87 & Myхососcaceae & $0.00 \%$ & $0.00 \%$ & $\begin{array}{r}\% \\
0.00\end{array}$ & $0.00 \%$ & $100.00 \%$ & $0.00 \%$ \\
\hline 88 & Oceanospirillaceae & $0.00 \%$ & $0.00 \%$ & $\begin{array}{r}\% \\
0.00\end{array}$ & $0.00 \%$ & $100.00 \%$ & $0.00 \%$ \\
\hline 89 & Solibacteraceae & $0.00 \%$ & $0.00 \%$ & $\begin{array}{r}\% \\
0.00\end{array}$ & $0.00 \%$ & $100.00 \%$ & $0.00 \%$ \\
\hline 90 & $\begin{array}{l}\text { Opitutaceae } \\
\text { Verrucomicrobia }\end{array}$ & $0.00 \%$ & $0.00 \%$ & $\begin{array}{r}\% \\
0.00\end{array}$ & $0.00 \%$ & $100.00 \%$ & $0.00 \%$ \\
\hline 91 & $\begin{array}{l}\text { subdivision } 3 \\
\text { Clostridiales Family XVII. }\end{array}$ & $0.00 \%$ & $0.00 \%$ & $\begin{array}{r}\% \\
0.00\end{array}$ & $0.00 \%$ & $100.00 \%$ & $0.00 \%$ \\
\hline 92 & Incertae Sedis & $0.00 \%$ & $0.00 \%$ & $\begin{array}{r}\% \\
0.00\end{array}$ & $0.00 \%$ & $100.00 \%$ & $0.00 \%$ \\
\hline 93 & Acidimicrobiaceae & $0.00 \%$ & $0.01 \%$ & $\begin{array}{r}\% \\
0.00\end{array}$ & $0.00 \%$ & $100.00 \%$ & $0.00 \%$ \\
\hline 94 & $\begin{array}{l}\text { Hyphomicrobiaceae } \\
\text { Thermoanaerobacteracea }\end{array}$ & $0.00 \%$ & $0.01 \%$ & $\begin{array}{r}\% \\
0.00\end{array}$ & $0.00 \%$ & $100.00 \%$ & $0.00 \%$ \\
\hline 95 & e & $0.00 \%$ & $0.00 \%$ & $\begin{array}{r}\% \\
0.00\end{array}$ & $0.00 \%$ & $100.00 \%$ & $0.00 \%$ \\
\hline 96 & Nitrospiraceae & $0.00 \%$ & $0.00 \%$ & $\begin{array}{r}\% \\
0.00\end{array}$ & $0.00 \%$ & $100.00 \%$ & $0.00 \%$ \\
\hline 97 & $\begin{array}{l}\text { Jonesiaceae } \\
\text { Clostridiales Family XVIII. }\end{array}$ & $0.00 \%$ & $0.00 \%$ & $\begin{array}{r}\% \\
0.00\end{array}$ & $0.00 \%$ & $100.00 \%$ & $0.00 \%$ \\
\hline 98 & Incertae Sedis & $0.00 \%$ & $0.00 \%$ & $\begin{array}{r}\% \\
0.00\end{array}$ & $0.00 \%$ & $100.00 \%$ & $0.00 \%$ \\
\hline 99 & Deferribacteraceae & $0.00 \%$ & $0.08 \%$ & $\begin{array}{r}\% \\
0.00\end{array}$ & $0.00 \%$ & $100.00 \%$ & $0.00 \%$ \\
\hline 00 & Frankiaceae & $0.00 \%$ & $0.00 \%$ & $\%$ & $0.00 \%$ & $100.00 \%$ & $0.00 \%$ \\
\hline
\end{tabular}


101 Geodermatophilaceae Unclassified

102 Actinomycetales

103 Verrucomicrobiaceae

104 Thermoleophilaceae Unclassified

105 Verrucomicrobia

106 Desulfohalobiaceae

107 Conexibacteraceae

108 Thermomicrobiaceae

109 Thermaceae

110 Acidobacteriaceae

111 Anaplasmataceae

112 Fibrobacteraceae

113 Desulfuromonadaceae

114 Spiroplasmataceae

115 Unclassified Firmicutes

116 Geobacteraceae

117 Beijerinckiaceae

118 Herpetosiphonaceae

119 Methylocystaceae

120 Thermodesulfobiaceae

121 Succinivibrionaceae Unclassified

122 Synergistetes

123 Bartonellaceae

124 Pasteuriaceae

125 Ktedonobacteraceae

126 Leptospiraceae Unclassified

127 Flavobacteriia 128 Thermotogaceae

\begin{tabular}{|c|c|c|c|c|c|}
\hline $0.00 \%$ & $0.15 \%$ & $\begin{array}{r}0.00 \\
\%\end{array}$ & $0.00 \%$ & $100.00 \%$ & $0.00 \%$ \\
\hline $0.00 \%$ & $0.00 \%$ & $\begin{array}{r}0.00 \\
\% \\
0.00\end{array}$ & $0.00 \%$ & $100.00 \%$ & $0.00 \%$ \\
\hline $0.00 \%$ & $0.00 \%$ & $\begin{array}{r}\% \\
0.00\end{array}$ & $0.00 \%$ & $100.00 \%$ & $0.00 \%$ \\
\hline $0.00 \%$ & $0.00 \%$ & $\begin{array}{r}\% \\
0.00\end{array}$ & $0.00 \%$ & $100.00 \%$ & $0.00 \%$ \\
\hline $0.00 \%$ & $0.00 \%$ & $\begin{array}{r}\% \\
0.00\end{array}$ & $0.00 \%$ & $100.00 \%$ & $0.00 \%$ \\
\hline $0.00 \%$ & $0.03 \%$ & $\begin{array}{r}\% \\
0.00\end{array}$ & $0.00 \%$ & $100.00 \%$ & $0.00 \%$ \\
\hline $0.00 \%$ & $0.01 \%$ & $\begin{array}{r}\% \\
0.00\end{array}$ & $0.00 \%$ & $100.00 \%$ & $0.00 \%$ \\
\hline $0.00 \%$ & $0.00 \%$ & $\begin{array}{r}\% \\
0.00\end{array}$ & $0.00 \%$ & $100.00 \%$ & $0.00 \%$ \\
\hline $0.00 \%$ & $0.00 \%$ & $\begin{array}{r}\% \\
0.00\end{array}$ & $0.00 \%$ & $100.00 \%$ & $0.00 \%$ \\
\hline $0.00 \%$ & $0.03 \%$ & $\begin{array}{r}\% \\
0.00\end{array}$ & $0.00 \%$ & $100.00 \%$ & $0.00 \%$ \\
\hline $0.00 \%$ & $0.13 \%$ & $\begin{array}{r}\% \\
0.00\end{array}$ & $0.00 \%$ & $100.00 \%$ & $0.00 \%$ \\
\hline $0.00 \%$ & $0.00 \%$ & $\begin{array}{r}\% \\
0.00\end{array}$ & $0.00 \%$ & $100.00 \%$ & $0.00 \%$ \\
\hline $0.00 \%$ & $0.00 \%$ & $\begin{array}{r}\% \\
0.00\end{array}$ & $0.00 \%$ & $100.00 \%$ & $0.00 \%$ \\
\hline $0.00 \%$ & $0.00 \%$ & $\begin{array}{r}\% \\
0.00\end{array}$ & $0.00 \%$ & $100.00 \%$ & $0.00 \%$ \\
\hline $0.00 \%$ & $0.03 \%$ & $\begin{array}{r}\% \\
0.00\end{array}$ & $0.00 \%$ & $100.00 \%$ & $0.00 \%$ \\
\hline $0.00 \%$ & $0.03 \%$ & $\begin{array}{r}\% \\
0.00\end{array}$ & $0.00 \%$ & $100.00 \%$ & $0.00 \%$ \\
\hline $0.00 \%$ & $0.00 \%$ & $\begin{array}{r}\% \\
0.00\end{array}$ & $0.00 \%$ & $100.00 \%$ & $0.00 \%$ \\
\hline $0.00 \%$ & $0.01 \%$ & $\begin{array}{r}\% \\
0.00\end{array}$ & $0.00 \%$ & $100.00 \%$ & $0.00 \%$ \\
\hline $0.00 \%$ & $0.00 \%$ & $\begin{array}{r}\% \\
0.00\end{array}$ & $0.00 \%$ & $100.00 \%$ & $0.00 \%$ \\
\hline $0.00 \%$ & $0.00 \%$ & $\begin{array}{r}\% \\
0.00\end{array}$ & $0.00 \%$ & $100.00 \%$ & $0.00 \%$ \\
\hline $0.00 \%$ & $0.00 \%$ & $\begin{array}{r}\% \\
0.00\end{array}$ & $0.00 \%$ & $100.00 \%$ & $0.00 \%$ \\
\hline $0.00 \%$ & $0.00 \%$ & $\begin{array}{r}\% \\
0.00\end{array}$ & $0.00 \%$ & $100.00 \%$ & $0.00 \%$ \\
\hline $0.00 \%$ & $0.00 \%$ & $\begin{array}{r}\% \\
0.00\end{array}$ & $0.00 \%$ & $100.00 \%$ & $0.00 \%$ \\
\hline $0.00 \%$ & $0.00 \%$ & $\begin{array}{r}\% \\
0.00\end{array}$ & $0.00 \%$ & $100.00 \%$ & $0.00 \%$ \\
\hline $0.00 \%$ & $0.00 \%$ & $\begin{array}{r}\% \\
0.00\end{array}$ & $0.00 \%$ & $100.00 \%$ & $0.00 \%$ \\
\hline $0.00 \%$ & $0.00 \%$ & $\%$ & $0.00 \%$ & $100.00 \%$ & $0.00 \%$ \\
\hline $0.00 \%$ & $0.00 \%$ & $\begin{array}{r}0.00 \\
\%\end{array}$ & $0.00 \%$ & $100.00 \%$ & $0.00 \%$ \\
\hline $0.00 \%$ & $0.00 \%$ & 0.00 & $0.00 \%$ & $100.00 \%$ & $0.00 \%$ \\
\hline
\end{tabular}


129 Dictyoglomaceae Unclassified

130 Desulfuromonadales Unclassified

131 Crenarchaeota Unclassified

132 Pleurocapsales Unclassified

133 Dehalococcoidetes

134 Victivallaceae

135 Hydrogenophilaceae

136 Synergistaceae

137 Williamsiaceae

138 Mycoplasmataceae

139 Cohaesibacteraceae Unclassified

140 Actinobacteria

141 Halothiobacillaceae

142 Chlamydiaceae

143 Oscillochloridaceae

144 Aurantimonadaceae

145 Xanthobacteraceae

146 Cystobacteraceae

\begin{tabular}{|c|c|c|c|c|c|}
\hline & & $\begin{array}{r}\% \\
0.00\end{array}$ & & & \\
\hline $0.00 \%$ & $0.00 \%$ & $\%$ & $0.00 \%$ & $100.00 \%$ & $0.00 \%$ \\
\hline & & 0.00 & & & \\
\hline $0.00 \%$ & $0.00 \%$ & $\%$ & $0.00 \%$ & $100.00 \%$ & $0.00 \%$ \\
\hline & & 0.00 & & & \\
\hline $0.00 \%$ & $0.00 \%$ & $\%$ & $0.00 \%$ & $100.00 \%$ & $0.00 \%$ \\
\hline & & 0.00 & & & \\
\hline $0.00 \%$ & $0.00 \%$ & $\%$ & $0.00 \%$ & $100.00 \%$ & $0.00 \%$ \\
\hline & & 0.00 & & & \\
\hline $0.00 \%$ & $0.01 \%$ & $\%$ & $0.00 \%$ & $100.00 \%$ & $0.00 \%$ \\
\hline & & 0.00 & & & \\
\hline $0.00 \%$ & $0.00 \%$ & $\%$ & $0.00 \%$ & $100.00 \%$ & $0.00 \%$ \\
\hline & & 0.00 & & & \\
\hline $0.00 \%$ & $0.00 \%$ & $\%$ & $0.00 \%$ & $100.00 \%$ & $0.00 \%$ \\
\hline & & 0.00 & & & \\
\hline $0.00 \%$ & $0.03 \%$ & $\%$ & $0.00 \%$ & $100.00 \%$ & $0.00 \%$ \\
\hline & & 0.00 & & & \\
\hline $0.00 \%$ & $0.00 \%$ & $\%$ & $0.00 \%$ & $100.00 \%$ & $0.00 \%$ \\
\hline & & 0.00 & & & \\
\hline $0.00 \%$ & $0.03 \%$ & $\%$ & $0.00 \%$ & $100.00 \%$ & $0.00 \%$ \\
\hline & & 0.00 & & & \\
\hline $0.00 \%$ & $0.01 \%$ & $\%$ & $0.00 \%$ & $100.00 \%$ & $0.00 \%$ \\
\hline & & 0.00 & & & \\
\hline $0.00 \%$ & $0.00 \%$ & $\%$ & $0.00 \%$ & $100.00 \%$ & $0.00 \%$ \\
\hline & & 0.00 & & & \\
\hline $0.00 \%$ & $0.00 \%$ & $\%$ & $0.00 \%$ & $100.00 \%$ & $0.00 \%$ \\
\hline & & 0.00 & & & \\
\hline $0.00 \%$ & $0.00 \%$ & $\%$ & $0.00 \%$ & $100.00 \%$ & $0.00 \%$ \\
\hline & & 0.00 & & & \\
\hline $0.00 \%$ & $0.00 \%$ & $\%$ & $0.00 \%$ & $100.00 \%$ & $0.00 \%$ \\
\hline & & 0.00 & & & \\
\hline $0.00 \%$ & $0.00 \%$ & $\%$ & $0.00 \%$ & $100.00 \%$ & $0.00 \%$ \\
\hline & & 0.00 & & & \\
\hline $0.00 \%$ & $0.00 \%$ & $\%$ & $0.00 \%$ & $100.00 \%$ & $0.00 \%$ \\
\hline & & 0.00 & & & \\
\hline $0.00 \%$ & $0.00 \%$ & $\%$ & $0.00 \%$ & $100.00 \%$ & $0.00 \%$ \\
\hline
\end{tabular}




\section{APPENDIX 3}

\section{Organisms Found in Produced Fluid and Core}

\# Genus

147 Aeromonadaceae

148 Methylobacteriaceae Unclassified

149 Bacteroidetes

150 Bradyrhizobiaceae

151 Nitrososphaeraceae

152 Leuconostocaceae

153 Rubrobacteraceae Unclassified

154 Methanosarcinales

155 Ectothiorhodospiraceae Thermoactinomycetacea

$156 \mathrm{e}$

157 Acidothermaceae

158 Dermatophilaceae Unclassified

159 Epsilonproteobacteria

160 Gordoniaceae

161 Comamonadaceae Unclassified

162 Acidobacteria

163 Mycobacteriaceae

164 Campylobacteraceae

165 Francisellaceae

166 Planococcaceae

167 Desulfovibrionaceae

168 Sphingobacteriaceae

169 Alcanivoracaceae

170 Dietziaceae

171 Rhizobiaceae

172 Chromatiaceae

173 Planctomycetaceae

174 Vibrionaceae

175 Bogoriellaceae

176 Nakamurellaceae Candidatus

177 Brocadiaceae

178 Legionellaceae

179 Dermabacteraceae

180 Piscirickettsiaceae

181 Parachlamydiaceae

182 Shewanellaceae

183 Unclassified Bacillales n

$0.00 \%$
$0.00 \%$

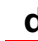

$0.00 \%$

$0.00 \%$

$0.00 \%$

$0.00 \%$

$0.00 \%$

\section{d}

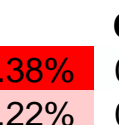

Core

$0.01 \%$

$0.22 \% \quad 0.00 \%$

$\%$ in

Pre-

Injectio

n

$0.00 \%$

$0.00 \%$

$0.00 \%$

$0.00 \%$

$0.00 \%$

$0.00 \%$

$0.00 \%$

$0.00 \%$

$0.00 \%$

$0.00 \%$

$0.61 \% \quad 0.03 \%$

$0.03 \% \quad 0.00 \%$

$0.00 \%$

$0.00 \%$

$0.00 \%$

$0.05 \%$

$0.01 \%$

$0.03 \% \quad 0.00 \%$

$0.00 \%$

$0.00 \%$

$0.00 \% \quad 0.00 \%$

$0.00 \%$

$0.00 \%$

$0.00 \%$

$0.00 \%$

$0.01 \% \quad 0.00 \%$

$0.00 \%$

$0.00 \%$

$0.09 \%$

$0.00 \%$

$0.00 \%$

$0.00 \%$

$0.00 \%$

$0.00 \%$

$0.00 \% \quad 0.00 \%$

$0.00 \%$

$0.00 \%$

$0.00 \%$

$0.13 \%$

$0.04 \%$

$0.00 \%$

$0.00 \%$

$0.00 \%$

$0.00 \%$

$0.00 \%$

$0.00 \% \quad 0.00 \%$

$0.00 \%$

$0.06 \%$

$0.00 \%$

$0.00 \%$

$0.00 \%$

$0.00 \%$

$0.00 \%$

$0.00 \%$

$0.25 \% \quad 0.13 \%$

$0.47 \% \quad 0.30 \%$

$0.00 \%$

$0.00 \%$

$0.00 \%$

$0.03 \% \quad 0.03 \%$

$0.00 \%$

$0.00 \%$

$0.00 \%$

$0.00 \%$

$0.00 \%$

$0.00 \%$

$0.00 \%$

$0.00 \%$

$0.01 \%$

$0.01 \%$

$0.00 \%$

$0.00 \%$

$0.00 \%$

$0.00 \%$

$0.08 \%$

$0.10 \%$

$0.00 \%$

$0.00 \% \quad 0.00 \%$

$0.00 \%$

$0.00 \%$

$0.01 \% \quad 0.01 \%$

$0.00 \%$

$0.00 \%$

$0.00 \%$

$0.00 \%$

$0.00 \%$

$0.00 \%$

$0.00 \%$

$0.00 \%$

$0.00 \%$

$0.00 \%$

$0.00 \%$

$0.00 \%$

$0.00 \%$

$0.00 \%$

$0.00 \%$

$0.00 \%$

$0.00 \%$
$\%$ in

Produce \% in

d Core

99.32\% $0.68 \%$

$98.97 \% \quad 1.03 \%$

$98.91 \% \quad 1.09 \%$

$98.66 \% \quad 1.34 \%$

$98.16 \% \quad 1.84 \%$

$97.75 \% \quad 2.25 \%$

$97.34 \% \quad 2.66 \%$

$95.63 \%$

$4.37 \%$

$7.44 \%$

$89.63 \%$

$86.77 \%$

$86.34 \%$

$10.37 \%$

$13.23 \%$

$13.66 \%$

$85.31 \%$

$14.69 \%$

$84.41 \%$

$84.18 \%$

$15.59 \%$

$15.82 \%$

$81.31 \%$

$18.69 \%$

$77.85 \%$

$22.15 \%$

$74.51 \%$

$25.49 \%$

$71.42 \%$

$28.58 \%$

$65.57 \%$

$34.43 \%$

$65.56 \%$

$34.44 \%$

$61.36 \%$

$38.64 \%$

$55.25 \%$

$44.75 \%$

$52.45 \%$

$47.55 \%$

$52.07 \%$

$47.93 \%$

$51.71 \%$

$48.29 \%$

$49.16 \%$

$50.84 \%$

$46.03 \%$

$53.97 \%$

$43.16 \%$

$56.84 \%$

$42.38 \%$

$57.62 \%$

$41.72 \%$

$58.28 \%$

$40.85 \%$

$59.15 \%$

$39.77 \%$

$60.23 \%$

$39.27 \%$

$60.73 \%$

$37.63 \%$

$62.37 \%$

$31.85 \%$

$68.15 \%$

$26.08 \%$

$73.92 \%$ 
184 Nocardiopsaceae Unclassified

185 Spartobacteria Unclassified

186 Oceanospirillales

187 Cardiobacteriaceae

188 Nocardioidaceae

189 Streptosporangiaceae

190 Deinococcaceae

191 Rarobacteraceae Unclassified

192 Euryarchaeota

193 Micromonosporaceae

194 Streptomycetaceae

195 Hyphomonadaceae

196 Methanosarcinaceae

197 Desulfobulbaceae

198 Marinilabiaceae

199 Desulfobacteraceae

200 Intrasporangiaceae Unclassified

201 Burkholderiales Unclassified

202 Alphaproteobacteria

203 Rikenellaceae Clostridiales Family XII.

204 Incertae Sedis

205 Erysipelotrichaceae

206 Acetobacteraceae Unclassified

207 Rhodobacterales

208 Coriobacteriaceae

209 Desulfonatronumaceae

210 Gallionellaceae

211 Thiotrichaceae Unclassified

212 Bifidobacteriales Unclassified

213 Campylobacterales

\begin{tabular}{|c|c|c|c|c|c|}
\hline $0.00 \%$ & $0.01 \%$ & $0.03 \%$ & $0.00 \%$ & $25.94 \%$ & $74.06 \%$ \\
\hline $0.00 \%$ & $0.02 \%$ & $0.11 \%$ & $0.00 \%$ & $17.94 \%$ & $82.06 \%$ \\
\hline $0.00 \%$ & $0.00 \%$ & $0.00 \%$ & $0.00 \%$ & $16.87 \%$ & $83.13 \%$ \\
\hline $0.00 \%$ & $0.00 \%$ & $0.00 \%$ & $0.00 \%$ & $16.32 \%$ & $83.68 \%$ \\
\hline $0.00 \%$ & $0.03 \%$ & $0.13 \%$ & $0.00 \%$ & $15.92 \%$ & $84.08 \%$ \\
\hline $0.00 \%$ & $0.00 \%$ & $0.00 \%$ & $0.00 \%$ & $15.71 \%$ & $84.29 \%$ \\
\hline $0.00 \%$ & $0.01 \%$ & $0.08 \%$ & $0.00 \%$ & $15.35 \%$ & $84.65 \%$ \\
\hline $0.00 \%$ & $0.00 \%$ & $0.00 \%$ & $0.00 \%$ & $15.27 \%$ & $84.73 \%$ \\
\hline $0.00 \%$ & $0.00 \%$ & $0.00 \%$ & $0.00 \%$ & $14.18 \%$ & $85.82 \%$ \\
\hline $0.00 \%$ & $0.02 \%$ & $0.11 \%$ & $0.00 \%$ & $12.88 \%$ & $87.12 \%$ \\
\hline $0.00 \%$ & $0.01 \%$ & $0.09 \%$ & $0.00 \%$ & $12.18 \%$ & $87.82 \%$ \\
\hline $0.00 \%$ & $0.00 \%$ & $0.00 \%$ & $0.00 \%$ & $10.39 \%$ & $89.61 \%$ \\
\hline $0.00 \%$ & $0.02 \%$ & $0.22 \%$ & $0.00 \%$ & $9.11 \%$ & $90.89 \%$ \\
\hline $0.00 \%$ & $0.00 \%$ & $0.00 \%$ & $0.00 \%$ & $8.73 \%$ & $91.27 \%$ \\
\hline $0.00 \%$ & $0.01 \%$ & $0.06 \%$ & $0.00 \%$ & $7.62 \%$ & $92.38 \%$ \\
\hline $0.00 \%$ & $0.00 \%$ & $0.01 \%$ & $0.00 \%$ & $7.56 \%$ & $92.44 \%$ \\
\hline $0.00 \%$ & $0.12 \%$ & $1.65 \%$ & $0.00 \%$ & $6.56 \%$ & $93.44 \%$ \\
\hline $0.00 \%$ & $0.00 \%$ & $0.02 \%$ & $0.00 \%$ & $3.97 \%$ & $96.03 \%$ \\
\hline $0.00 \%$ & $0.05 \%$ & $1.23 \%$ & $0.00 \%$ & $3.61 \%$ & $96.39 \%$ \\
\hline $0.00 \%$ & $0.00 \%$ & $0.00 \%$ & $0.00 \%$ & $3.22 \%$ & $96.78 \%$ \\
\hline $0.00 \%$ & $0.00 \%$ & $0.00 \%$ & $0.00 \%$ & $2.32 \%$ & $97.68 \%$ \\
\hline $0.00 \%$ & $0.00 \%$ & $0.54 \%$ & $0.00 \%$ & $0.73 \%$ & $99.27 \%$ \\
\hline $0.00 \%$ & $0.00 \%$ & $0.05 \%$ & $0.00 \%$ & $0.71 \%$ & $99.29 \%$ \\
\hline $0.00 \%$ & $0.00 \%$ & $0.41 \%$ & $0.00 \%$ & $0.03 \%$ & $99.97 \%$ \\
\hline $0.00 \%$ & $0.00 \%$ & $0.07 \%$ & $0.00 \%$ & $0.00 \%$ & $\begin{array}{r}100.00 \\
\% \\
100.00\end{array}$ \\
\hline $0.00 \%$ & $0.00 \%$ & $0.01 \%$ & $0.00 \%$ & $0.00 \%$ & $\begin{array}{r}\% \\
100.00\end{array}$ \\
\hline $0.00 \%$ & $0.00 \%$ & $0.00 \%$ & $0.00 \%$ & $0.00 \%$ & $\begin{array}{r}\% \\
100.00\end{array}$ \\
\hline $0.00 \%$ & $0.00 \%$ & $0.00 \%$ & $0.00 \%$ & $0.00 \%$ & $\%$ \\
\hline $0.00 \%$ & $0.00 \%$ & $0.00 \%$ & $0.00 \%$ & $0.00 \%$ & $\begin{array}{r}100.00 \\
\%\end{array}$ \\
\hline $0.00 \%$ & $0.00 \%$ & $0.00 \%$ & $0.00 \%$ & $0.00 \%$ & $\begin{array}{r}100.00 \\
\%\end{array}$ \\
\hline
\end{tabular}




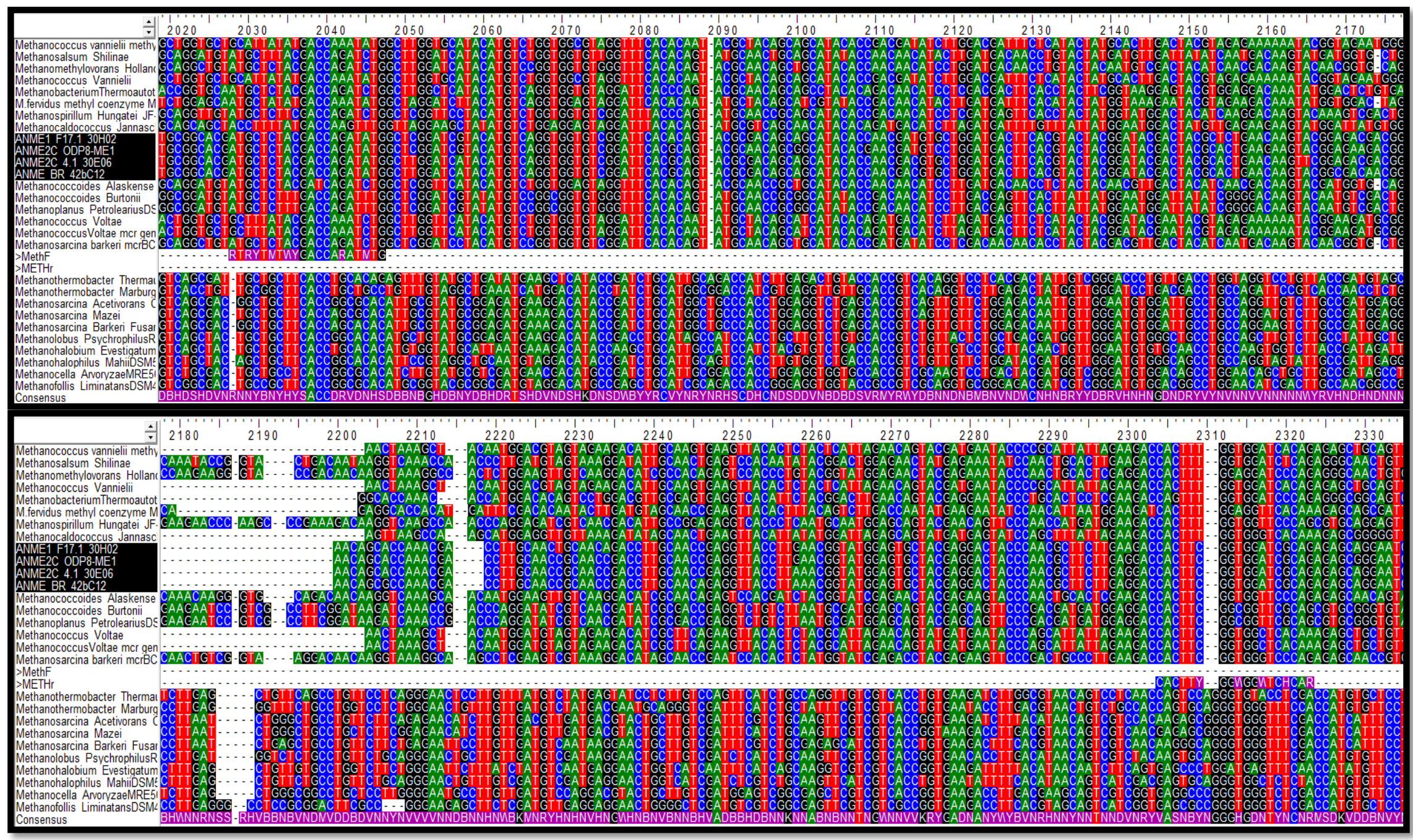

Appendix 4- Alignment of methyl coenzyme reductase subunit a (McrA) across several species of methanogenic and methanotrophic Archaea. ANME species are noted in black. Commonly used methanogen detection primers, METH-F and METH-R from Colwell et al. (2008), are also shown in the alignment. A consensus sequence is shown at the bottom of each alignment. 